Antonio da Silva Jucá Junior

\title{
Gestão de projetos em empresas de base tecnológica desenvolvedoras de software: análise do nível de maturidade e aplicabilidade de escritórios de projetos
}

Dissertação apresentada à Escola de Engenharia de São Carlos da Universidade de São Paulo, como parte dos requisitos para a obtenção do Título de Mestre em Engenharia de Produção.

Orientador: Prof. Dr. Daniel Capaldo Amaral 
"Seja a mudança que você quer ver."

Ghandi 
Este trabalho é dedicado aos meus pais (Donilda e Antonio) que sempre se fizeram um porto seguro para minhas dúvidas e um grande incentivo para minhas certezas. 


\section{Agradecimentos}

Este trabalho é fruto da contribuição de uma série de pessoais sem as quais não teria sido possível concluí-lo.

À Capes pelo incentivo e apoio financeiro dado durante boa parte do trabalho.

Ao Cluster São Carlos de Tecnologia e ao Paulo Mascarenhas pelo apoio e por acreditar na contribuição deste trabalho.

As minhas amizades da universidade que me acompanharam em todos os momentos felizes que tive nesta época: Fiat, Leandro, Ferdinando, Funil, JP, Mickey, Nilson e todos os outros que não são citados aqui mas que foram igualmente importantes.

Aos meus colegas do Grupo de Engenharia Integrada: Fiat, Karina, Sanderson, Savi, Régis, Elaine, Roriz, Andréia, Janaína, Angelita e todos os demais colegas do laboratório que não foram citados.

A nossa equipe (de amigos) do laboratório que viabilizam nossas idéias: Cris, Fernandinho e Francis.

Meus mais sinceros agradecimentos e admiração aos professores Henrique e Sérgio que durante as conversas contribuíram muito para o andamento do trabalho.

Ao meu orientador e amigo Daniel pela paciência, dedicação e competência permitindo que as idéias inicias apresentadas a ele se transformassem neste trabalho.

E por último, gostaria de registrar aqui minha cumplicidade para com a pessoa que me faz sentir sempre melhor, me acompanhando e incentivando. Juliana, além de agradecimentos, gostaria de declarar minha admiração pela pessoa que você é. 


\section{Sumário}

AGRADECIMENTOS...................................................................................... III

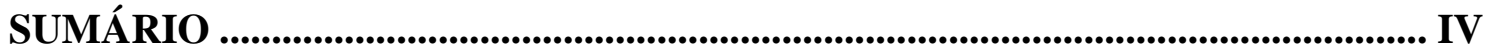

LISTA DE FIGURAS .................................................................................... VI

LISTA DE TABELAS ..................................................................................... VII

LISTA DE QUADROS .......................................................................................... VIII

LISTA DE GRÁFICOS ................................................................................ IX

LISTA DE ABREVIATURAS E SIGLAS .........................................................

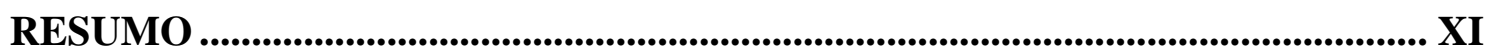

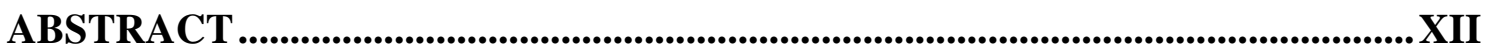

1 INTRODUÇÃO ..................................................................................................

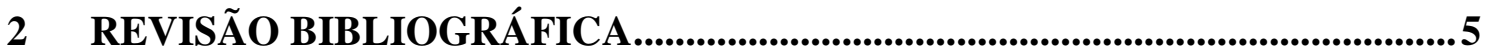

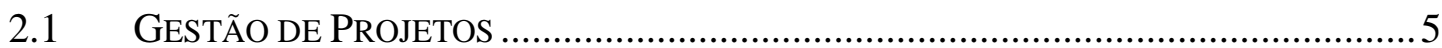

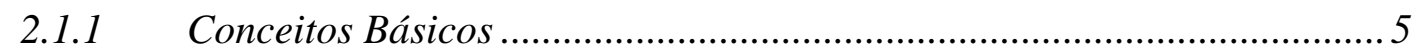

2.1.2 Áreas de conhecimento do gerenciamento de projetos............................ 10

2.1.3 Projetos e tipos de estruturas organizacionais....................................... 16

2.1.4 Caracterização de Tipologias de Projetos.............................................. 19

2.1.5 Maturidade em Gestão de Projetos..........................................................2 26

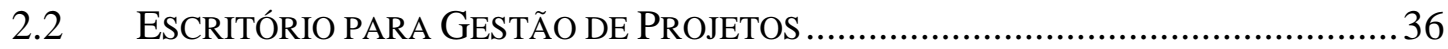

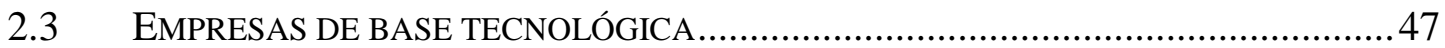

2.3.1 Contextualização do ambiente de trabalho..............................................4 47

2.3.2 Vantagens e barreiras encontradas ........................................................51

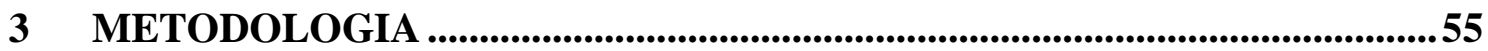

3.1 OBJETIVOS Do TRABALHo E QUeSTÕES DE PESQUISA …....................................55

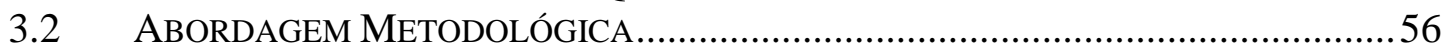

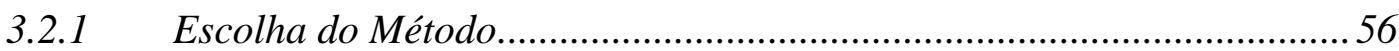

3.2.2 Modelo Teórico e Definições Operacionais .............................................58

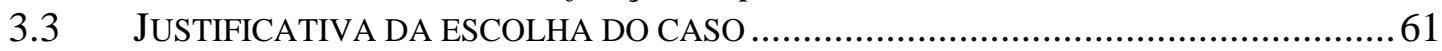

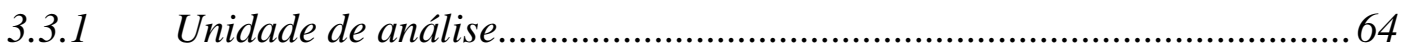

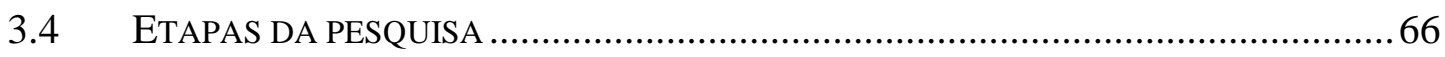

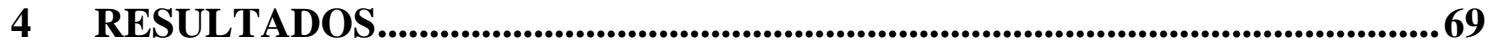

4.1 SÍNTESE DE SERVIÇOS E FUNCIONALIDADES DO ESCRITÓRIO DE PROJETOS .......69

4.2 CARACTERIZAÇÃO DA GESTÃO DE PROJETOS NAS EMPRESAS …........................73

4.2.1 Apresentação das empresas e tipos de projetos...................................... 73 
4.2.2 Descrição do modelo e método para avaliação do nível de maturidade 79

4.2.3 Resultados do diagnóstico .................................................................... 86

4.3 DISCUSSÃO SOBRE O NÍVEL DE MATURIDADE DAS EMPRESAS ESTUDADAS ........93

4.4 ANÁLISE DA APLICABILIDADE DO ESCRITÓRIO DE PROJETOS ........................... 100

5 CONCLUSÕES E CONSIDERAÇÕES FINAIS ......................................102

REFERÊNCIAS BIBLIOGRÁFICAS ..........................................................................107

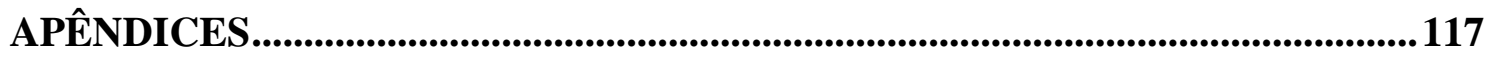

ApÊNDice A - Questionário de Maturidade Organizacional em Gestão de

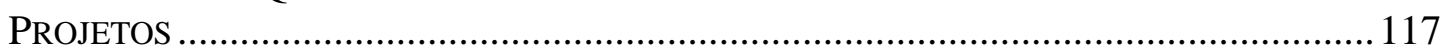

APÊNDICE B - QUESTIONÁRIO PARA CARACTERIZAÇÃo dOS PROJETOS NAS PEQUENAS

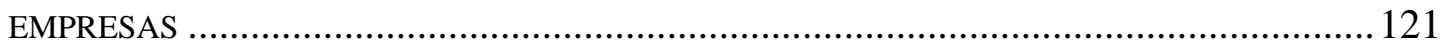

ApÊNDICE C - TABela de PRÁtiCAS de Gerenciamento de PROJETOS PARA

DIAGNÓSTICO NAS EMPRESAS ENTREVISTADAS..................................................... 124 


\section{Lista de Figuras}

FIGURA 1 - GRUPO DE PROCESSOS NA GESTÃO DE PROJETO (PMI, 2004).......................... 8 Figura 2 - Áreas de Conhecimento e Processos de Gestão de Projetos (PMI, 2004). 8

FIGURA 3 - ESTRUTURA ORGANIZACIONAL FUNCIONAL (FONTE: PMBOK, 2004). ......... 18 FIGURA 4 - ESTRUTURA ORGANIZACIONAL PROJETIZADA (FONTE: PMBOK, 2004)........ 18 FIGURA 5 - CICLO DE PROJETOS NO DESENVOLVIMENTO DE PRODUTOS (VERZUH, 1999).

FIGURA 6 - TIPOLOGIA BIDIMENSIONAL PARA PROJETOS (SHENHAR E DVIR, 1996)... 23 FIGURA 7 - ClASSIFICAÇÃO DOS PROJETOS DE ACORDO COM ABERNATHY E CLARK (1984). 24

Figura 8 - Tipologias de PROJETOS (TRAdUÇÃo DE EVARISTO E FENEMA, 1999). 25 FIGURA 9 - NÍVEIS DE MATURIDADE SEGUNDO A REPRESENTAÇÃO POR ESTÁGIOS (CMMI, 2002). .29

Figura 10 - Modelo de MATURIDAde OPM3 SEGUNDO o (PMI, 2004; OPM3, 2003).30 FigURA 11 - MODELO DE MATURIDADE PARA GESTÃO DE PROJETOS (KERZNER, 2000).

FiguRA 12 - MODELO DE MATURIDADE PROJECTFRAMEWORK (SEI, 1999)................ FigurA 13 - NÍVEIS DE ATUAÇÃo DO ESCRITÓRIO DE PROJETOS (CRAWFORD, 2002). 44

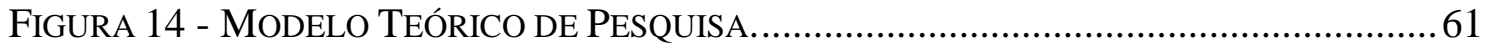

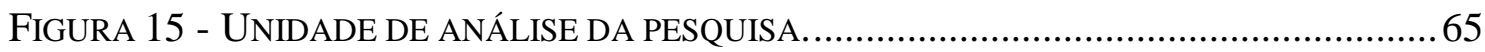

FIGURA 16 - DIVISÃO ENTRE TIPOS DE ESTUDO DE CASO (YIN, 2001) ...........................66

FIGURA 17 - DEMONSTRAÇÃO DA LÓGICA UTILIZADA PARA A COMPILAÇÃO DOS

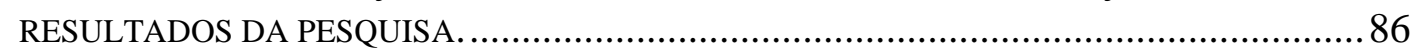

FIGURA 18 - USO DO ESCRITÓRIO DE PROJETOS NAS EMPRESAS DE BASE TECNOLÓGICA.100 


\section{Lista de Tabelas}

Tabela 1 - Número de Empresas no Brasil, Por Porte e Setor de Atividade.

ERRO! INDICADOR NÃO DEFINIDO.

TABELA 2 - PARTICIPAÇÃO DAS MICRO E PEQUENAS EMPRESAS NA ECONOMIA BRASILEIRA. ERRO! INDICADOR NÃO DEFINIDO.

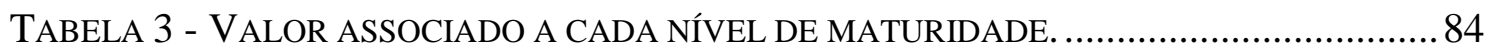

TABELA 4 - RESULTADOS DA PESQUISA, POR ÁREA DE CONHECIMENTO. ..........................93

TABELA 5 - RESULTADOS DA PESQUISA, POR NÍVEL DE MATURIDADE DAS ATIVIDADES... 94 


\section{Lista de Quadros}

QUADRO 1 - RELACIONAMENTO ENTRE ÁREAS DE CONHECIMENTO E O CICLO DE VIDA DO

PROJETO.

QUADRO 2 - TIPOS DE ESTRUTURAS ORGANIZACIONAIS PARA GESTÃO DE PROJETOS

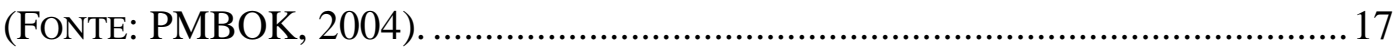

QUADRO 3 - COMPILAÇÃO DOS ASPECTOS TEÓRICOS DE PROJETOS..................................25

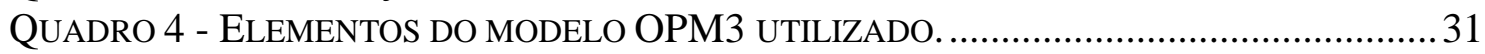

QUADRO 5 - RESUMO DOS SERVIÇOS DO ESCRITÓRIO DE PROJETOS SEGUNDO VALERIANO

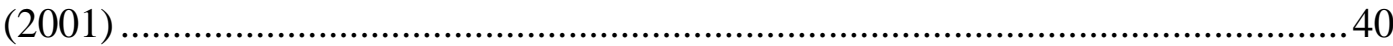

QUADRO 6 - RESUMO DOS SERVIÇOS DO ESCRITÓRIO DE PROJETOS SEGUNDO HELDMAN (2003).

QUADRO 7 - CRITÉRIOS PARA A ESCOLHA DOS CASOS A SEREM ESTUDADOS....................63

QUADRO 8 - CARACTERIZAÇÃO DO TRABALHO DE PESQUISA.............................................68

QUADRO 9 - SÍNTESE DE POSSÍVEIS SERVIÇOS DE UM ESCRITÓRIO DE PROJETOS DE ACORDO

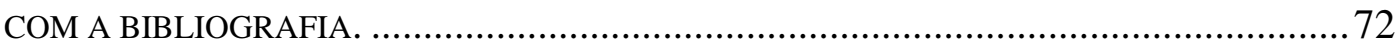

QUADRO 10 - CARACTERIZAÇÃO DA TIPOLOGIA DE PROJETOS NAS EMPRESAS ESTUDADAS.

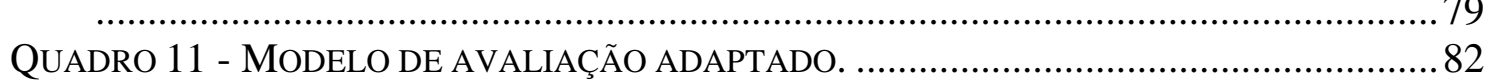

QUADRO 12 - GRUPO DE MELHORES PRÁTICAS IDENTIFICADAS. ..................................... 82

QUADRO 13 - EXEMPLO DOS RESULTADOS DAS PESQUISAS POR ÁREAS DE

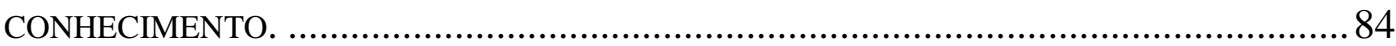

QUADRO 14 - SISTEMA DE CONTAGEM PARA CONSOLIDAÇÃO DOS RESULTADOS DA

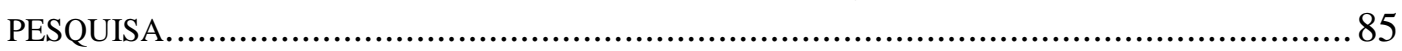

QUADRO 15 - RELAÇÃO ENTRE VALORES OBTIDOS E NÍVEL DE MATURIDADE...................94 


\section{Lista de Gráficos}

GRÁFICO 1 - NÍVEL DE MATURIDADE DA EMPRESA A: (A) GRÁFICO DE BARRAS; (B)

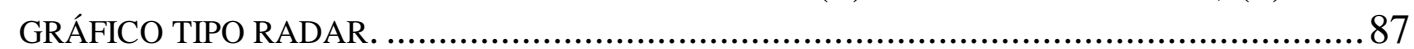

GRÁFICO 2 - NÍVEL DE MATURIDADE DA EMPRESA B: (A) GRÁFICO DE BARRAS; (B)

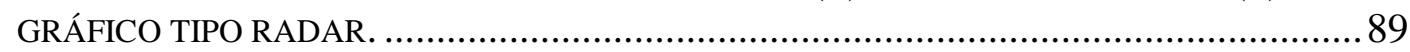

GRÁFICO 3 - NÍVEL DE MATURIDADE DA EMPRESA C: (A) GRÁFICO DE BARRAS; (B)

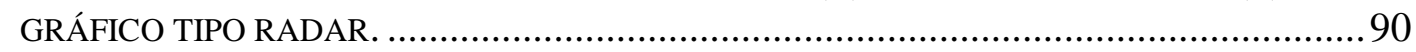

GRÁFICO 4 - NÍVEL DE MATURIDADE DA EMPRESA D: (A) GRÁFICO DE BARRAS; (B)

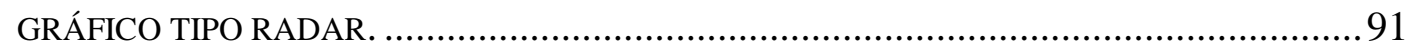

GRÁFICO 5 - NÍVEL DE MATURIDADE DA EMPRESA E: (A) GRÁFICO DE BARRAS; (B)

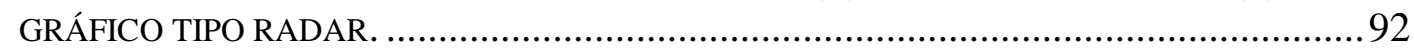

GRÁFICO 6 - COMPARAÇÃO ENTRE OS RESULTADOS DA PESQUISA, POR ÁREA DE

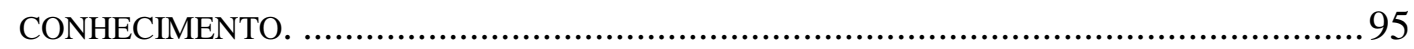

GRÁFICO 7 - COMPARAÇÃO ENTRE OS RESULTADOS DA PESQUISA, POR NÍVEL DE

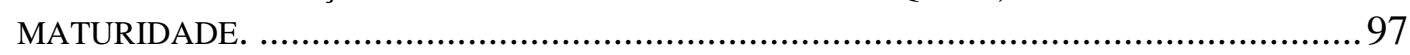

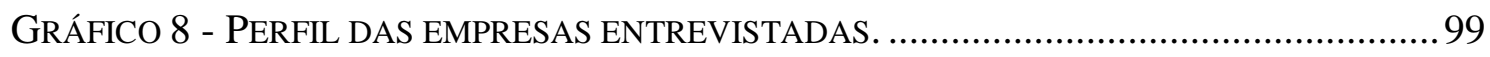




\section{Lista de Abreviaturas e Siglas}

$\begin{array}{ll}\text { APM } & \text { Association of Project Managers } \\ \text { BoK } & \text { Body of Knowledge } \\ \text { CEMPRE } & \text { Cadastro Central de Empresas } \\ \text { CMM } & \text { Capability Maturity Model } \\ \text { CMMI } & \text { Capability Maturity Model Integration } \\ \text { EMBRAPA } & \text { Empresa Brasileira de Pesquisa Agropecuária } \\ \text { IPMA } & \text { International Project Management Association } \\ \text { IBGE } & \text { Instituto Brasileiro de Geografia e Estatística } \\ \text { ISO } & \text { International Organization for Standardization } \\ \text { OPM3 } & \text { Organizational Project Management Maturity Model } \\ \text { ParqTec } & \text { Parque de Alta Tecnologia de São Carlos } \\ \text { PMBOK } & \text { Project Management Body of Knowledge } \\ \text { PMI } & \text { Project Management Institute } \\ \text { PMO } & \text { Project Management Office } \\ \text { PMMM } & \text { Project Management Maturity Model } \\ \text { SIMPI } & \text { Sindicato da Micro e Pequena Indústria do Estado de São Paulo } \\ \text { SEBRAE } & \text { Serviço de Apoio às Micro e Pequenas Empresas } \\ \text { SEI } & \text { Software Engineering Institute } \\ \text { SOFTEX } & \text { Sociedade para Promoção da Excelência do Software Brasileiro }\end{array}$




\section{Resumo}

JUCÁ JUNIOR, A.S. (2005). Gestão de projetos em empresas de base tecnológica da área de software: análise do nível de maturidade e aplicabilidade de escritórios de projetos. Dissertação (Mestrado) - Departamento de Engenharia de Produção, Escola de Engenharia de São Carlos, Universidade de São Paulo.

Dentro da literatura sobre gestão de projetos, trabalhos que estudam o uso do escritório de projetos dedicam-se, quase que exclusivamente, a citar modelos e exemplos bem sucedidos nas grandes empresas, em especial àquelas com estruturas projetizadas como bens de capital e engenharia. Há uma tendência de estas empresas exigirem práticas semelhantes de seus fornecedores. Esta exigência se intensifica nas pequenas empresas de base tecnológica, pois comumente realizam projetos complexos, com risco considerável para os seus clientes. A implantação de escritório de projetos é um mecanismo fundamental para apoiar a utilização das técnicas e metodologias nessa área, porém, exige um investimento significativo em infra-estrutura e profissionais qualificados. Este trabalho analisa o nível de maturidade em gestão de projetos de uma amostra de empresas de base tecnológica desenvolvedoras de software e avalia o potencial de adoção do escritório de projetos. O grau de maturidade foi avaliado segundo um modelo adaptado do OPM3. Foi realizada ainda a identificação e sistematização dos serviços que podem ser oferecidos por um escritório de projetos, segundo a literatura especializada. Ao final, o trabalho faz uma análise dos possíveis serviços que poderiam ser disponibilizados por um escritório de projetos para uso das empresas estudadas.

Palavras-chave: maturidade em gestão de projetos, escritório de projetos, empresa de base tecnológica. 


\begin{abstract}
JUCÁ JUNIOR, A.S. (2005). Project Management in technology based firms of software development: project maturity analysis and project office applicability. Dissertação (Mestrado) - Departamento de Engenharia de Produção, Escola de Engenharia de São Carlos, Universidade de São Paulo.
\end{abstract}

Inside project management literature most of available researches about project offices mainly discuss reference models and examples of best practices in big companies, especially the ones with project oriented structure such as engineering and industrial goods firms. There is a trend for those firms to demand similar project management practices from their suppliers. This kind of requirement is intensified for technology based firms once they usually develop complex projects which contains many risks for their customers. The project office implementation in technology based firms is an important mechanism to support the use of project management techniques and methodologies but it demands a significant investment in infrastructure and qualified professionals. This research analyze the project management maturity level of a software development technology based firms sample and the project office adoption potential on these firms. The maturity level was analyzed according an adapted model of OPM3. In addition, it was identified and systemized services that can be offered for those firms by a project office, according the specialized literature. By the end, this research presents an analysis about different kinds of services that a common project office could offer for those firms studied.

Keywords: project management maturity, project office, technology based firms. 


\section{Introdução}

Este trabalho dedica-se a estudar o tema da gestão de projetos devido a sua importância na estruturação e acompanhamento das atividades de projetos, utilização adequada dos recursos da organização e absorção do conhecimento gerado durante todas as fases do projeto. Assim, a gestão de projetos possibilita uma maior eficiência nas funções que são necessárias para realizarmos os projetos.

O uso das práticas de gestão de projetos - antes comum somente às grandes empresas do setor de infra-estrutura como construção civil, energia e grandes programas governamentais, como programas espaciais e militares - tem tomado maiores proporções e abrangência no momento que as empresas intensificam o uso da tecnologia da informação.

Estas empresas são exigidas por padrões crescentes de qualidade nos produtos e serviços prestados para consumidores e outras empresas, dependem de equipes de trabalho muitas vezes dispersas e desenvolvem novos produtos de uma forma cada vez mais rápida e com objetivos estratégicos.

Com o aprofundamento da subcontratação e terceirização existem pequenas empresas que realizam projetos complexos, inteiros ou partes essenciais de projetos de suas empresas clientes. Elas são obrigadas a rever a forma que gerenciam seus projetos de forma que corresponda às suas novas e reais necessidades. Ainda com relação a essas pequenas empresas, existem algumas as quais este trabalho tem como foco da pesquisa que se destacam devido ao alto valor tecnológico agregado.

Alguns autores exemplificam este alto valor agregado como sendo o alto conteúdo tecnológico inserido a seus produtos e serviços (MARCOVITCH, SANTOS E DUTRA, 1986), enquanto há autores que definem este valor tecnológico agregado por meio de uma competência rara ou exclusiva em termos de produtos ou processos, viáveis comercialmente, que incorporam grau elevado de conhecimento científico (TORKOMIAN e FERRO, 1988). 
Embora não restritas simplesmente ao conjunto de micro e pequenas empresas, mas sendo na maioria classificadas como tal, a este conjunto de empresas que são geralmente encontradas em setores como informática, biotecnologia, robótica, telecomunicações e desenvolvimento de novos materiais, dá-se o nome de empresas de base tecnológica.

De acordo com a necessidade já contextualizada de gestão de projetos, essas empresas recorrem às teorias existentes que foram elaboradas pensando na realidade das grandes corporações que por sua vez, gerenciam seus projetos de forma mais intensa há mais tempo.

Assim, o trabalho que deve ser realizado por estas empresas para entendimento e adaptação da teoria existente não se apresenta como uma tarefa fácil. Nota-se, dessa forma, que apesar do papel fundamental dessas pequenas empresas para a economia do país e do cenário mundial; Em termos de gerenciamento de projetos, elas ainda são raramente citadas como exemplos de melhores práticas.

Portanto, o estudo da gestão de projetos nas empresas de base tecnológica visando o desenvolvimento de técnicas e teorias coerentes com as suas características torna-se muito importante e de grande interesse para as comunidades que estudam estes temas e para as próprias empresas que podem utilizar as informações geradas a partir desta pesquisa.

Um exemplo importante é o conceito de escritório de projetos. Ele é um dos mecanismos que torna possível a gestão eficiente de projetos nas grandes corporações, centralizando os serviços de coleta de informações, desenvolvimento de padrões e fornecendo apoio de consultoria para os gerentes de projeto. Embora seja um instrumento essencial para a gestão de projetos, esta estrutura demanda um custo de desenvolvimento e operação que, no caso de grandes empresas especializadas em projeto, se torna atrativo ao ser dividido entre os projetos da corporação.

Os autores que pesquisam este conceito destacam que o uso do escritório de projetos é função de fatores próprios da organização como tipos dos projetos realizados, estrutura organizacional e o nível de maturidade de gerenciamento de projetos.

Dessa forma, a individualidade do uso do escritório de projetos, bem como suas funções e abrangência dentro da organização dependem do estágio de implantação, das necessidades de cada organização e da complexidade dos projetos existentes.

Com o objetivo de descrever de forma sistematizada e detalhada a relação que existe entre a adoção de um escritório de projetos e as características dos projetos das 
empresas estudadas este trabalho estuda uma amostra de empresas de base tecnológica desenvolvedoras de software que se encontra no Pólo de Alta Tecnologia de São Carlos.

Seguindo a relação sugerida de interdependência entre escritório de projetos, maturidade em gerenciamento de projetos e tipos de projetos executados - segundo autores que discutem o tema - este trabalho avalia o nível de maturidade das empresas e os tipos de projetos executados.

Assim, foram compiladas, a partir da teoria sobre o tema, as principais atividades de gerenciamento de projetos que poderiam se beneficiar da adoção do escritório de projetos, seja por meio do apoio, execução ou centralização dos resultados destas atividades pelo escritório de projetos. Foi realizada uma revisão sistemática sobre escritórios de projeto, identificando os diferentes tipos e as principais atividades de apoio que podem ser oferecidas. Durante esta síntese foram identificadas novas atividades pelo pesquisador que foram incluídas neste trabalho.

A pesquisa realizada ainda fez um diagnóstico da aplicabilidade do conceito do escritório de projetos em um grupo de pequenas empresas de base tecnológica considerando o nível de maturidade em gestão de projetos e os tipos de projetos existentes nestas empresas.

As atividades do gerenciamento de projetos nas empresas que participaram da pesquisa foram identificadas e diagnosticadas quanto ao nível de maturidade apresentado baseando-se em um modelo de avaliação pré-existente.

Os resultados obtidos - síntese dos serviços do escritório de projetos e nível de maturidade das empresas - foram analisados em conjunto, permitindo a elaboração de várias considerações sobre o potencial de aplicação dos escritórios de projetos em empresas de base tecnológica. Essa discussão foi orientada a responder as questões iniciais desta pesquisa, além das sugestões de futuros trabalhos.

Os resultados apresentados contribuem para enriquecer o tema de gerenciamento de projetos, na medida em que: 1) Propõe e utiliza um método para levantamento do grau de maturidade em gerenciamento de projetos, e; 2) Estuda uma amostra de empresas de base tecnológica com relevância nos diferentes cenários que atuam, disponibilizando informações interessantes que permitam o inicio de novos trabalhos de científicos que visem melhorar as práticas destas empresas.

Entretanto, a contribuição desta pesquisa reside, não só no tema de gerenciamento de projetos, mas também para o estudo de empresas de base tecnológica uma vez que levanta e discute deficiências encontradas nas empresas estudadas e que 
podem ser encontradas em outras empresas. Permite-se ainda que novos trabalhos que se proponham mitigar as causas dessas deficiências e tratá-las, partam de alguns resultados interessantes desta pesquisa.

Como forma de desdobrar esta discussão de forma estruturada, este trabalho está organizado em 5 capítulos. Este primeiro, (Introdução) apresentou o trabalho e o contextualiza dentro do cenário atual, fazendo referência ainda aos temas tratados, justificando a relevância da pesquisa.

Em seguida, no segundo capítulo (Revisão Bibliográfica), encontra-se a síntese teórica dos conceitos-chave utilizados na pesquisa, ou seja, gestão e projetos, escritório de projetos e pequenas empresas.

O terceiro capítulo (Metodologia) apresenta os objetivos do trabalho e a abordagem e método de pesquisa utilizado como forma de responder às questões de pesquisa.

No quarto capítulo (Resultados do Trabalho), são apresentados os resultados do trabalho de campo contendo uma síntese dos serviços do escritório de projetos e o levantamento do nível de maturidade das empresas estudadas.

No capítulo cinco (Conclusões e Considerações Finais), são tecidas algumas conclusões e considerações a cerca dos resultados obtidos lançando novas possibilidades para trabalhos futuros.

No último capítulo (Referências Bibliográficas), são apresentadas as referências dos trabalhos utilizados nesta pesquisa. 


\section{Revisão Bibliográfica}

Neste capítulo de revisão bibliográfica são definidos os conceitos que serão tratados em capítulos posteriores, ou seja, Gestão de Projetos, Escritório de Projetos e Empresas de Base Tecnológica; o objetivo é a apresentação dos conceitos-chave.

\subsection{Gestão de Projetos}

\subsubsection{Conceitos Básicos}

Os conceitos de gestão de projetos têm sido aprimorados nos últimos anos no sentido de obtenção de um entendimento comum por parte dos profissionais e organizações envolvidas com as práticas de gestão de projetos; isso explica o interesse crescente pela disciplina de gestão de projetos. A sua intensa utilização dentro das áreas de tecnologia da informação, serviços de informação e desenvolvimento de novos produtos contribui também para o incremento da importância do tema (Crawford, 2002).

Autores que estudam a gestão de projetos justificam o aumento da discussão sobre o tema de outras formas; Kate (2000) observa que o aumento da complexidade do mundo dos negócios faz com que as empresas necessitem de uma maior capacidade de coordenar, gerenciar e controlar suas atividades de maneira a responder mais rapidamente aos estímulos externos. Essa coordenação e controle de atividades, foco da gestão de projetos, estão intimamente ligadas ao sucesso da implementação de estratégias de negócios por meio de projetos.

Rad e Raghavan (2000) acrescentam que a gestão de projetos é uma das disciplinas que mais cresce em praticamente todas as indústrias no mundo de hoje. Seus principais objetivos, segundo os autores, giram em torno de manter um balanço lógico e eficiente entre custo, prazo, qualidade e escopo dos objetivos ou produtos do projeto. 
Entretanto, seu uso não é novo, sendo a gestão de projetos encontrado em grandes projetos, sejam governamentais ou privados, como exemplo nas indústrias no ramo de construção, responsáveis por grandes obras de infra-estrutura como rodovias, hidroelétricas, usinas nucleares, pontes entre outras, ou mesmo em grandes empresas prestadoras de serviços, alimentícias, do ramo automobilístico, instituições financeiras ou departamentos de defesa. Todos estes setores há décadas já adotam técnicas de gestão de projetos, seja para atender o mercado com eficiência e eficácia, seja para redução de custos ou aumento da qualidade de seus produtos e serviços.

Devido à sua abrangência, praticamente todas as áreas de conhecimento estudadas pelo homem tomam o conceito de "projeto" emprestado; isso ocorre devido à sua aplicabilidade nas mais diversas áreas e facilita o estudo da gestão de projetos, dado que dificilmente alguém ainda não tenha participado e vivenciado a realidade de algum projeto qualquer.

O tema tratado é encontrado atualmente em diversas fontes que se propõem a estudá-lo, portanto este campo de estudo encontra-se repleto de definições e conceitos quase todos com significados muito próximos. Estes estudos geralmente estão reunidos em publicações chamadas de corpo de conhecimento ("body of knowledge" - BoK) e algumas instituições e associações criam suas próprias compilações, de acordo com a especificidade necessária para as técnicas, competências, procedimentos e ferramentas utilizadas.

Como exemplo destas fontes, citam-se:

- APM's BoK - Association of Project Managers (UK);

- $\quad$ PMBOK - Project Management Institute (USA);

- IPMA - International Project Management Association (Holanda);

- AIPM's - Competency Standards for Project Management (Austrália);

- ISO 10006 - Guideline to Quality in Project Management (Internacional);

O objetivo destes documentos, além de identificar e descrever as melhores práticas aplicáveis a maior parte dos projetos, é servir como vocabulário comum para os profissionais da área.

Assim, existem várias visões e interpretações do que seria gestão de projetos, as quais se assemelham em termos de processos, etapas e aplicações. 
A norma ISO 10006 (1997) define projeto como sendo "um processo único consistindo de um grupo de atividades coordenadas e controladas com datas para início e término, empreendido para alcance de um objetivo conforme requisitos específicos, incluindo limitações de tempo, custo e recursos".

Segundo o APMBOK (2000), a gestão de projetos é considerada a maneira mais eficiente de se obter mudanças únicas. Essencialmente isso é possível, se:

- Os objetivos forem atingidos, em termos de tempo, custo, qualidade ou outros parâmetros técnicos de desempenho;

- Existir um plano de trabalho para atingir as metas, como forma de garantir que avanços são realizados de maneira a viabilizarem essas metas;

- Técnicas e ferramentas apropriadas de gestão de projetos forem utilizadas para planejar, acompanhar e manter o progresso do projeto;

- Forem formadas equipes com profissionais capacitados em gestão de projetos, incluindo um gerente de projeto, que será a pessoa responsável pelos resultados do projeto;

O PMBOK (2004), um guia de autoria do Standards Committee (Comitê de Padronização) do Project Management Institute, PMI (2004), procura contemplar os principais aspectos que podem ser abordados na gestão de um projeto genérico. $\mathrm{O}$ "PMBOK Guide" é mundialmente reconhecido, além de ser aceito, desde 1999, como padrão de gestão de projetos pelo ANSI - American National Standards Institute.

Para o PMI (2004) um projeto pode ser definido em termos de suas características distintivas, como sendo empreendimentos que requerem empenhos temporários para criar produtos ou serviços únicos. Assim, podem ser destacados dois conceitos intrínsecos desta definição: um referente à temporalidade, ou seja, todo projeto tem um começo e um fim bem determinado e outro que se refere à singularidade, ou seja, que o produto ou serviço é, de algum modo, diferente de todos os similares feitos anteriormente.

Para o PMI (2004), a gestão de projetos deve ser entendida como sendo a aplicação de conhecimentos, habilidades e técnicas para projetar atividades que visem atingir os requisitos do projeto. Neste sentido, a gestão de projetos é divida em nove 
áreas do conhecimento, escopo, tempo, custo, qualidade, comunicação, recursos humanos, risco, aquisição e integração.

Além da decomposição das nove áreas do conhecimento, o ciclo de vida de um projeto pode ser entendido como a composição de alguns processos ou conjunto de atividades; assim a gestão é formada pelas seguintes fases: iniciação, planejamento, execução, controle e encerramento do projeto (PMBOK, 2004), conforme Figura 1.

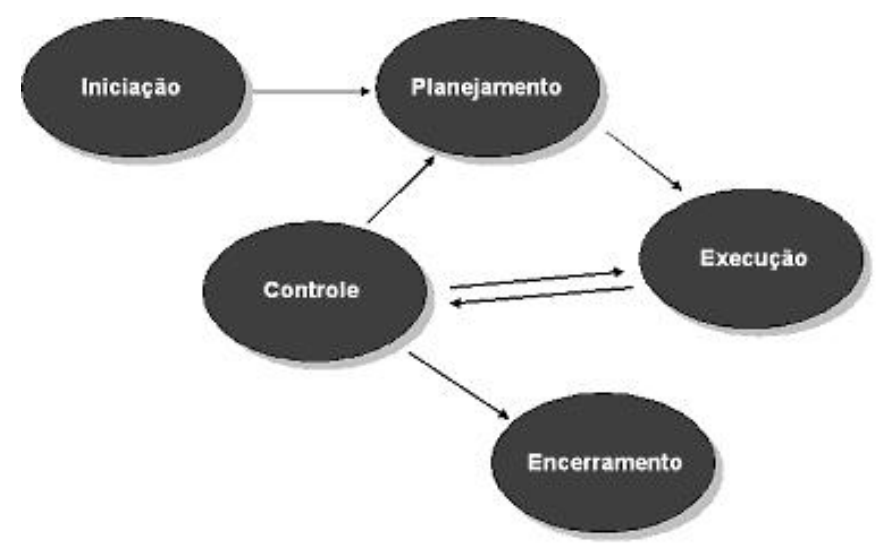

Figura 1 - Grupo de processos na gestão de projeto (PMI, 2004).

De acordo com o andamento do projeto, diversos conhecimentos são utilizados em momentos diferentes, como representado na Figura 2.

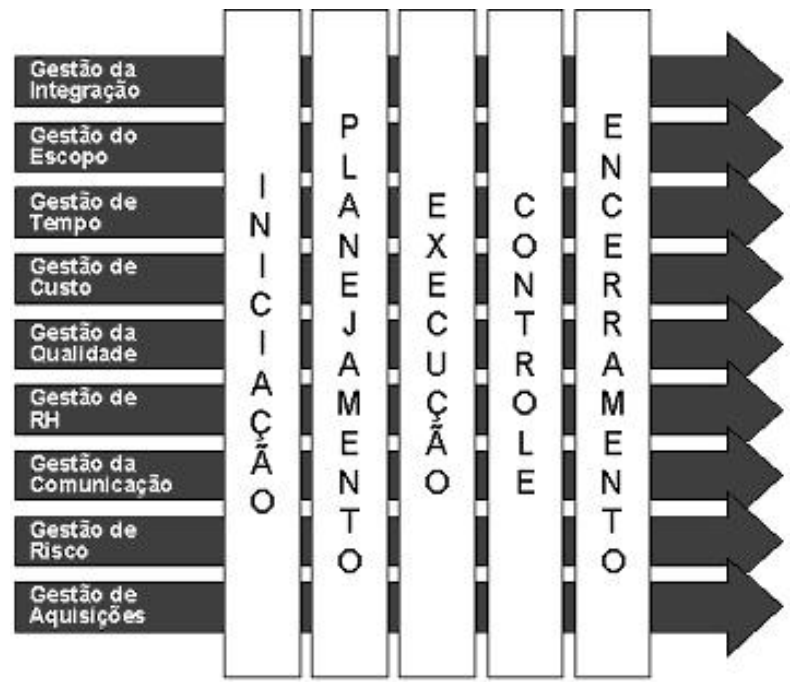

Figura 2 - Áreas de Conhecimento e Processos de Gestão de Projetos (PMI, 2004).

Dessa forma, durante todo o ciclo de vida do projeto determinadas áreas do conhecimento são requisitadas com informações e procedimentos de forma a se atingir a etapa de encerramento do projeto, como observado no Quadro 1. 
Quadro 1 - Relacionamento entre Áreas de Conhecimento e o Ciclo de Vida do Projeto.

\begin{tabular}{|c|c|c|c|c|c|}
\hline ÁREAS & Iniciação & Planejamento & Execução & Controle & Encerramento \\
\hline $\begin{array}{l}\text { Integração do } \\
\text { Gerenciamento } \\
\text { de Projetos }\end{array}$ & & $\begin{array}{l}\text { Desenvolvimento } \\
\text { do plano do projeto }\end{array}$ & $\begin{array}{l}\text { Execução do } \\
\text { plano do projeto }\end{array}$ & $\begin{array}{l}\text { Controle } \\
\text { integrado de } \\
\text { mudanças }\end{array}$ & \\
\hline $\begin{array}{l}\text { Gerenciamento } \\
\text { do Escopo do } \\
\text { Projeto }\end{array}$ & Iniciação & $\begin{array}{l}\text { Planejamento do } \\
\text { escopo } \\
\text { Detalhamento do } \\
\text { escopo }\end{array}$ & & $\begin{array}{l}\text { Verificação do } \\
\text { escopo } \\
\text { Controle de } \\
\text { mudança do } \\
\text { escopo }\end{array}$ & \\
\hline $\begin{array}{l}\text { Gerenciamento } \\
\text { de Tempo do } \\
\text { Projeto }\end{array}$ & & $\begin{array}{l}\text { Definição das } \\
\text { atividades } \\
\text { Seqüenciamento } \\
\text { das atividades } \\
\text { Estimativa da } \\
\text { duração das } \\
\text { atividades } \\
\text { Desenvolvimento } \\
\text { do cronograma }\end{array}$ & & $\begin{array}{l}\text { Controle do } \\
\text { cronograma }\end{array}$ & \\
\hline $\begin{array}{l}\text { Gerenciamento } \\
\text { de Custos do } \\
\text { Projeto }\end{array}$ & & $\begin{array}{l}\text { Planejamento dos } \\
\text { recursos } \\
\text { Estimativa dos } \\
\text { custos } \\
\text { Orçamento dos } \\
\text { custos }\end{array}$ & & $\begin{array}{l}\text { Controle de } \\
\text { custo }\end{array}$ & \\
\hline $\begin{array}{l}\text { Gerenciamento } \\
\text { da Qualidade } \\
\text { do Projeto }\end{array}$ & & $\begin{array}{l}\text { Planejamento da } \\
\text { qualidade }\end{array}$ & $\begin{array}{l}\text { Garantia da } \\
\text { qualidade }\end{array}$ & $\begin{array}{l}\text { Controle da } \\
\text { qualidade }\end{array}$ & \\
\hline $\begin{array}{l}\text { Gerenciamento } \\
\text { de Recursos } \\
\text { Humanos do } \\
\text { Projeto }\end{array}$ & & $\begin{array}{l}\text { Planejamento } \\
\text { organizacional } \\
\text { Montagem da } \\
\text { equipe }\end{array}$ & $\begin{array}{l}\text { Desenvolvimento } \\
\text { da equipe }\end{array}$ & & \\
\hline $\begin{array}{l}\text { Gerenciamento } \\
\text { da } \\
\text { Comunicação } \\
\text { do Projeto }\end{array}$ & & $\begin{array}{l}\text { Planejamento das } \\
\text { comunicações }\end{array}$ & $\begin{array}{l}\text { Distribuição das } \\
\text { informações }\end{array}$ & $\begin{array}{l}\text { Relato de } \\
\text { desempenho }\end{array}$ & $\begin{array}{l}\text { Encerramento } \\
\text { administrativo }\end{array}$ \\
\hline $\begin{array}{l}\text { Gerenciamento } \\
\text { dos Riscos do } \\
\text { Projeto }\end{array}$ & & $\begin{array}{l}\text { Planejamento da } \\
\text { gerência de riscos } \\
\text { Identificação dos } \\
\text { riscos } \\
\text { Análise quantitativa } \\
\text { dos riscos } \\
\text { Análise qualitativa } \\
\text { dos riscos } \\
\text { Planejamento de } \\
\text { respostas e riscos }\end{array}$ & & $\begin{array}{l}\text { Controle e } \\
\text { monitoração dos } \\
\text { riscos }\end{array}$ & \\
\hline $\begin{array}{l}\text { Gerenciamento } \\
\text { das } \\
\text { Aquisições do } \\
\text { Projeto }\end{array}$ & & $\begin{array}{l}\text { Planejamento das } \\
\text { aquisições } \\
\text { Preparação das } \\
\text { aquisições }\end{array}$ & $\begin{array}{l}\text { Pedido de } \\
\text { propostas } \\
\text { Seleção de } \\
\text { fornecedores } \\
\text { Administração de } \\
\text { contratos }\end{array}$ & & $\begin{array}{l}\text { Encerramento } \\
\text { dos contratos }\end{array}$ \\
\hline
\end{tabular}

Fonte: Project Management Body of Knowledge - PMBOK, 2004.

Com base nos conceitos apresentados, alguns termos que serão discutidos neste trabalho possuem uma ampla interpretação que muitas vezes está relacionada à sua natureza e foco prático. No entanto, como forma de homogeneizar os conceitos, adotarse-á o padrão empregado pelo PMBOK (2004). 


\subsection{2 Áreas de conhecimento do gerenciamento de projetos}

Dentro da bibliografia estudada para gerenciamento de projetos, o PMBOK (2004) descreve as áreas de conhecimento; dentro de cada área existe um conjunto de atividades do campo do gerenciamento de projetos que são exigidas em diferentes etapas do ciclo de vida de um projeto, de acordo com o Quadro 1.

Este grupo de atividades é descrito abaixo de maneira mais detalhada para completo entendimento e utilização posterior neste trabalho.

\subsubsection{Gerenciamento de integração do projeto}

O gerenciamento de integração do projeto inclui os processos e as atividades necessárias para identificar, definir, combinar, unificar e coordenar os diversos processos e atividades de gerenciamento de projetos dentro dos grupos de processos de gerenciamento de projetos. No contexto do gerenciamento de projetos, a integração inclui características de unificação, consolidação, articulação e ações integradoras que são essenciais para o término do projeto, para atender com sucesso às necessidades do cliente e das partes interessadas e para gerenciar as expectativas. Os processos de gerenciamento de integração do projeto incluem:

- Desenvolver o termo de abertura do projeto - desenvolvimento do termo de abertura do projeto que autoriza formalmente um projeto;

- Desenvolver a declaração do escopo preliminar do projeto desenvolvimento da declaração do escopo preliminar do projeto que fornece uma descrição de alto nível do escopo;

- Desenvolver o plano de gerenciamento do projeto - documentação das ações necessárias para definir, preparar, integrar e coordenar todos os planos auxiliares em um plano de gerenciamento do projeto;

- Orientar e gerenciar a execução do projeto - execução do trabalho definido no plano de gerenciamento do projeto para atingir os requisitos do projeto definidos na declaração do escopo do projeto;

- Monitorar e controlar o trabalho do projeto - monitoramento e controle dos processos necessários para iniciar, planejar, executar e encerrar um projeto para atender aos objetivos de desempenho definidos no plano de gerenciamento do projeto; 
- Controle integrado de mudanças - revisão de todas as solicitações de mudança, aprovação de mudanças e controle de mudanças nas entregas e nos ativos de processos organizacionais;

- Encerrar o projeto - finalização de todas as atividades entre todos os grupos de processos do projeto para encerrar formalmente o projeto.

\subsubsection{Gerenciamento do escopo do projeto}

O gerenciamento do escopo do projeto inclui os processos necessários para garantir que o projeto inclua todo o trabalho necessário, e somente ele, para terminar o projeto com sucesso. O gerenciamento do escopo do projeto trata principalmente da definição e controle do que está e do que não está incluído no projeto. Os processos de gerenciamento do escopo do projeto incluem:

- Planejamento do escopo - criação de um plano de gerenciamento do escopo do projeto que documenta como o escopo do projeto será definido, verificado e controlado e como a estrutura analítica do projeto (EAP) será criada e definida;

- Definição do escopo - desenvolvimento de uma declaração do escopo detalhada do projeto como a base para futuras decisões do projeto;

- Criar EAP - subdivisão das principais entregas do projeto e do trabalho do projeto em componentes menores e mais facilmente gerenciáveis;

- Verificação do escopo - formalização da aceitação das entregas do projeto terminadas;

- Controle do escopo - controle das mudanças no escopo do projeto.

\subsubsection{Gerenciamento de tempo do projeto}

O gerenciamento de tempo do projeto inclui os processos necessários para realizar o término do projeto no prazo. Os processos de gerenciamento de tempo do projeto incluem:

- Definição da atividade - identificação das atividades específicas do cronograma que precisam ser realizadas para produzir as várias entregas do projeto;

- Seqüenciamento de atividades - identificação e documentação das dependências entre as atividades do cronograma; 
- Estimativa de recursos da atividade - estimativa do tipo e das quantidades de recursos necessários para realizar cada atividade do cronograma;

- Estimativa de duração da atividade - estimativa do número de períodos de trabalho que serão necessários para terminar as atividades individuais do cronograma;

- Desenvolvimento do cronograma - análise dos recursos necessários, restrições do cronograma, durações e seqüências de atividades para criar o cronograma do projeto;

- Controle do cronograma - controle das mudanças no cronograma do projeto.

\subsubsection{Gerenciamento de custos do projeto}

O gerenciamento de custos do projeto inclui os processos envolvidos no planejamento e controle de custos, de modo que seja possível terminar o projeto dentro do orçamento aprovado. Os processos de gerenciamento de custos do projeto incluem:

- Estimativa de custos - desenvolvimento de uma aproximação dos custos dos recursos necessários para terminar as atividades do projeto;

- Orçamentação - agregação dos custos estimados de atividades individuais ou pacotes de trabalho para estabelecer uma linha de base dos custos;

- Controle de custos - controle dos fatores que criam as variações de custos e controle das mudanças no orçamento do projeto.

\subsubsection{Gerenciamento da qualidade do projeto}

$\mathrm{O}$ gerenciamento da qualidade do projeto inclui os processos e as atividades da organização executora que determinam as responsabilidades, os objetivos e as políticas de qualidade, de modo que o projeto atenda às necessidades que motivaram sua realização. Ele implementa o sistema de gerenciamento da qualidade através da política e dos procedimentos, com atividades de melhoria contínua dos processos conduzidas do início ao fim, conforme adequado. Os processos de gerenciamento da qualidade do projeto incluem:

- Planejamento da qualidade - identificação dos padrões de qualidade relevantes para o projeto e determinação de como satisfazê-los; 
- Realizar a garantia da qualidade - aplicação das atividades de qualidade planejadas e sistemáticas para garantir que o projeto emprega todos os processos necessários para atender aos requisitos.

- Realizar o controle da qualidade - monitoramento de resultados específicos do projeto a fim de determinar se eles estão de acordo com os padrões relevantes de qualidade e identificação de maneiras de eliminar as causas de um desempenho insatisfatório.

\subsubsection{Gerenciamento de recursos humanos do projeto}

$\mathrm{O}$ gerenciamento de recursos humanos do projeto inclui os processos que organizam e gerenciam a equipe do projeto. Esta equipe é composta de pessoas com funções e responsabilidades atribuídas para execução das atividades do projeto. Embora seja comum esta atribuição de funções e responsabilidades, os membros da equipe devem estar envolvidos em grande parte do planejamento e da tomada de decisões do projeto. $\mathrm{O}$ envolvimento dos membros da equipe desde o início acrescenta especialização durante o processo de planejamento e fortalece o compromisso com o projeto. $\mathrm{O}$ tipo e o número de membros da equipe do projeto muitas vezes podem mudar conforme o projeto se desenvolve. Os membros da equipe do projeto podem ser chamados de pessoal do projeto. Os processos de gerenciamento de recursos humanos do projeto incluem:

- Planejamento de recursos humanos - identificação e documentação de funções, responsabilidades e relações hierárquicas do projeto, além da criação do plano de gerenciamento de pessoal;

- Contratar ou mobilizar a equipe do projeto - obtenção dos recursos humanos necessários para terminar o projeto;

- Desenvolver a equipe do projeto - melhoria de competências e interação de membros da equipe para aprimorar o desempenho do projeto;

- Gerenciar a equipe do projeto - acompanhamento do desempenho de membros da equipe, fornecimento de feedback, resolução de problemas e coordenação de mudanças para melhorar o desempenho do projeto.

\subsubsection{Gerenciamento das comunicações do projeto}

O gerenciamento das comunicações do projeto inclui os processos necessários para garantir a geração, coleta, distribuição, armazenamento, recuperação e destinação 
final das informações sobre o projeto de forma oportuna e adequada. Os processos de gerenciamento das comunicações do projeto fornecem as ligações críticas entre pessoas e informações que são necessárias para comunicações bem-sucedidas. Os gerentes de projetos podem gastar um tempo excessivo na comunicação com a equipe do projeto, partes interessadas, cliente e patrocinador. Todos os envolvidos no projeto devem entender como as comunicações afetam o projeto como um todo. Os processos de gerenciamento das comunicações do projeto incluem:

- Planejamento das comunicações - determinação das necessidades de informações e comunicações das partes interessadas no projeto;

- Distribuição das informações - colocação das informações necessárias à disposição das partes interessadas no projeto no momento oportuno;

- Relatório de desempenho - coleta e distribuição das informações sobre o desempenho, inclusive relatório de andamento, medição do progresso e previsão;

- Gerenciar as partes interessadas - gerenciamento das comunicações para satisfazer os requisitos das partes interessadas no projeto e resolver problemas com elas.

\subsubsection{Gerenciamento de riscos do projeto}

O gerenciamento de riscos inclui os processos que tratam da realização de identificação, análise, respostas, monitoramento e controle, e planejamento do gerenciamento de riscos em um projeto. Os objetivos do gerenciamento de riscos do projeto são aumentar a probabilidade e o impacto dos eventos positivos e diminuir a probabilidade e o impacto dos eventos adversos nos objetivos do projeto. Os processos de gerenciamento de riscos do projeto incluem:

- Planejamento do gerenciamento de riscos - decisão de como abordar, planejar e executar as atividades de gerenciamento de riscos de um projeto;

- Identificação de riscos - determinação dos riscos que podem afetar o projeto e documentação de suas características;

- Análise qualitativa de riscos - priorização dos riscos para análise ou ação adicional subseqüente através de avaliação e combinação de sua probabilidade de ocorrência e impacto; 
- Análise quantitativa de riscos - análise numérica do efeito dos riscos identificados nos objetivos gerais do projeto;

- Planejamento de respostas a riscos - desenvolvimento de opções e ações para aumentar as oportunidades e reduzir as ameaças aos objetivos do projeto;

- Monitoramento e controle de riscos - acompanhamento dos riscos identificados, monitoramento dos riscos residuais, identificação dos novos riscos, execução de planos de respostas a riscos e avaliação da sua eficácia durante todo o ciclo de vida do projeto.

\subsubsection{Gerenciamento de aquisições do projeto}

$\mathrm{O}$ gerenciamento de aquisições do projeto inclui os processos para comprar ou adquirir os produtos, serviços ou resultados necessários de fora da equipe do projeto para realizar o trabalho. Apresenta duas perspectivas de aquisição: a organização como comprador ou fornecedor do produto, serviço ou resultados sob um contrato.

O gerenciamento de aquisições do projeto inclui os processos de gerenciamento de contratos e de controle de mudanças necessários para administrar os contratos ou pedidos de compra emitidos por membros da equipe do projeto autorizados. O gerenciamento de aquisições do projeto também inclui a administração de qualquer contrato emitido por uma organização externa (o comprador) que está adquirindo o projeto da organização executora (o fornecedor) e a administração de obrigações contratuais estabelecidas para a equipe do projeto pelo contrato. Os processos de gerenciamento de aquisições do projeto incluem:

- Planejar compras e aquisições - determinação do que comprar ou adquirir e de quando e como fazer isso;

- Planejar contratações - documentação dos requisitos de produtos, serviços e resultados, e identificação de possíveis fornecedores;

- Solicitar respostas de fornecedores - obtenção de informações, cotações, preços, ofertas ou propostas, conforme adequado;

- Selecionar fornecedores - análise de ofertas, escolha entre possíveis fornecedores e negociação de um contrato por escrito com um fornecedor;

- Administração de contrato - gerenciamento do contrato e da relação entre o comprador e o fornecedor, análise e documentação do desempenho 
atual ou passado de um fornecedor a fim de estabelecer ações corretivas necessárias e fornecer uma base para futuras relações com o fornecedor, gerenciamento de mudanças relacionadas ao contrato e, quando adequado, gerenciamento da relação contratual com o comprador externo do projeto;

- Encerramento do contrato - término e liquidação de cada contrato, inclusive a resolução de quaisquer itens em aberto e o encerramento de cada contrato.

\subsubsection{Projetos e tipos de estruturas organizacionais}

De acordo com PMBOK (2004) projetos fazem, tipicamente, parte de uma organização maior - corporações, agências do governo, instituições de saúde, organismos internacionais, associações profissionais e outros. Assim a maturidade da organização com respeito a sistemas de gerência de projeto, cultura, estilo, estrutura organizacional e a existência do escritório de gerência de projetos também, influenciar o projeto.

Organizações orientadas a projeto são aquelas cujas operações consistem, basicamente, de projetos. Estas organizações se enquadram em duas categorias:

- Organizações cujas receitas se originam primariamente do desenvolvimento de projetos para terceiros - empresas de arquitetura, empresas de engenharia, consultores, empreiteiros, entre outros.

- Organizações que adotaram o modelo de gerência por projeto.

Estas organizações tendem a ter sistemas de gerenciamento voltados para a gerência de projetos. Por exemplo, seus sistemas financeiros são freqüentemente projetos especificamente para contabilizar, acompanhar e relatar múltiplos projetos.

Organizações não orientadas a projeto freqüentemente carecem de sistemas de gerenciamento projetados para suportar as necessidades dos projetos de forma efetiva e eficiente. A ausência de sistemas orientados a projetos normalmente dificulta a tarefa de gerenciamento de cada projeto. Em alguns casos, as organizações não orientadas a projetos têm departamentos, ou outras unidades administrativas, operando por projetos com sistemas de apoio adequados.

A equipe de gerência do projeto deve estar bastante consciente da forma como os sistemas da organização afetam o projeto. Por exemplo, se a organização recompensa seus gerentes funcionais pelas horas de sua equipe alocadas a projeto, as equipes do 
projeto podem precisar implementar controles que assegurem que as pessoas alocadas ao projeto estão, efetivamente, trabalhando no projeto.

A estrutura da organização executora freqüentemente restringe a disponibilidade ou as condições sob as quais os recursos se tornam disponíveis para o projeto. A estrutura das organizações pode enquadrar-se em diferentes tipos, da funcional a projetizada, com uma variedade de combinações entre elas, como descrito no Quadro 2.

\begin{tabular}{|c|c|c|c|c|c|}
\hline \multirow{2}{*}{$\begin{array}{ll}\text { Caracteristicasso } & \text { Tipo de } \\
\text { dos Projetos }\end{array}$} & \multirow{2}{*}{ Funcional } & \multicolumn{3}{|c|}{ Matricial } & \multirow{2}{*}{ Projetizada } \\
\hline & & Matriz Fraca & Matriz Equilibrada & Matriz Forte & \\
\hline $\begin{array}{l}\text { Autoridade do } \\
\text { Gerente do Projeto }\end{array}$ & $\begin{array}{l}\text { Pouca ou } \\
\text { Nenhuma }\end{array}$ & Limitada & $\begin{array}{l}\text { De Baixa a } \\
\text { Moderada }\end{array}$ & $\begin{array}{l}\text { De Moderada } \\
\text { a Alta }\end{array}$ & $\begin{array}{c}\text { De Alta a Quase } \\
\text { Total }\end{array}$ \\
\hline $\begin{array}{l}\text { Percentual do Pessoal da } \\
\text { Organização Executora } \\
\text { Alocado em Tempo Integral } \\
\text { ao Projeto }\end{array}$ & $\begin{array}{l}\text { Virtualmente } \\
\text { Nenhum }\end{array}$ & $0-25 \%$ & $15-60 \%$ & $50-95 \%$ & $85-100 \%$ \\
\hline $\begin{array}{l}\text { Alocação do Gerente do } \\
\text { Projeto }\end{array}$ & $\begin{array}{l}\text { Tempo } \\
\text { Parcial }\end{array}$ & $\begin{array}{l}\text { Tempo } \\
\text { Parcial }\end{array}$ & $\begin{array}{l}\text { Tempo } \\
\text { Integral }\end{array}$ & $\begin{array}{l}\text { Tempo } \\
\text { Integral }\end{array}$ & $\begin{array}{l}\text { Tempo } \\
\text { Integral }\end{array}$ \\
\hline $\begin{array}{l}\text { Designações mais Comuns } \\
\text { para o Papel do Gerente do } \\
\text { Projeto }\end{array}$ & $\begin{array}{l}\text { Coordenador } \\
\text { de Projetol } \\
\text { Lider de Projeto }\end{array}$ & $\begin{array}{l}\text { Coordenador } \\
\text { de Projetol } \\
\text { Lider de Projeto }\end{array}$ & $\begin{array}{c}\text { Gerente } \\
\text { de Projetol } \\
\text { Diretor de Projeto }\end{array}$ & $\begin{array}{l}\text { Gerente } \\
\text { de Projetol } \\
\text { Gerente de } \\
\text { Programa } \\
\end{array}$ & $\begin{array}{l}\text { Gerente } \\
\text { de Projetol } \\
\text { Gerente de } \\
\text { Programa } \\
\end{array}$ \\
\hline $\begin{array}{l}\text { Suporte Administrativo } \\
\text { ao Gerente do Projeto }\end{array}$ & $\begin{array}{l}\text { Tempo } \\
\text { Parcial }\end{array}$ & $\begin{array}{l}\text { Tempo } \\
\text { Parcial }\end{array}$ & $\begin{array}{l}\text { Tempo } \\
\text { Parcial }\end{array}$ & $\begin{array}{l}\text { Tempo } \\
\text { Integral }\end{array}$ & $\begin{array}{l}\text { Tempo } \\
\text { Integral }\end{array}$ \\
\hline
\end{tabular}

Quadro 2 - Tipos de estruturas organizacionais para gestão de projetos (Fonte: PMBOK, 2004).

De acordo com a definição encontrada no PMBOK (2004), a clássica organização com estrutura funcional descrita na Figura 3 é uma hierarquia onde cada funcionário tem um superior bem definido. Os membros da equipe são agrupados por especialidade, tais como produção, marketing, engenharia e contabilidade, em um primeiro nível, com a engenharia ainda subdividida em organismos funcionais que suportam o negócio das grandes organizações (mecânica e elétrica). As organizações com estrutura funcional também têm projetos, mas o escopo percebido do projeto está limitado às fronteiras da função: o departamento de engenharia executa seu trabalho independente do departamento de manufatura ou marketing considerando uma organização com estrutura funcional. 


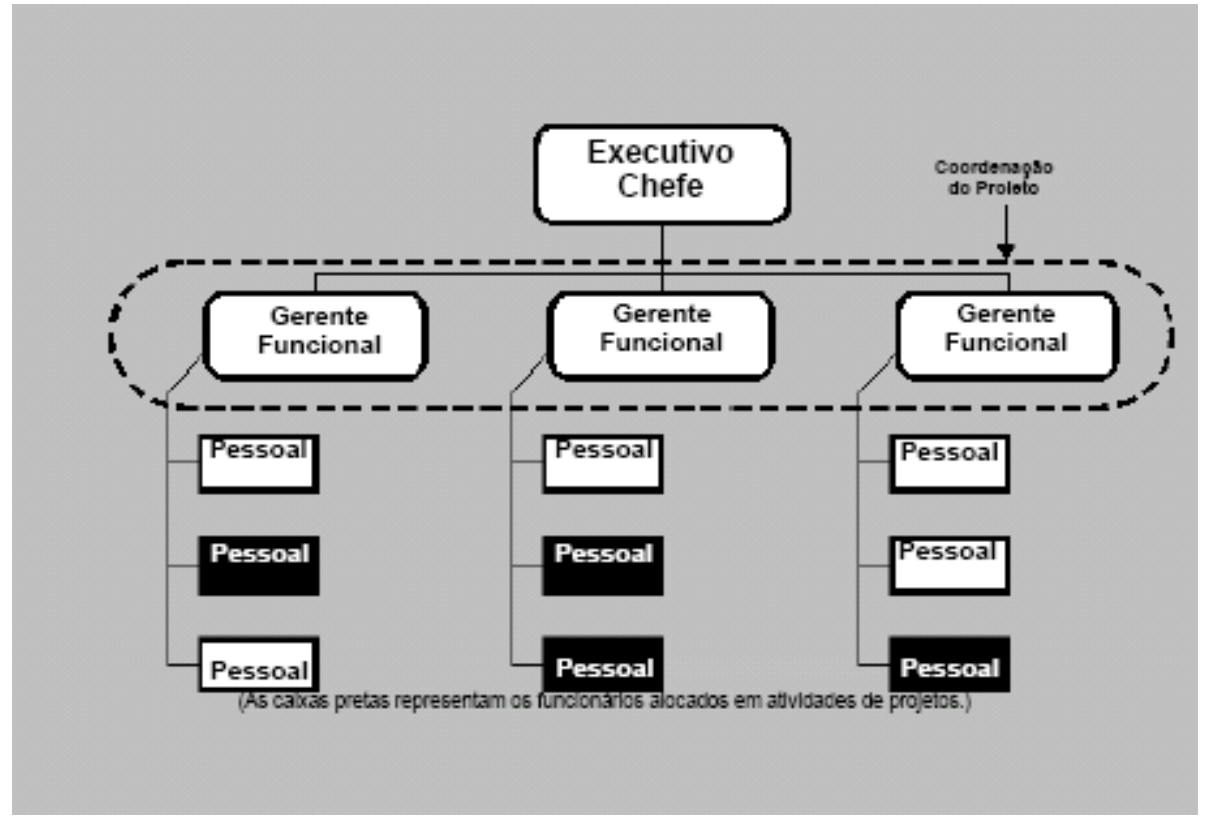

Figura 3 - Estrutura organizacional funcional (Fonte: PMBOK, 2004).

De forma análoga, temos do outro lado do espectro a organização com estrutura projetizada como mostrado na Figura 4. Neste tipo de organização, os membros das equipes freqüentemente trabalham juntos, em um mesmo local físico e a maioria dos recursos da organização está envolvida em projetos e os gerentes de projeto têm grande autoridade e independência. Organizações com estrutura projetizada normalmente possuem unidades organizacionais denominadas departamentos. Entretanto, estes departamentos ou se reportam diretamente ao gerente de projeto, ou fornecem serviços de suporte aos diversos projetos existentes.

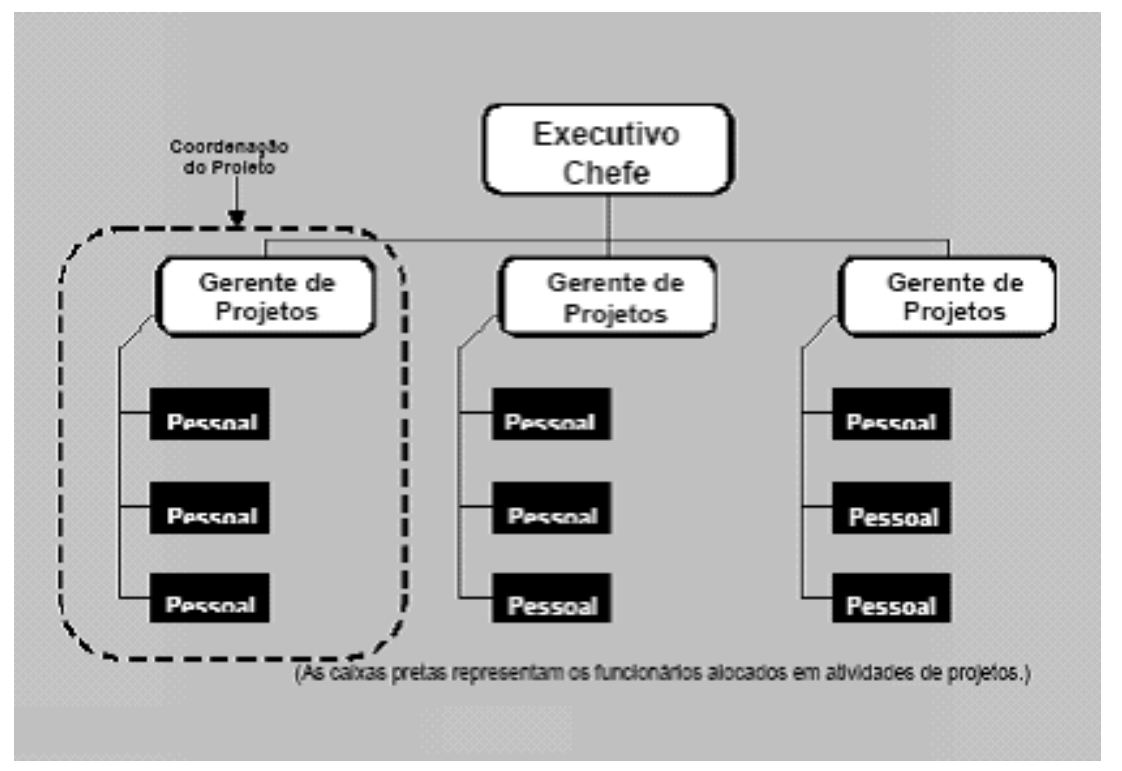

Figura 4 - Estrutura organizacional projetizada (Fonte: PMBOK, 2004). 
Existem ainda organizações com estruturas matriciais, isto é, estruturas que não são funcionais ou projetizadas, mas estão entre estes dois pólos. De acordo com a influência do gerente de projeto ou o do projeto dentro da organização ela pode ser matricial fraca, quando tende mais para o funcional ou matricial forte, se aproximando da estrutura projetizada.

Ainda de acordo com o PMBOK (2004), nas organizações modernas encontramse todos estes tipos de estruturas e em diferentes níveis. Por exemplo, em uma organização com estrutura fundamentalmente funcional, pode ser necessário criar uma equipe especial de projetos para empreender um projeto de caráter crítico e esta equipe pode ter muitas das características de um projeto em uma organização projetizada.

\subsubsection{Caracterização de Tipologias de Projetos}

Talvez uma das grandes deficiências da teoria de gestão de projetos seja a pequena distinção feita entre os tipos de projetos e sua estratégia, bem como os problemas gerenciais envolvidos (SHENHAR e DVIR, 1996).

De acordo com Pinto e Covin (1989, pg. 49), "a tendência que prevalece entre a maioria das escolas tem sido caracterizar todos os projetos como fundamentalmente similares". Igualmente, textos e handbooks freqüentemente atribuem um conjunto de elementos para as atividades de projetos como organizar, planejar, controlar e monitorar (CLELAND e KING, 1983; KERZNER, 1994). Associações profissionais também reafirmam os mesmos preceitos de como gerenciar todos os projetos de uma maneira uniforme, discutindo ferramentas, processos, técnicas e atividades para todos os tipos de projetos.

Diversos autores divergem desta abordagem universal e caracterizam projetos segundo alguma tipologia proposta. Estes autores (KNAPP e MOORE, 2000; EVARISTO e FENEMA, 1999; BLAKE, 1978; WHEELWRIGHT e CLARK, 1992; SHENHAR e DVIR, 1996; CLARK e FUJIMOTO, 1991) propõem tipos e classificações de diferentes projetos enfatizando que diferentes projetos exigem diferentes formas de gestão e levam em consideração aspectos específicos dos projetos, como os diferentes graus de inovação, configuração das equipes e complexidade do produto que se deseja obter.

A formação de tipologias é discutida por Doty e Glick (1994). Estes autores sugerem que elas devem fornecer os critérios necessários para a construção de teorias. Entretanto, ressaltam que tipologias não fornecem regras para tomada de decisão na 
classificação de organismos. Elas identificam múltiplos tipos ideais, cada um deles uma combinação única dos atributos relevantes e que podem ser associados a certo organismo (DOTY e GLICK, 1994, pg.232). Neste trabalho ainda, os autores discutem a construção de teorias baseadas em tipologias, apresentando os critérios a serem observados no processo de modelagem da teoria.

Também na literatura de desenvolvimento de novos produtos existem propostas para classificações e tipologias de projetos de novos produtos e do seu modo de desenvolvimento. Elas podem ser adaptadas para um estudo mais genérico dentro da gestão de projetos, uma vez que de acordo com Verzuh (1999) o desenvolvimento de novos produtos costuma ocorrer na forma de projetos ou programas de projetos como observado na Figura 5. O autor ainda destaca a similaridade entre as características do desenvolvimento de novos produtos e a gestão de projetos na medida em que é realizado de uma só vez e resulta em um produto único. Assim tipologias destinadas ao desenvolvimento de novos produtos e à gestão de projetos não são mutuamente excludentes, mas complementares.

\section{Ciclo de projeto}

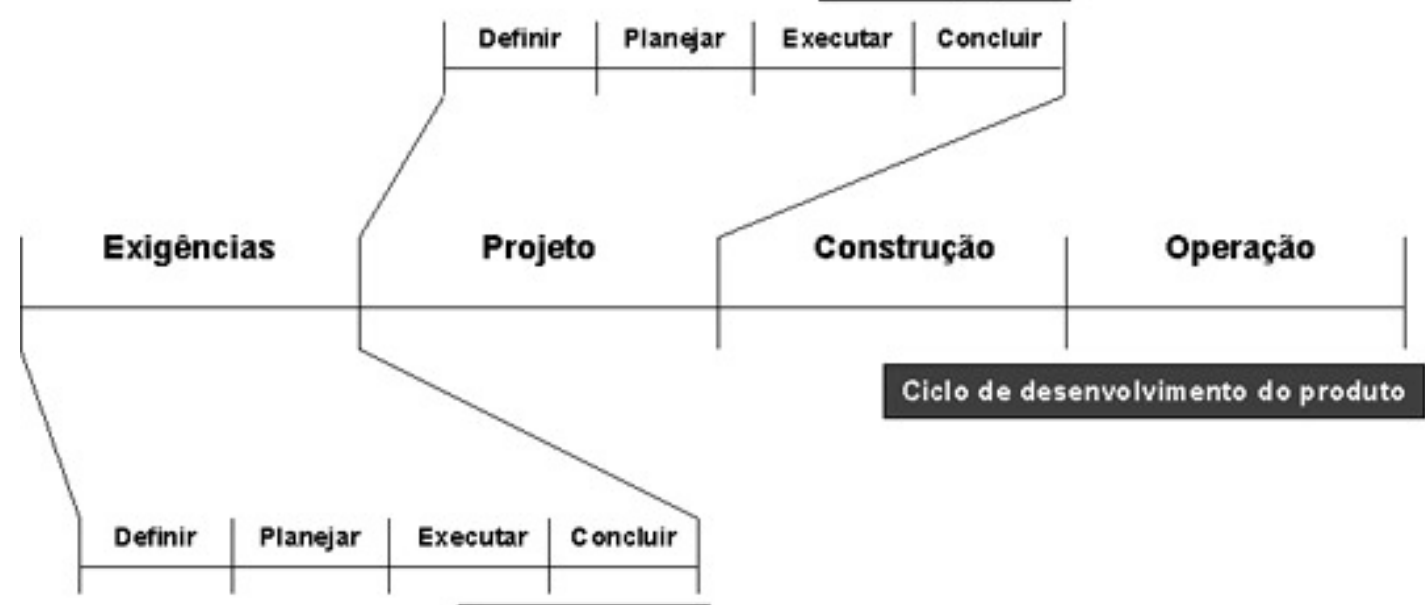

Ciclo de projeto

Figura 5 - Ciclo de projetos no desenvolvimento de produtos (VERZUH, 1999).

Rozenfeld e Amaral (1999), no campo do desenvolvimento de produtos, procuram identificar os fatores que afetam a gestão destes tipos de projeto específicos. Neste sentido, eles reconhecem a necessidade da criação de uma tipologia e destacam diversos autores que identificam possíveis critérios: grau de inovação, qualidade, interface com o usuário, tecnologia, estrutura interna, cultura, estratégia, relacionamento interprojetos e mercado. 
Não existe um consenso na literatura quanto à melhor tipologia a ser adotada. Diversos autores propõem soluções de acordo com visões distintas da gestão do projeto e sua preocupação fundamental no momento de definição da tipologia. Abaixo são apresentadas algumas destas classificações:

Wheelwright e Clark (1992) afirmam que diferentes dimensões podem ser utilizadas para classificar projetos em diferentes categorias ou tipos e complementam que estas classificações são importantes, pois, para os autores, além de facilitar a própria forma de gerenciamento, possibilita que planos de projeto sejam mais realistas no que se refere ao uso dos recursos.

Em trabalho realizado por meio de um estudo de caso em projetos para o desenvolvimento de novos produtos, os autores apresentam uma tipologia baseada no mapeamento dos projetos de acordo com o grau de mudança apresentado dentro do portfólio da empresa:

- Projetos derivativos ou incrementais: Desenvolvimento de produtos e processos derivados, híbridos ou simplesmente melhorias. Englobam desde projetos para versões com custo reduzido até a melhoria de algum processo de produção. Tais projetos podem incluir mudanças incrementais nos produtos, nos processos ou em ambas as dimensões e demandam uma quantidade relativamente pequena de recursos, uma vez que estendem produtos e processos já existentes;

- Projetos plataforma: Projetos de novas soluções para o mercado oferecendo uma nova base para novos produtos e processos a serem desenvolvidos posteriormente. Acarretam em uma utilização maior de recursos e se bem gerenciados e executados, oferecem melhorias em termos de custo, qualidade e desempenho para toda a nova linha de produtos a serem lançados;

- Projetos com quebra de paradigma: Projetos que envolvem uma quantidade significante de mudança e caso tenham sucesso, resultam em um novo conceito de produto ou processo, possibilitando inclusive, a entrada em novos mercados. As equipes de projetos desta natureza devem ter liberdade de propor novos processos que suportem tal inovação; 
- Projetos de pesquisa e desenvolvimento: O foco dos projetos desta natureza está na criação de conhecimento e sua estrutura geralmente se encontra separada daquela destinada a explorar tecnologias e mercados já conhecidos; mais tarde estas tecnologias desenvolvidas passam para o mercado em forma de novos produtos;

Knapp e Moore (2000) categorizam projetos utilizando conceitos variados de complexidade, tamanho, prioridade e risco. A complexidade dos projetos pode ser mensurada levando em consideração os aspectos: experiências positivas com projetos análogos; a complexidade do que estará sendo entregue, seja produtos, sistemas ou processos; o número de grupos envolvidos no projeto; e a complexidade da tecnologia envolvida.

Os autores com o auxílio de tabelas dividem os projetos em cada um dos conceitos propostos com o intuito de oferecer um manual de autodiagnóstico para os projetos na organização e por meio de um sistema de pontuação, criar categorias de projetos que podem demandar níveis diferentes de tratamento.

Shenhar e Dvir (1996) fizeram um estudo de caso múltiplo em 26 projetos com uma abordagem qualitativa e aplicam questionários em mais de 120 projetos. Ao final, discutem e propõem uma classificação para projetos baseada em duas variáveis, incerteza tecnológica e a complexidade do número de componentes ou subprojetos necessários.

O primeiro aspecto analisado pelos autores refere-se ao grau de complexidade das partes ou componentes envolvidos no projeto. Os projetos podem ser classificados de três formas diferentes (SENHAR e DVIR, 1996):

Projetos: associados ao uso de componentes que juntos desempenharão uma única atividade; segundo os autores, tocadores de CD são exemplos de projetos;

Sistemas: projetos que demandam o uso de vários projetos de subsistemas, cada um desempenhando funções diferentes e como exemplo, citam um projeto de um novo avião que é composto por diversos componentes que realizam ou possuem funções diversas;

Programas: projetos que necessitam de vários sistemas para seu sucesso, por exemplo, um projeto de sistema de defesa de um país, composto por aeronaves, satélites, bases militares, etc.

O segundo aspecto analisado envolve os níveis de incerteza tecnológica, classificando os projetos como segue: 
Tipo A: Projetos com baixa incerteza tecnológica; geralmente associados a projetos que utilizam tecnologias já dominadas pela empresa e pelo mercado. Ex: projetos de construção de estradas.

Tipo B: Projetos com incerteza tecnológica média; envolvem projetos que exigem a adaptação de tecnologias já existentes e que não atendem as necessidades específicas do projeto. Ex: projetos industriais.

Tipo C: Projetos de alta incerteza tecnológica; envolvem tecnologias já desenvolvidas, mas ainda não utilizadas. Ex: projetos de sistemas de defesa.

Tipo D: Projetos de altíssima incerteza tecnológica; projetos que exigem tecnologias que serão desenvolvidas durante o projeto. Ex: programas espaciais.

Dessa maneira, os autores criam uma sistemática para a caracterização dos projetos para desenvolvimento de novos produtos (ver Figura 6) que pode ser empregada para classificar os projetos já existentes e projetos a serem planejados, como forma de melhorar as possíveis formas de gerenciá-los.

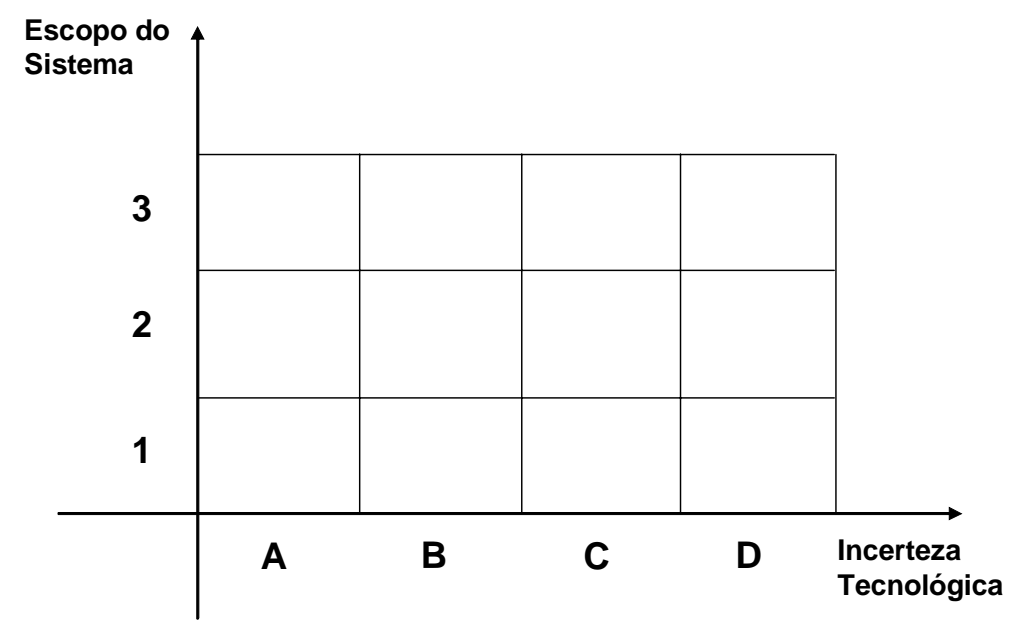

Figura 6 - Tipologia bidimensional para projetos (SHENHAR e DVIR, 1996).

Textos mais antigos também reforçam a classificação baseada em aspectos de inovação tecnológica. Blake (1978) sugere uma distinção normativa entre projetos que apresentam um grau de mudança baixo (projeto alfa) e aqueles que se caracterizam como contendo um grau elevado de mudanças (projeto beta).

Tushman e Anderson (1986) discutem as implicações entre inovação radical e incremental dentro da gestão do ciclo de vida do produto. As reflexões destes autores tornam-se importantes para a gestão de projetos, especialmente na definição da estratégia de um programa de projetos. 
Abernathy e Clark (1984) dividem os possíveis projetos de acordo com o tipo de inovação, tecnológica ou mercadológica, classificando os projetos de desenvolvimento de acordo com seu posicionamento nas duas escalas de inovação de acordo com a Figura 7:

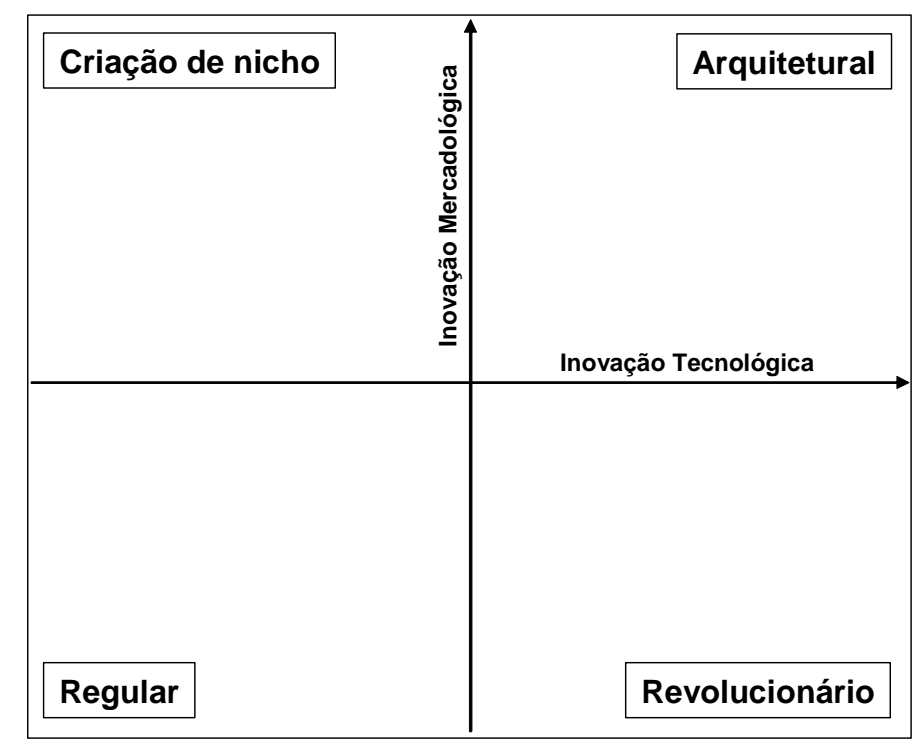

Figura 7 - Classificação dos projetos de acordo com Abernathy e Clark (1984).

- Criação de nicho: Projetos em que a inovação se concentra no posicionamento do produto em um novo mercado;

- Arquitetural: Projetos cuja inovação está no posicionamento em um novo $\underline{\text { mercado }}$ por meio do uso de uma nova tecnologia;

- Regular: Projetos que não possuem inovação em nenhuma das dimensões, e;

- Revolucionário: Projetos que apesar de agregarem inovação em tecnologia, não criam novos mercados.

Abernathy e Clark destacam que dependendo deste posicionamento, um novo projeto reforça ou se contrapõe aos desenvolvimentos anteriores.

Evaristo e Fenema (1999) dividem os projetos de acordo com aspectos de multiplicidade de projetos e localização das equipes. A partir das variáveis propostas, os autores sugerem um universo de possibilidades, demonstrado na Figura 8, e por último propõem um forma de transição entre os tipos, motivadas por necessidades de negócio e disponibilidade de melhores ferramentas de tecnologia da informação. 


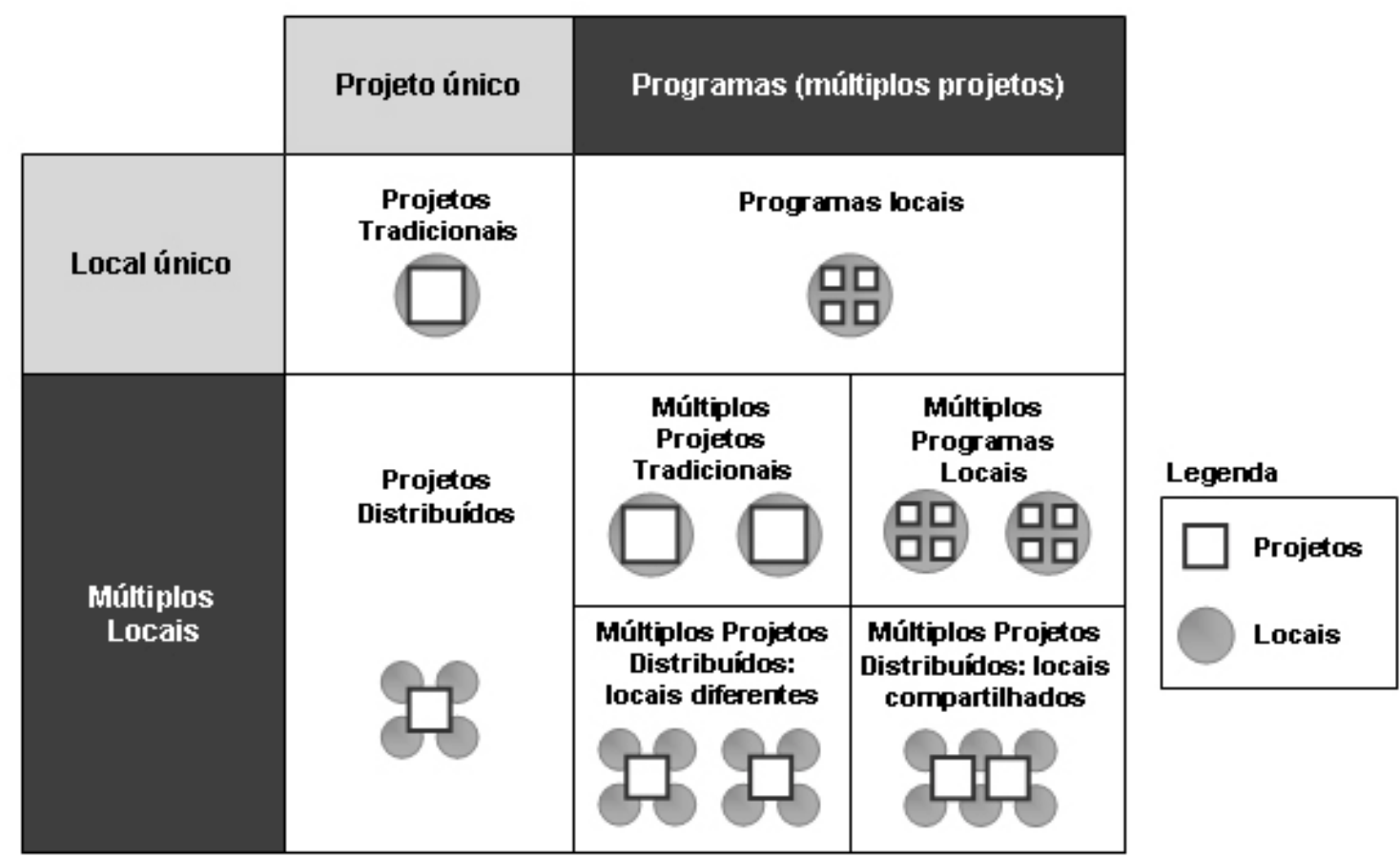

Figura 8 - Tipologias de Projetos (tradução de EVARISTO E FENEMA, 1999).

A Quadro 3 apresenta um resumo dos critérios citados e referências que os evidenciam.

Quadro 3 - Compilação dos aspectos teóricos de projetos.

\begin{tabular}{|c|c|}
\hline Aspectos Considerados do Projeto & Referência \\
\hline 1 - Tecnologia envolvida. & Knapp e Moore (2000). \\
\hline $\begin{array}{l}2 \text { - Complexidade tecnológica e de } \\
\text { interface do produto ou serviço. }\end{array}$ & $\begin{array}{l}\text { Knapp e Moore (2000); Shenhar e Dvir } \\
\text { (1996); Rozenfeld e Amaral (1999); }\end{array}$ \\
\hline $\begin{array}{l}3 \text { - Configuração das equipes (tamanho, } \\
\text { quantidade, localização). }\end{array}$ & $\begin{array}{l}\text { Knapp e Moore (2000); Evaristo e Fenema } \\
\text { (1999). }\end{array}$ \\
\hline 4 - Quantidade de recursos utilizados & Knapp e Moore (2000). \\
\hline 5 - Grau de inovação & $\begin{array}{l}\text { Blake (1978); Wheelwright e Clark (1992); } \\
\text { Shenhar e Dvir (1996); Tushman e Anderson } \\
\text { (1986); Abernathy \& Clark (1984). }\end{array}$ \\
\hline
\end{tabular}

Portanto, observa-se na teoria que os aspectos utilizados para diferenciar os tipos de projeto, quanto à forma de gestão, são: grau de inovação (item 5), complexidade do produto (item 1 e 2 ) e a configuração das equipes do projeto (itens 3 e 4). Outras formas de classificação podem ser citadas para projetos, levando em consideração aspectos organizacionais como estratégia, portfólio, ou aspectos financeiros como rentabilidade e investimentos necessários. Neste trabalho, os aspectos que serão resgatados e utilizados na pesquisa de campo (veja os capítulos 3 e 4) são: "grau de inovação", "complexidade do produto" e "configuração das equipes". 


\subsubsection{Maturidade em Gestão de Projetos}

As práticas de gestão de projetos exigem constantes aprimoramentos para se alcançar níveis crescentes de sofisticação, seja para o simples acompanhamento de atividades de projeto em uma pequena organização ou para uma infra-estrutura centralizada de gestão estratégico de programas de uma grande empresa; todos devem repensar constantemente a forma de gerenciar seus projetos.

Assim, durante a fase de encerramento, a equipe de trabalho pode avaliar a forma que o projeto foi gerenciado propondo alterações nas etapas ou documentos de projeto que apresentaram alguma irregularidade. Este procedimento permite não só o crescimento da equipe, mas a evolução de toda a organização nas práticas de gestão de projetos e remete ao conceito de maturidade organizacional.

Entretanto, para que a organização evolua nas práticas de gestão de projetos, ela necessita identificar e desenvolver certas "potencialidades", tradução feita a partir da expressão inglesa "capability", termo encontrado em bibliografias que estudam a melhoria de práticas e processos (SEI, 1997). O dicionário Webster (2004) define "capability" como "uma qualidade ou faculdade de ser capaz de se desenvolver" ou simplesmente como utilizado no texto, "potencialidade".

O desenvolvimento das "potencialidades" organizacionais em gestão de projetos requer a revisão freqüente dos processos que a empresa possui; freqüentemente o desenvolvimento de uma "potencialidade" afeta outras. Assim, certas "potencialidades" podem ou não reforçar ou regular as demais, tornando ainda mais difícil discernir quais ações têm maiores e melhores impactos.

O PMI (2004) define maturidade como sendo um guia que descreve os pontos a serem desenvolvidos ou alcançados, bem como os caminhos a serem percorridos para determinada mudança. A partir do uso desse guia, os responsáveis pelas mudanças podem planejá-las de forma mais eficiente e auxiliar as organizações a desenvolverem potencialidades estratégicas.

Segundo Kerzner (2000), a maturidade em gestão de projetos deve ser entendida como sendo o desenvolvimento de sistemas e processos que são, por natureza, repetitivos e garantam uma alta probabilidade de que cada um deles seja um sucesso. Entretanto, processos e sistemas repetitivos não são garantias de sucesso, eles apenas aumentam a sua probabilidade. Ainda de acordo com o pesquisador, a maturidade e a excelência em gestão de projetos não podem ser alcançadas sem a existência de um planejamento estratégico para a gestão de projetos. 
Várias propostas de modelos de maturidade foram elaboradas com o objetivo de auxiliar as empresas na busca pela melhoria de seus processos de gestão de projetos, facilitando o entendimento sobre a evolução entre diferentes níveis de sofisticação das práticas de gestão. Assim o conceito de maturidade adquire um aspecto de avaliação, também conhecido como modelo de maturidade.

Portanto, o modelo de maturidade em projetos é apresentado como sendo, além de uma forma de mensurar o estágio de organização na habilidade das empresas gerenciarem seus projetos para atingir seus objetivos, um plano de crescimento nas práticas de gerência de projetos.

Os modelos discutidos neste trabalho foram selecionados por serem os mais comentados, discutidos e estudados na teoria de maturidade e pelos profissionais em gestão de projetos. No entanto, foram selecionados modelos que além da gestão de projetos, auxiliam na melhoria de outros processos de forma mais ampla como o Capability Maturity Model - CMM (SEI, 1997). Deve-se salientar no entanto que vários outros modelos não serão discutidos neste trabalho, por exemplo: US Federal Aviation Administration Integrated Capability Maturity Model (http://www.faa.gov/aio/); SPICE (http://www.sqi.gu.edu.au/spice/); Project Management Maturity Model de Knapp e Moore Pty Ltd. (http://www.knappandmoore.com.au/pdf/white_paper.PDF), entre outros, pelo fato de terem sido elaborados a partir de modelos já tratados neste trabalho e apresentarem, por isso, um grau elevado de similaridade entre eles.

\subsubsection{Capability Maturity Model}

Um dos pioneiros e mais conhecidos modelos de maturidade e melhoria de processos, o Capability Maturity Model ou CMM foi desenvolvido pelo Software Engineering Institute, instituto ligado ao Carnegie Mellon University (SEI, 1997).

Este modelo é utilizado como base para dezenas de outros modelos de maturidade e seu foco é o processo de desenvolvimento de software dando grande ênfase às atividades de definição, especificação e teste dos softwares.

A classificação de maturidade no CMM é dividida em cinco níveis:

- O primeiro nível - inicial - é caracterizado por um processo de desenvolvimento informal, no qual os projetos habitualmente ultrapassam os prazos e custos originais. Nesse nível, não há um ambiente propício para o desenvolvimento e manutenção de software. 
- No segundo nível - repetição - os planos desenvolvidos são baseados no passado e, portanto, são mais realistas. São estabelecidas políticas de manutenção de projetos e procedimentos de implementação destas políticas.

- O terceiro nível - definição - é marcado pela existência de processos bem definidos, melhorando assim o desempenho dos projetos.

- No quarto nível - gerência - os processos e produtos são quantitativamente controlados.

- O quinto nível - otimização - a maturidade é consolidada e a gestão de projetos é institucionalizada, possibilitando a criação de um processo de melhoria contínua.

Atualmente este modelo evoluiu para o Capability Maturity Model Integration CMMI. Este modelo é uma síntese do modelo CMM, inicialmente desenvolvido apenas para software, com outros modelos de melhoria desenvolvidos pela SEI, respectivamente para a engenharia de sistemas, engenharia de software, desenvolvimento integrado de produtos e processos e ainda o desenvolvimento de fornecedores. O CMMI pode ser utilizado a partir de uma de suas representações, contínua ou por estágios.

A representação contínua utiliza seis níveis diferentes de "potencialidades" a serem desenvolvidas e pontos a serem atingidos. O modelo foca nos grupos de processos divididos por categorias (gestão de processos, gestão de projetos, engenharia e suporte) e relacionados a estes grupos de processos encontram certas "potencialidades" a serem trabalhadas. Seu uso está, portanto, relacionado aos grupos de processos; toma-se como exemplo, uma empresa que tem por objetivo a redução do tempo que leva para um produto novo ir para o mercado; os processos a serem melhorados a partir deste objetivo são aqueles relacionados com a gestão de projetos, mais precisamente com aqueles associados ao planejamento e ao controle $\mathrm{e}$ monitoramento do projeto, como forma de garantir o tempo de entrega do produto final; assim, utilizando a representação contínua, a organização escolhe quais "potencialidades" ela deve desenvolver.

Já a representação por estágios, herança do modelo anterior, organiza as áreas de processos a serem desenvolvidas em cinco níveis de maturidade (Figura 9) como forma 
de guiar o processo de melhoria. Assim, para cada nível desejado, alguns grupos de processos são sugeridos para serem melhorados, ou seja, os níveis de maturidade oferecem uma seqüência para a otimização dos processos de forma organizada e racional.

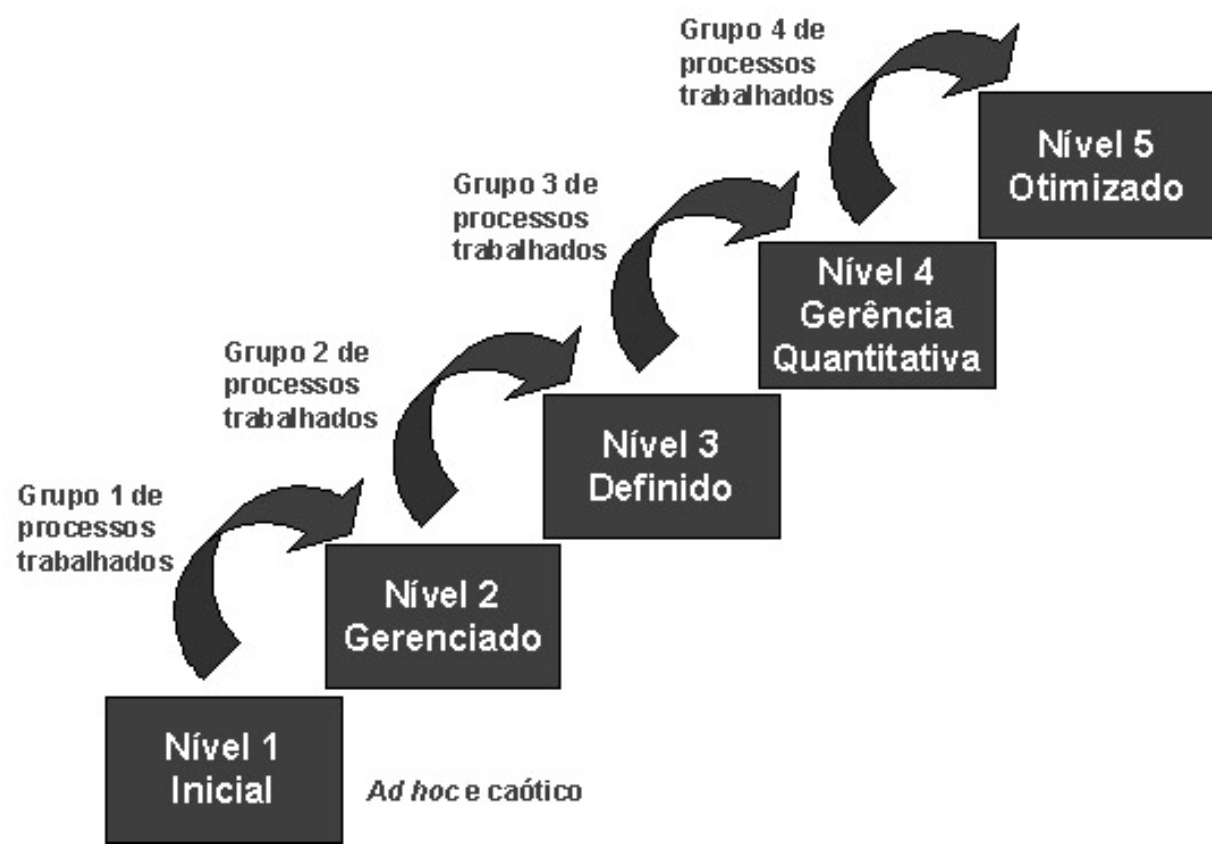

Figura 9 - Níveis de maturidade segundo a representação por estágios (CMMI, 2002).

Entretanto, apesar do CMMI ter sido criado para a utilização em todas as organizações, antes de ser utilizado em pequenas organizações se faz necessário uma interpretação própria quanto ao seu emprego nestas empresas (CMMI, 2002).

A idéia básica do CMM - maturidade dividida em níveis, dos quais o último é uma condição de aprendizagem e aprimoramento contínuos - está presente na maioria dos outros modelos.

\subsubsection{Project Management Maturity Model}

OPM3 é a sigla do Organizational Project Management Maturity Model, um projeto liderado pelo Project Management Institute que teve início em 1998, com o objetivo de propor um modelo de maturidade genérico. Profissionais que trabalham com gestão de projetos provenientes de diferentes culturas e diversos tipos e tamanhos de empresas participaram como voluntários e contribuíram para a elaboração deste guia.

Em seu simpósio de 2001, o PMI (2004) apresentou um relatório com os resultados parciais do projeto: haviam identificado vários modelos de maturidade. No entanto, um longo caminho ainda teria que ser percorrido até chegar a um modelo 
oficial do PMI para a gestão organizacional de projetos, com a mesma abrangência que o PMBOK como guia para a gestão do projeto individual (SCHLICHTER, 2001).

Desta forma, foram realizadas buscas e análises com dezenas de modelos e frameworks sobre as práticas de gestão de projetos. Mais de 30 mil profissionais da área foram consultados através de surveys. Antes da construção do modelo, foi reunido um total de 170 melhores práticas em uma pesquisa de campo.

As melhores práticas foram avaliadas segundo os critérios:

- Realmente contribui para a maturidade em gestão de projetos na organização?

- A organização tem condições de implementá-la diretamente, sem a necessidade de pré-requisitos?

- Permitem o uso de critérios de desempenho como forma de medir a eficiência da implementação?

O modelo OPM3 (2003), Figura 10, propõe um checklist para avaliar o estágio de competência das organizações, apresentando os passos necessários para a evolução em direção a um próximo estágio.

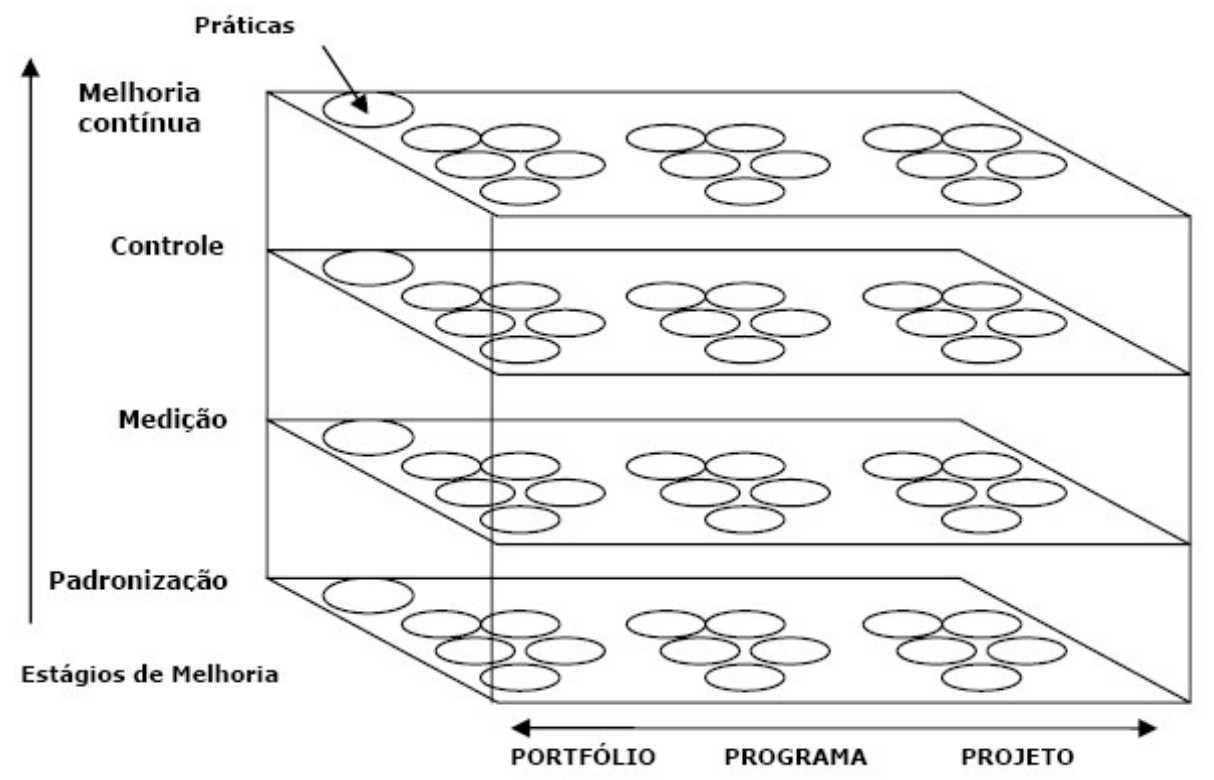

Figura 10 - Modelo de Maturidade OPM3 segundo o (PMI, 2004; OPM3, 2003).

Conforme a Figura 10, esse modelo utiliza quatro níveis de maturidade: 
- Padronizado - para as melhores práticas que são realizadas de maneira comum para todos os projetos;

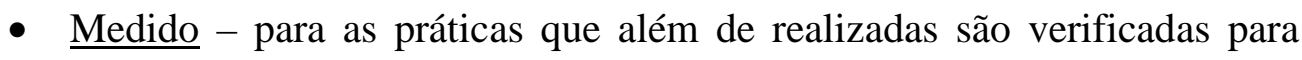
todos os projetos;

- $\underline{\text { Controlado }}$ - os resultados das práticas, além de medidos são confrontados e avaliados, e;

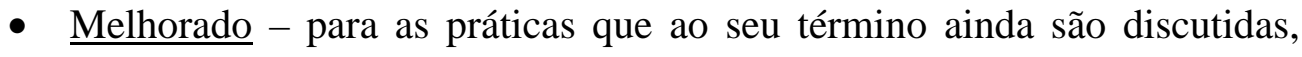
propostas e implementadas modificações de melhoria para próximos projetos.

O OPM3 faz referência tanto aos projetos quanto aos programas e portfólio da empresa e prescreve três elementos básicos: 1) Corpo de conhecimento (PMBOK, 2004); 2) Modelo de avaliação; 3) Check-list de melhorias; como observado no Quadro 4:

Quadro 4 - Elementos do modelo OPM3 utilizado.

\begin{tabular}{|l|l|}
\hline Conhecimento & $\begin{array}{l}\text { Utiliza o conjunto de definições e conceitos do próprio PMI } \\
\text { (PMBOK), como padrão para gestão de projetos, assim, seu modelo } \\
\text { de maturidade exige um conhecimento prévio neste padrão já } \\
\text { existente. }\end{array}$ \\
\hline Avaliação & $\begin{array}{l}\text { Oferece uma ferramenta de avaliação que indica pontos fortes e fracos } \\
\text { com relação ao conjunto de melhores práticas adotado pelo PMI, dessa } \\
\text { forma, a empresa decide quais melhores práticas ou grupo de melhores } \\
\text { práticas a serem trabalhadas. Dependendo do resultado da avaliação, a } \\
\text { empresa pode optar entre parar ou continuar o processo de melhoria } \\
\text { em determinada área. }\end{array}$ \\
\hline Melhorias & $\begin{array}{l}\text { Depois de identificadas as melhores práticas a serem alcançadas, um } \\
\text { conjunto de "potencialidades" são disponibilizados como um check- } \\
\text { list em que são relacionadas às competências necessárias para cada } \\
\text { melhor prática. }\end{array}$ \\
\hline
\end{tabular}

Dessa maneira, além de um referencial teórico com conceitos e técnicas já existentes, o OPM3 (2003) possibilita que a empresa identifique internamente as “potencialidades" capazes de levá-la a um estágio mais alto de maturidade. Assim, o 
OPM3 (2003) se apresenta como uma forma da empresa utilizar as melhores práticas do setor juntamente com aspectos internos positivos, isso é possível por meio do uso de um autodiagnóstico presente no modelo.

Portanto, depois do PMBOK, o modelo OPM3 se apresenta como um segundo passo para a construção de um padrão para gestão de projetos, programas e portfólios pelo PMI.

\subsubsection{Project Management Maturity Model}

Kerzner (2000) propõe a análise da maturidade na gestão de projetos por meio de um modelo com cinco fases conhecido como Project Management Maturity Model.

A primeira fase, denominada embrionária, acontece quando as primeiras evidências em gestão de projetos são percebidas pela empresa.

A segunda fase refere-se ao reconhecimento da importância em gestão de projetos pela alta administração.

A terceira fase, ao reconhecimento das necessidades em gestão de projetos pela linha gerencial da empresa.

A quarta fase corresponde ao crescimento da função de gestão de projetos.

A última fase corresponde à maturidade organizacional em projetos (KERZNER, 2000).

Este modelo progressivo pode ser observado na Figura 11.

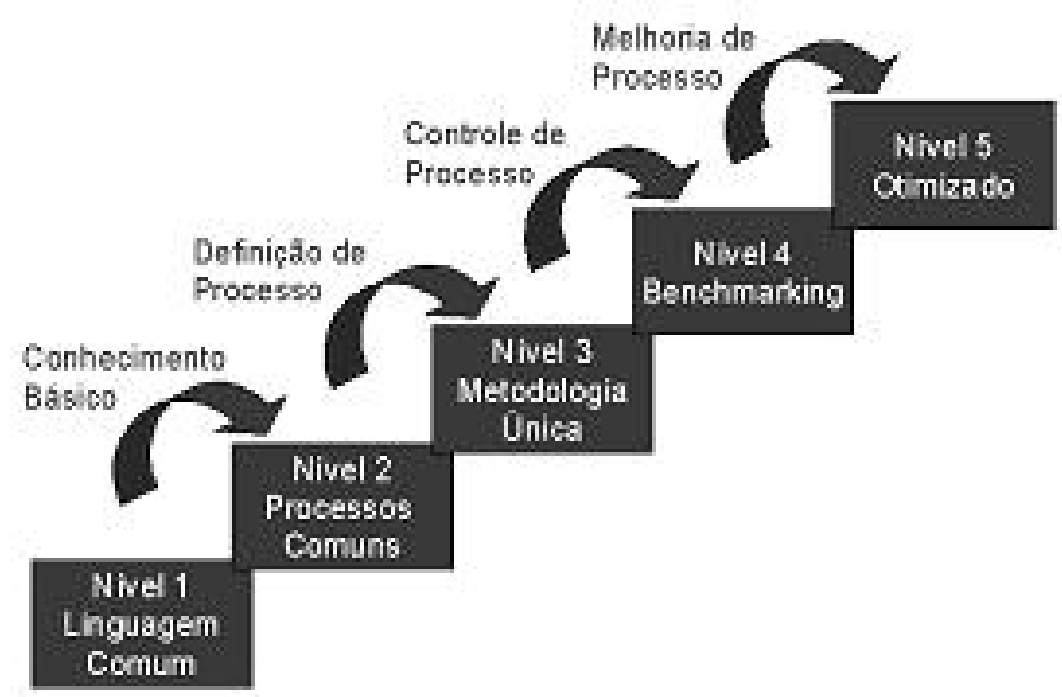

Figura 11 - Modelo de maturidade para gestão de projetos (KERZNER, 2000).

O modelo de Kerzner possui uma representação de níveis e seu diagnóstico é realizado a partir de um questionário com 183 questões disponíveis em uma ferramenta 
baseada na WEB que ao serem devidamente respondidas, indicam o nível de maturidade que a organização encontra-se nas práticas de gestão de projetos.

O modelo também descreve, a partir do questionário respondido, os pontos fortes e fracos da organização como forma de auxiliá-la na busca pela melhoria nas práticas de gestão de projetos.

\subsubsection{ESI Maturity Model}

Em 1999, a empresa de consultoria na área de gestão de projetos, ESI International lançou seu próprio modelo de maturidade aplicado à gestão de projetos. Denominado ProjectFRAMEWORK, seu objetivo é o aperfeiçoamento contínuo da gestão de projetos nas organizações, através da integração de pessoas, processos e tecnologia.

O ProjectFRAMEWORK propõe apoiar as organizações:

- Identificando pontos fortes e fracos no processo de gestão de projetos;

- Estabelecendo uma referência na capacitação em gerência de projetos;

- Tornando-se orientados a projetos e com resultados mais previsíveis;

- Lançando um programa de melhoria contínua, e;

- Integrando princípios e processos de gestão eficaz de projetos na estrutura e nos processos organizacionais.

O modelo do ESI incorporou as idéias de progressividade e de níveis de maturidade do modelo CMM, cujo campo de aplicação restringe-se às organizações que desenvolvem software, ao mesmo tempo em que trata detalhadamente as práticas descritas nos nove campos de conhecimento no PMBOK, definindo objetivos de desempenho para cada um deles. Isto permite diagnosticar adequadamente os processos de gestão de projetos e reduzir o escopo de melhorias a serem introduzidas no plano de ação resultante, visando passar de um nível ou estágio de maturidade para o nível superior.

Na Figura 12 encontra-se uma figura representativa dos elementos do modelo de maturidade formulado pelo ESI e a sua composição básica: 


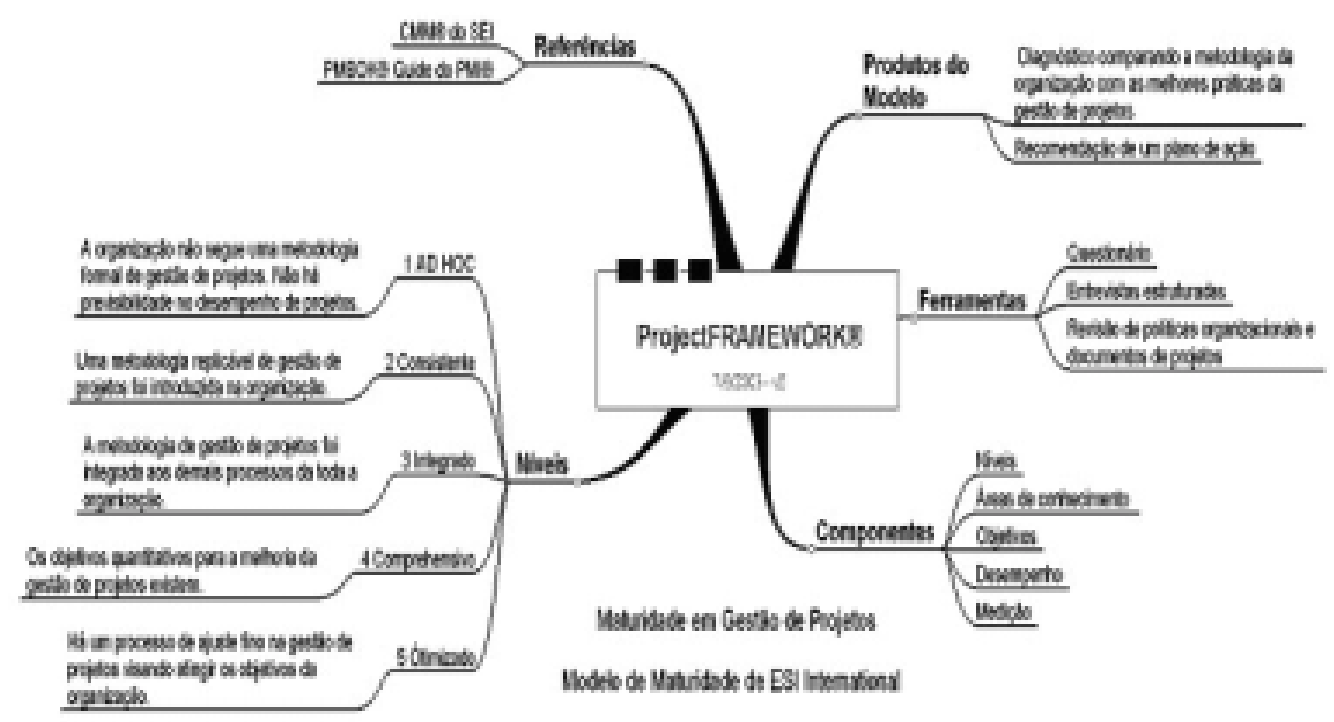

Figura 12 - Modelo de Maturidade Projectframework (SEI, 1999).

\subsubsection{Modelo de Maturidade segundo Rabechini}

Este modelo foi proposto por pesquisadores da Universidade de São Paulo em 2002 quando analisaram diversos modelos de maturidade e após trabalharem com casos reais em empresas através de questionários.

Nestes questionários, os autores incorporaram indicadores relativos às quatro dimensões principais da competência e da maturidade de qualquer organização: estratégia, estrutura, processos e comportamento.

Estratégia, estrutura e processos são dimensões relativas à organização. Comportamento, uma dimensão relativa a pessoas, abrangendo seu grau de conhecimento sobre projetos, sua competência para administrá-los e suas atitudes.

- Estratégia - a competência da organização pode ser avaliada por meio de indicadores como a integração dos projetos na administração estratégica da organização, o interesse e a participação dos altos executivos na administração dos projetos, a existência de sistemas de informação sobre projetos e a existência de alguma forma de administração de portfólio, entre outros.

- Estrutura - a competência da organização pode ser avaliada por meio de indicadores como a existência de uma estrutura organizacional para a administração de projetos, a definição da figura do gerente de projeto, a existência de equipes e de critérios e regras para a montagem dessas estruturas, bem como para a participação de pessoas. 
- Processos - a competência da organização pode ser avaliada por meio de indicadores como a existência de procedimentos para administrar o ciclo de vida do projeto, com fases e "filtros" de avaliação ao longo do processo. Os processos da organização competente procuram dar base sólida ao processo decisório, reduzindo o grau de incerteza e criando condições para o planejamento preciso das variáveis escopo, prazo e custo do projeto. Adicionalmente, a organização dispõe de alguma forma de sistematização de suas práticas e orientação de seus funcionários, por meio de um manual ou instruções.

- Comportamento - a competência das pessoas pode ser avaliada por meio de seu grau de informação sobre projetos, seu domínio de conceitos e técnicas de administração de projetos, bem como por suas atitudes favoráveis em relação aos projetos e ferramentas para administrá-los.

Por outro lado, os autores entendem que a maturidade organizacional distribui-se em pelo menos três estágios ou níveis:

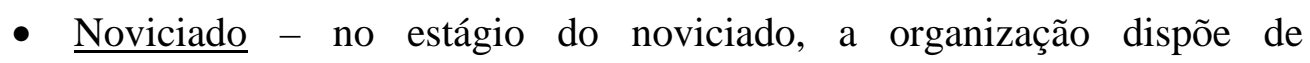
pouquíssimas ferramentas para administrar projetos. Elas existem, mas têm uma convivência conturbada com as atividades funcionais. Segundo o autor, esse era o estágio em que se encontravam muitas organizações industriais ainda em meados da década de 1990, quando não havia ainda pressões tão intensas para atingir resultados, especialmente em projetos de desenvolvimento de produtos. A organização que se encontra no estágio do noviciado, no entanto, sente a necessidade de ferramentas para administrar projetos e já superou a fase da total alienação em relação aos projetos e sua administração.

- Aprendizagem - a organização começa a aprender e está em busca de técnicas e conceitos sobre projetos e como administrá-los. Seus executivos e técnicos, em particular as pessoas mais diretamente envolvidas com encomendas, desenvolvimento de produtos e tecnologia, administram projetos de forma rudimentar e procuram convencer os colegas das vantagens dessa nova idéia. A estrutura organizacional disponível, no entanto, não facilita o trabalho dos gerentes de projetos, 
uma vez que a definição de autoridade e responsabilidades ainda não está muito clara e as pessoas não sabem direito como participar de equipes. A alta administração preocupa-se com o potencial de vantagem competitiva dos projetos e apóia a busca de soluções. Ainda há algum grau de desconforto com os projetos dentro da estrutura funcional, que é fortemente privilegiada. A organização busca uma forma de sistematizar a gestão do ciclo de vida.

- Maturidade - não há um estágio definitivo para a competência. A organização competente encontra-se em estágio de aprendizagem e aprimoramento contínuos. Todos os processos e estruturas estão implantados, a alta administração está comprometida, mas há uma busca contínua de conhecimento, exemplos alheios, participação em eventos como simpósios e conferências. Os projetos são encarados como parceiros das atividades funcionais e não há mais a atitude desfavorável dos estágios anteriores. Há um contingente apreciável de pessoas preparadas para gerenciar projetos e participar de equipes. Há procedimentos claramente definidos para planejar, executar, acompanhar e avaliar projetos. Há uma preocupação em aprender com a experiência dos projetos.

\subsection{Escritório para Gestão de Projetos}

Conforme descrito por Crawford (2002), a não ser que todos os projetos que uma empresa desenvolve sejam conceituados, planejados, executados e encerrados de uma maneira sistemática - usando as metodologias comprovadas de gestão de projetos será impossível para uma organização manter o controle de quais atividades adicionam valor e quais somente drenam recursos.

A necessidade da gestão estruturada de projetos individuais é amplamente aceita nas organizações. As práticas com este objetivo encontram-se difundidas nas empresas e é extensa a literatura disponível que trata da gestão individual de projetos.

Entretanto, a gestão de um projeto individual, do ponto de vista organizacional é insuficiente. Os projetos precisam, de acordo com as possibilidades inerentes à maturidade organizacional, ser medidos e comparados para possibilitar decisões alinhadas com a gestão estratégica. Somente desta maneira é possível uma adequada 
alocação de recursos, as escolhas de quais projetos se tornarão ativos e quais outros serão encerrados ou postergados.

Com o objetivo de satisfazer tal necessidade, autores como Crawford (2002) e Levine (2003) indicam que é necessário o estabelecimento de um departamento estratégico ou central de projetos que pode receber diferentes nomes, entre eles, talvez mais amplamente difundido: Escritório de Projetos. Em linhas gerais, o escritório de projetos, do inglês "Project Office" - PO, é a função estabelecida para facilitar as atividades da gestão de projetos e trazer melhorias ao próprio processo de gestão da organização, através da gestão do portfólio e do alinhamento de projetos com a estratégia corporativa (Crawford, 2002).

Gonsalez e Rodrigues (2002) descrevem a evolução histórica do escritório de gestão de projetos lembrando que este pode ser encontrado como entidade relativamente bem definida desde meados dos anos 60, nos grandes projetos militares, aeroespaciais e de construção civil. Denominavam-se esses escritórios como Escritórios de Controle de Projetos, pois os especialistas em projetos da época possuíam apenas funções de controle e de ações corretivas, ou seja, foco na detecção e correção de problemas.

No final da década de 70 , até meados da década de 80 , com o surgimento dos primeiros softwares de gestão, o escritório mudou para expandir sua cobertura inicial para outros projetos de áreas diferentes, porém, ainda isolados. Para isso, membros das áreas funcionais, não especialistas em projetos, foram alocados nos escritórios que assumiram a função de suporte aos projetos.

No final da década de 80 e meados da década de 90, as ferramentas de gestão e todas as demais ferramentas computacionais sofreram uma revolução, facilitando o trabalho de controle e suporte dos escritórios de projetos. Com isso, gradativamente, o foco de atuação dos escritórios foi mudando de projetos relativamente simples e isolados para um ambiente de multiprojetos e projetos complexos, de funções de controle e suporte para uma gestão global e alinhada com as estratégias organizacionais.

A centralização das atividades de gestão de projetos possui vantagens no que se referem as possíveis reduções de tempo e custo, facilidade de comunicação, padronização de documentos, uniformidade dos processos entre outros.

Diversos autores fazem referência ao escritório de projetos utilizando outros termos que são nada mais que sinônimos, Crawford (2002) lista alguns dos nomes que são utilizados para designar o escritório de projetos: 
- Escritório estratégico de projetos;

- Escritório de apoio ao projeto;

- Escritório de apoio ao programa;

- Escritório de gerência de projeto;

- Escritório de apoio à gerência de projeto;

- Escritório do programa.

Independente dos nomes que o designam, o escritório de projetos pode ser melhor caracterizado a partir dos papéis e serviços que ele presta na organização.

Diversos autores tratam das possibilidades de papéis e funcionalidades encontradas para um escritório de projetos e somente a avaliação das necessidades específicas de uma organização pode definir a gama de atividades que serão de sua responsabilidade (VALERIANO, 2001; HELDMAN, 2003; CLELAND e IRELAND, 2002; CRAWFORD, 2002; LEVINE, 2000).

Valeriano (2001) destaca a individualidade do uso do escritório de projetos, suas funções e abrangência dentro da organização, que por sua vez dependem do estágio de implantação, das necessidades de cada organização e da complexidade dos projetos existentes, e relaciona algumas possíveis atribuições para o escritório dentro da organização. Para tanto o autor divide a atuação do escritório em três diferentes fases.

Estágio inicial do uso do escritório de projetos:

- Prestação de serviços de controle de prazos e custos;

- Elaboração de relatórios multiprojetos e interdepartamentais;

- Treinamento em aspectos específicos de gestão de projetos;

- Ligações com os gerentes departamentais e, em especial, com os gerentes de recursos empresariais;

- Melhoria contínua de processos de gestão de projeto, e;

- Levantamento e arquivo de "lições aprendidas".

Em estágios intermediários, mantêm-se os anteriores com o acréscimo de:

- Arquivo do histórico de projetos;

- Administração dos processos de gestão de projeto; 
- Consultoria interna sobre gestão de projeto;

- Desenvolvimento e aperfeiçoamento de métodos e padrões, e;

- Apoio a reuniões de avaliações e revisões de projetos.

Estágios avançados e de acordo com o nível de autoridade atribuído, os anteriores e mais:

- Análise e aprovação de propostas de projetos segundo objetivos estratégicos da organização e critérios complementares;

- Distribuição de recursos de acordo com prioridades estabelecidas;

- Identificação de conflitos e recomendação para solução;

- Revisão crítica e avaliação de projetos, e;

- Atuação externa com focos nos clientes e patrocinadores.

Algumas possíveis atuações especiais demandam um nível maior de autoridade:

- "Celeiro de gerentes de projeto", tratando de sua formação, treinamento e plano de carreira, e;

- Gerência direta dos projetos da organização.

Como benefícios visíveis do uso do escritório para a organização, o autor lista:

- Maior alinhamento dos projetos com os objetivos da organização;

- Maior profissionalismo da gerência de projeto;

- Maior produtividade das equipes de projeto;

- Maior racionalidade na distribuição de recursos;

- Criação, desenvolvimento e aperfeiçoamento de métodos e padrões de gestão;

- Uniformidade de tratamento perante as partes interessadas, seja as da própria organização, seja as externas, notadamente clientes e patrocinadores.

- Criação e expansão da cultura de projetos na organização, e; 
- Decorrente utilização como importante parte de um sistema de informações estratégicas.

Para Valeriano (2001), os possíveis tipos de escritórios de projetos que podem desempenhar diferentes papéis dentro da empresa são: apoio a projetos, treinamento, consultoria, métodos e padrões e gerência de projetos.

Quadro 5 - Resumo dos serviços do escritório de projetos segundo Valeriano (2001)

\begin{tabular}{|c|c|}
\hline \multirow{16}{*}{$\begin{array}{r}\text { Serviços } \\
\text { prestados de } \\
\text { acordo com } \\
\text { Valeriano (2001) }\end{array}$} & Prestação de serviços de controle de prazos e custos; \\
\hline & Elaboração de relatórios multiprojetos e interdepartamentais; \\
\hline & Treinamento em aspectos específicos de gestão de projetos; \\
\hline & $\begin{array}{l}\text { Ligações com os gerentes departamentais e, em especial, com os } \\
\text { gerentes de recursos empresariais; }\end{array}$ \\
\hline & Melhoria contínua de processos de gestão de projeto, e; \\
\hline & $\begin{array}{l}\text { Levantamento e arquivo de "lições aprendidas".Dispõem de } \\
\text { especialistas que dão suporte aos gerentes de projetos; }\end{array}$ \\
\hline & Arquivo do histórico de projetos; \\
\hline & Administração dos processos de gestão de projeto; \\
\hline & Consultoria interna sobre gestão de projeto; \\
\hline & Desenvolvimento e aperfeiçoamento de métodos e padrões, e; \\
\hline & Apoio a reuniões de avaliações e revisões de projetos. \\
\hline & $\begin{array}{l}\text { Análise e aprovação de propostas de projetos segundo objetivos } \\
\text { estratégicos da organização e critérios complementares; }\end{array}$ \\
\hline & Distribuição de recursos de acordo com prioridades estabelecidas; \\
\hline & Identificação de conflitos e recomendação para solução; \\
\hline & Revisão crítica e avaliação de projetos, e; \\
\hline & Atuação externa com focos nos clientes e patrocinadores. \\
\hline
\end{tabular}

Segundo Heldman (2003), os escritórios de projetos alocam os profissionais para trabalharem como gerentes, e ainda, dependendo do tamanho, dispõem de especialistas para auxiliar os gerentes no planejamento, nas estimativas e nas atividades de verificação das premissas de negócio do projeto. Atuam como mentores para os gerentes de projeto principiantes e como consultores para os experientes.

Dessa maneira, o escritório de projetos se encarrega da manutenção e arquivamento da documentação do projeto. Todos os documentos e informações são reunidos e rastreados pelo escritório para futura referência. Esse escritório compara, ainda, o andamento do projeto em relação às suas metas, e passa os resultados para as equipes; avalia o desempenho dos projetos ativos e sugere ações corretivas ao avaliar os projetos concluídos quanto a seu atendimento ao trio de restrições (tempo, custo e qualidade), identificando se o projeto cumpriu os prazos definidos, permaneceu dentro do orçamento e se sua qualidade foi aceitável. 
Ainda segundo o autor, os escritórios de gestão de projetos estão se consagrando nas organizações modernas e, se não existir outro motivo, servem pelo menos como ponto de coleta da documentação do projeto. Alguns escritórios são bastante sofisticados e prescrevem os padrões e as metodologias a serem usados em todas as fases do projeto, na empresa. Outros fornecem todas essas funções, além de serviços de consultoria em gestão.

Quadro 6 - Resumo dos serviços do escritório de projetos segundo Heldman (2003).

Serviços Dispõem de especialistas que dão suporte aos gerentes de projetos;

prestados de Manutenção e arquivamento da documentação do projeto;

acordo com Avalia a evolução e o desempenho do projeto;

Heldman (2003) Prescrevem padrões e metodologias de gestão.

Fonte: adaptado de HELDMAN, 2003.

De acordo com Cleland e Ireland (2002), o escritório deve ser entendido como um grupo de apoio que provê serviços aos gerentes de projeto, dirigentes e gerentes funcionais trabalhando em projetos. Ainda segundo os autores, o escritório de projeto não pode ser considerado uma unidade de tomada de decisão que substitui tanto dirigentes como gerentes de projeto. Ele prepara, no entanto, informação e relatórios que apóiam o processo de tomada de decisão do dirigente e gerentes de projeto.

Para Cleland e Ireland (2002), o escritório de projetos pode ser tão simples como umas poucas pessoas preparando e mantendo cronograma, até várias pessoas realizando planejamento, informes, garantia de qualidade, coleta de informações de desempenho, e funcionar como um centro de comunicação para vários projetos. $\mathrm{O}$ escritório de projeto é definido pelas necessidades de negócios da organização e cresce com tais necessidades.

Para os autores, o escritório de projetos pode desempenhar funções como:

- Apoio para o planejamento do projeto: mantém a metodologia e as variações dos processos padrão, armazena e atualiza as planilhas para o planejamento, armazena e recupera as lições aprendidas, mantém as medidas de progresso, disponibiliza consultas sobre estimativas de custos e prazos;

- Auditoria do projeto: processa listas de comprovação das “milestones", apóia a intervenção em um projeto devido a deficiências, mantém um registro das ações corretivas; 
- Apoio para o controle do projeto: mantém um registro e o acompanhamento do controle de mudanças, mantém as ações de controle de mudanças e os elementos de conclusão, valida e acompanha as respostas de tempo de trabalho, efetua análise de tendências dos avanços, apóia a elaboração de informes sobre o andamento do projeto, efetua sínteses e resumos dos projetos;

- $\quad$ Apoio para equipes de projeto: participa dos exercícios de integração da equipe, ensina e dirige as técnicas de gestão de projetos;

- Desenvolvimento de habilidades para gerência de projetos: efetua avaliações de habilidades para projetos futuros, participa das avaliações do rendimento do projeto, apóia a aprendizagem contínua das equipes de projetos, mantém as linhas básicas e as mudanças na metodologia do projeto;

- Manutenção do processo de gerência de projetos: Identifica as demandas gerais de treinamento para o processo, mantém políticas, procedimentos e práticas para a gerência de projetos, institucionaliza a gerência do projeto;

- Recursos para a gerência de projetos: avalia as necessidades de ferramentas para os projetos e a organização, avalia a idoneidade e a compatibilidade das ferramentas, coordena o treinamento nas ferramentas utilizadas pelas equipes de projeto, proporciona conhecimentos técnicos sobre as ferramentas, recomenda prioridade para os projetos novos;

- Apoio executivo para projetos: recomenda a alocação de recursos entre os projetos, revisa as avaliações do rendimento dos projetos, serve como consultoria de gerência de projetos para executivos;

- Relatórios dos projetos: coleta e valida a informação de forma periódica ou contínua, prepara e distribui relatórios, prepara relatórios para os dirigentes;

- Problemas: estabelece um registro e rastreia os problemas para o gerente de projetos, fecha os problemas depois de solucioná-los, mantém história dos problemas para a consulta; 
- $\quad$ Riscos: identifica, quantifica e mitiga os riscos, rastreia os riscos e fecha os eventos de risco, prepara planos de contingência;

- Itens de ações: estabelece um registro e o acompanhamento dos itens das ações, fecha os itens das ações depois de seu término, mantém história das ações;

- Comunicações: prepara um plano de comunicações, atualiza o plano de comunicações, se necessário, distribui relatórios para os stakeholders, mantém cópias registradas das comunicações;

- Cronograma: prepara os cronogramas em um sistema automatizado, mantém o estado do cronograma conforme o progresso informado, produz cronogramas, quando necessários;

- Custos: prepara o orçamento, mantém o orçamento baseado nos gastos, informa o estado do orçamento;

- Qualidade: prepara planos de garantia e de controle de qualidade, mantém os planos de garantia e de controle de qualidade, prepara planos de testes e de demonstração, mantém os registros dos testes;

Consulta interna sobre gerência de projetos: serve como fonte para consultas e apoio na solução de problemas e aplicação das técnicas em gerência de projetos para todas as fases do projeto, a fim de melhorar os planos, recuperar os projetos e aconselhar sobre técnicas e sucessos.

Mesmo sendo tão variados os possíveis serviços prestados por um escritório de projetos dentro de uma organização, seu sucesso está também relacionado com a maneira que se dá sua implantação, algumas regras básicas devem ser obedecidas como (CLELAND e IRELAND, 2002):

- Definir os serviços a serem prestados pelo escritório de projeto. Obter o acordo do dirigente e do gerente de projeto sobre os serviços. O escritório de projeto inicial pode desenvolvê-los, mas é importante ter um escopo de trabalho ajustado;

- Definir as competências e os papéis para o pessoal do escritório de projeto, pois eles determinarão a quantidade do apoio que pode ser fornecido. 
- Definir e anunciar o início do escritório de projeto. Ter um plano para sucessos iniciais no apoio a gerentes de projetos e dirigentes. Comemorar os sucessos iniciais.

- Trabalhar com muita atenção com dirigentes e gerentes de projeto para entender suas necessidades e atendê-las. Como os gerentes de projeto são liberados do trabalho de rotina que o escritório de projeto desempenha requisitos adicionais podem emergir;

- Desenvolver os serviços do escritório de projeto à medida que cresce o envolvimento com os clientes;

- Entregar apenas os melhores produtos aos clientes.

Assim, o escritório de projeto deve ter o apoio dos dirigentes para sua iniciação. O sucesso do escritório de projeto será determinado pelos clientes, que são aqueles que recebem os produtos e serviços do escritório de projeto. Os principais clientes são os próprios dirigentes, gerentes ou líderes de projeto, membros da equipe do projeto, gerentes funcionais e os stakeholders.

Crawford (2002) destaca o papel estratégico do escritório de projetos e afirma que não existe um modelo único, devendo atender às necessidades da organização em que ele se insere. Assim, a existência ou não, bem como os serviços e papéis do escritório de projetos vão depender do grau de sofisticação, negócio e cultura da organização. Para o autor, existem papéis bem claros exercidos por eles, como observado da Figura 13.

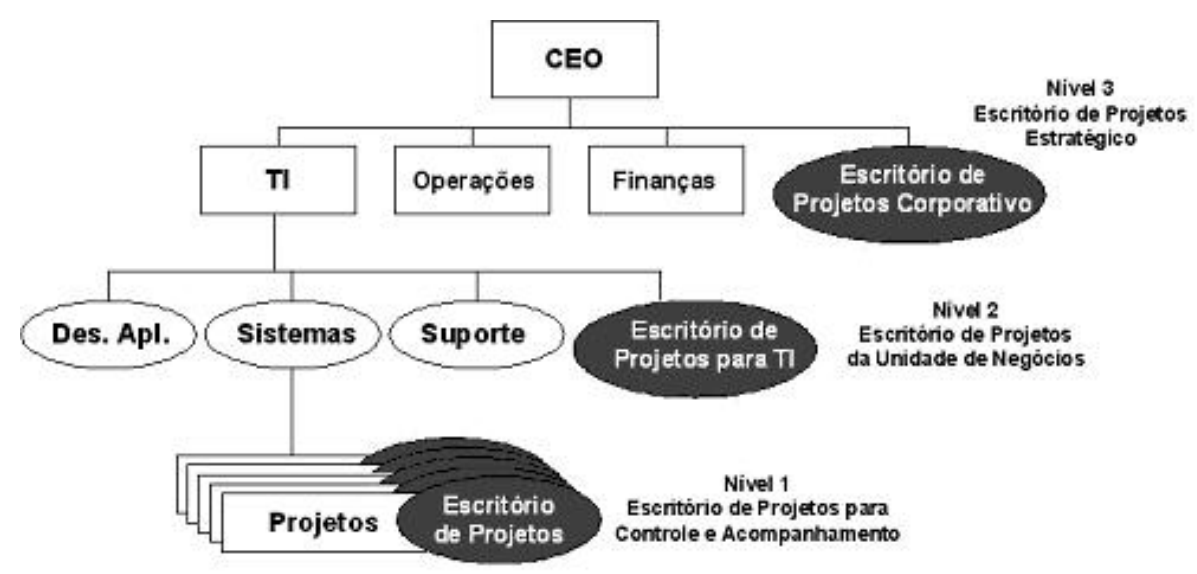

Figura 13 - Níveis de atuação do Escritório de Projetos (CRAWFORD, 2002). 
O primeiro nível do escritório de projetos, ou o nível de escritório de projetos para controle e acompanhamento, são característicos de grandes e complexos projetos únicos como a construção de uma barragem ou um prédio. Estes escritórios são totalmente voltados ao projeto que o criou, sendo grande parte do seu esforço voltado à integração de cronogramas e orçamentos com os programas maiores existentes na empresa.

Já o nível número 2 de escritório de projetos, aquele destinado a uma unidade de negócios específica, tem a importante característica de realizar a gestão de recursos da unidade; assim, é necessário criar métricas para priorização dos vários projetos existentes no departamento que competem por recursos entre si, citam-se como projetos neste nível os programas que não pertencem a uma única unidade como a construção de uma nova plataforma de uma aeronave.

O terceiro nível de escritório de projetos é uma extensão do segundo, no entanto, ele gerencia projetos de todas as unidades de negócio, ou seja, ele decide, de todos os projetos existentes na organização, quais receberão os recursos requisitados. Dessa forma, esta estrutura permite viabilizar projetos e programas que estão alinhadas as estratégias de toda a organização e não somente de uma unidade de negócio. Neste nível encontram-se os escritórios estratégicos para determinadas regiões em que são decididos quais projetos serão executados e quais serão descartados; como exemplo, pode ser considerado o escritório de projetos para a América Latina de alguma grande montadora de veículos.

Para Crawford (2002, pg. 77), existem seis componentes primários a qualquer escritório de projetos que crescem em habilidade e complexidade na medida que seu papel se aproxima da esfera estratégica da organização:

- Apoio a projetos - refere-se ao trabalho de planejamento, criação de agenda, controle de custos, administração, controles e outras tarefas técnicas mais detalhadas - que são constantemente referenciadas simplesmente como ciência da gestão de projetos. Entretanto, existe um conjunto de responsabilidades do gerente de projeto tão importante quanto este conjunto, como liderança, negociação, motivação, construção de times, facilitação, análise, formalizações, estímulo à criação e afins. Dessa maneira, como forma de auxiliar o gerente de projetos a 
desempenhar essas funções, o escritório de projetos pode tomar papéis de apoio como controle e agendas de atividades.

- Ferramentas de software - o escritório de projetos pode centralizar a seleção, aquisição, utilização e manutenção de ferramentas computacionais de apoio à gerência de projetos. Assim, o escritório pode ser responsável por identificar necessidades e oferecer soluções de software, tomando decisões de viabilidade de aquisição, risco de implantação, dificuldades de integração e auxiliando as equipes na capacitação e treinamento para uso de ferramentas recentemente adquiridas entre outros aspectos que norteiam o apoio computacional na gerência de projetos.

- Processos, padrões e metodologias - o desenvolvimento de procedimentos e metodologias é ainda de responsabilidade do escritório de projetos. Neste sentido, é de suma importância que ele sirva como uma biblioteca para o armazenamento de padrões, se apresentando como expertise para a utilização destes, bem como no registro das lições aprendidas na forma de melhores práticas.

- Treinamento - sendo considerado como foco central para o gerente de projetos e equipe de projeto, o escritório tem papel importante na identificação de habilidades e competências para gerentes de projetos. Deve ser entendido ainda como um potencial organizador de cursos e treinamentos para toda a organização, no sentido de engajar, capacitar e formar, em diferentes níveis, para a metodologia de gestão de projetos.

- Consultoria - quando requisitado, deve servir ainda como um mentor para problemas relacionados ao estabelecimento de estruturas voltadas a projetos, oferecendo consultoria para as diversas áreas da organização. Assim, todos devem ver o escritório de projetos como uma fonte de especialistas cujo foco concentra-se nas habilidades de gestão de projetos.

- Gerentes de projeto - o escritório concentra um banco de dados referente a gerentes de projetos, suas competências e habilidades destinadas ao uso em diferentes tipos de projetos. Esses gerentes ficam, portanto, dedicados 
em tempo integral ou parcial à gestão de projetos dentro do escritório de projetos.

O conceito de escritório de projetos pode ainda, desempenhar funções de uma comunidade de prática, registrando melhores práticas e servindo como centralização das informações referentes à gestão de projetos (CRAWFORD, 2002, pg. 195).

A lista consolidada a seguir apresenta possibilidades a serem consideradas, baseadas na literatura revista e utilizando as classificações propostas pelo Gartner Group (apud LEVINE, 2000):

- Serviços de Gestão de Projetos: Treinamento de gerentes e times de projeto e fornecimento de serviços profissionais para a organização;

- Métodos, Processos e Padrões de Medição: Desenvolvimento e manutenção;

- Centro de revisões e análise de projetos: Captação e manutenção de informação dos projetos e adoção na organização de melhores práticas colhidas internamente e no mercado;

- Planejamento de Projetos: Centro de competência e reuso de planos de projetos e modelos;

- Planejamento de Recursos: Histórico de recursos, prazos e custos e identificação de conflitos e sinergias entre projetos.

\subsection{Empresas de base tecnológica}

\subsubsection{Contextualização do ambiente de trabalho}

Desde a década de 90, observam-se mudanças na estrutura das organizações econômicas, principalmente em países como Estados Unidos, Japão e países europeus. Algumas destas mudanças e respectivos resultados são descritos por Perrow (1992), que cita a criação das redes de pequenas empresas, as quais geram riquezas, viabilizam a transferência de tecnologias e participam com uma parcela considerável na absorção de novos campos de trabalho.

Outros autores também concordam com o fato do ambiente tecnológico internacional ter evoluído muito rapidamente desde o início dos anos 1980. Segundo Cassiolato (1999, p.164), "paralelamente à difusão de uma grande variedade de 
inovações por toda a economia, evidencia-se uma mudança de paradigma das tecnologias intensivas em capital e energia e de produção inflexível e de massa para tecnologias intensivas em informação, flexíveis e computadorizadas”.

Associada a tais mudanças observa-se uma intensificação da competição entre empresas e países, confrontados aos mesmos desafios: diminuição de custos, melhoria da qualidade e produtividade de seus produtos e serviços, busca de maior competitividade, criação de novos empregos mais bem qualificados, assim como a necessidade de se criar e, sobretudo, gerenciar novos conhecimentos de toda natureza.

À medida que se consolida esse novo paradigma global, conhecido como $A$ Economia da Informação e do Conhecimento, o tema da inovação, especialmente no contexto da criação e do desenvolvimento de novas empresas de base tecnológica, torna-se cada vez mais relevante devido à importância estratégica que tais empresas representam para o crescimento econômico dos países e a modernização de seus sistemas produtivos.

Continuar definindo uma empresa de base tecnológica ou como também é chamada, de alta tecnologia, encontra-se uma tarefa complexa, uma vez que os parâmetros usados para tal classificação são relativos, ou seja, o que é ser pequeno, ou mesmo, medir uma tecnologia não admite respostas únicas. Ainda neste sentido, A referência à alta tecnologia, por sua vez, se relaciona não à existência de possíveis "baixas tecnologias", mas sim ao uso de tecnologias até então pouco utilizadas, ou então, pouco tradicionais como é o caso de empresas de setores como telecomunicações, redes de computadores e genética.

Marcovitch, Santos e Dutra (1986) afirmam que "empresas de alta tecnologia são aquelas criadas para fabricar produtos ou serviços que utilizam alto conteúdo tecnológico". Torkomian e Ferro (1988) ainda as conceituam como empresas que dispõem de competência rara ou exclusiva em termos de produtos ou processos, viáveis comercialmente, que incorporam grau elevado de conhecimento científico. São encontradas principalmente em setores como informática, biotecnologia, robótica e novos materiais.

Piekarski e Torkomian (2004a) observam que para desenvolverem novas tecnologias, as empresas precisam dispor de recursos tangíveis (por exemplo, financeiros) e intangíveis (por exemplo, tecnológicos). Esses autores ainda afirmam que os recursos tecnológicos, ou competências complementares, podem ser alcançados por 
meio de relações com outras empresas e instituições, ou seja, por meio de uma rede de cooperação.

Desta forma, as redes são consideradas uma forma de ação coletiva, na qual a cooperação pode ser sustentada ao longo do tempo como um arranjo efetivo; os incentivos para o aprendizado e disseminação de informações são criados, permitindo que idéias se transformem em ação rapidamente; a qualidade ilimitada é relevante quando os recursos são variáveis e o ambiente, incerto; e há várias forma de aplicar e ampliar os recursos intangíveis, tais como o conhecimento tácito e a inovação tecnológica (POWELL, 1990, apud PIEKARSKI e TORKOMIAN, 2004a).

A criação das empresas de base tecnológica, dadas as suas características, tem se mostrado como um mecanismo eficaz no crescimento econômico de uma região. $\mathrm{O}$ crescimento no número de empresas, ao invés do crescimento das grandes empresas, propicia uma melhor distribuição da renda e o surgimento de novas oportunidades para o aproveitamento de recursos naturais e humanos.

O processo de criação da empresa de base tecnológica pode se dar de três formas básicas (TORKOMIAN e FERRO, 1988):

- A primeira forma seria a criação através de pessoas que deixaram uma empresa inicial e começam a atuar no mesmo ramo, ou seja, tornam-se concorrentes. As razões para este fenômeno são variadas, possíveis frustrações ou mesmo a busca de maior autonomia de vida ou financeira. Este processo é possível em mercados que se encontram no início do seu ciclo de vida e que permitem uma fácil penetração.

- Uma segunda razão seria a criação da nova empresa estimulada por uma grande organização que viria neste fato a possibilidade de enxugar custos, focar melhor no negócio específico e até como uma forma de valorizar certos funcionários chave e garantir a fidelidade tecnológica da empresa recém criada.

- Por último, mas não menos comum, a criação com origem em instituições de pesquisa, onde o pesquisador em questão vê na criação da empresa uma forma de concretizar e implementar um trabalho ou pesquisa que possua grande potencial de geração de algum negócio. 
Ainda com relação ao processo de criação dessas empresas destaca-se a influência do ambiente institucional que as empresas se inserem. Este ambiente pode ser formado por diferentes agentes: universidades, incubadoras, clusters, instituições de fomento, pólos tecnológicos e empresas de capital de risco. Estes agentes possuem um papel importante na vida de uma pequena empresa no sentido de permitir ou fomentar alguns negócios que, por capacidade isolada da empresa, talvez fossem inatingíveis.

Um fenômeno atual e em evidência em relação às empresas de base tecnológica, a busca da cooperação como arma para a competitividade tem levado estas empresas a se unirem formando aglomerações.

Estudos nos países em desenvolvimento mostram que as empresas que se localizam em clusters têm mais chances de sobrevivência e de crescimento do que empresas similares isoladas (LEVISTKY, 1996). Isto se deve a necessidade de intenso investimento em conhecimento, que por sua vez depende de processos de aprendizado interativos (LEMOS, 1999). Os clusters permitem o estabelecimento de laços de cooperação que possibilitam às empresas um maior acesso às informações e conhecimento.

Encontram-se na literatura diferentes formas de denominação para essas aglutinações de empresas: redes, clusters, arranjos produtivos, pólos e parques tecnológicos. Cada um destes termos se justifica por evidenciar uma determinada característica destas organizações.

Este trabalho não visa discutir ou legitimar os diferentes termos encontrados na teoria sobre o assunto; dessa forma o termo utilizado para o agrupamento das empresas que serão estudadas será o de pólo tecnológico sem, entretanto, questionar a conveniência das demais expressões.

Diversos autores vêm procurando estudar a formação dessas aglomerações empresariais, com vistas a identificar os aspectos mais relevantes destas formações quando inseridas na economia regional (HARDING et al., 2002; PIEKARSKI e TORKOMIAN, 2004b; CASSIOLATO e LASTRES, 2003).

A dinâmica de formação de redes de empresas como a estudada neste trabalho pode ser determinada por estas empresas realizarem atividades semelhantes e/ou utilizarem mão-de-obra específica disponível em poucas regiões (p.ex. produção de software), ou utilizarem as mesmas matérias-primas (p.ex. indústria petroquímica), ou necessitarem das mesmas condições climáticas ou de solo para sua produção (p.ex. produção de chocolates, frutas, etc.), por fornecerem para um mesmo cliente que exige 
proximidade (p.ex. fornecedores de autopeças localizados próximos às montadoras), por processos históricos e culturais, etc.

Independentemente da dinâmica que determina a formação de uma aglomeração empresarial, a característica mais marcante que é, de fato, comum a todos, é a forte concentração em uma mesma região. Dessa forma, a identificação dos mesmos passa obrigatoriamente pela análise dessa variável, pelo menos para identificar potenciais aglomerações.

\subsubsection{Vantagens e barreiras encontradas}

De acordo com Cândido e Dias (1998), para a grande maioria dos estudiosos das empresas de base tecnológica, este tipo de empresa apresenta características semelhantes, sendo que as encontradas com maior facilidade, de acordo com os autores são:

- Gestão integrada - na maioria das vezes sendo exercida pelo próprio empreendedor;

- Estrutura leve, sem complexidade - na maioria das vezes, não existe divisão de tarefas e os funcionários são altamente qualificados;

- Estreito contato pessoal entre direção, funcionários, fornecedores e clientes, devido ao tamanho da empresa e da pouca formalidade existente;

- Integração relativamente forte na comunidade à qual pertencem os seus proprietários, empregados, concorrentes, fornecedores, etc.;

- Utilização acentuada de mão de obra familiar podendo ocasionar problemas de sucessão na empresa, pois este assunto, muitas vezes, não é discutido e a determinação do sucessor só é atendida após o afastamento do até então dirigente;

- Ausência de planejamento, principalmente em longo prazo;

- Baixa utilização dos instrumentos de Marketing, Recursos Humanos, Informática, etc.; 
- Falta de força particular nas negociações entre comprador e vendedor os pequenos e médios empresários não têm poder de barganha frente às negociações.

Para Rothwell e Dodgson (1992), de uma maneira geral, a capacidade de inovação das empresas de base tecnológica, especialmente nos países desenvolvidos, está relacionada a uma série de fatores, dentre os quais podem ser citados:

- A facilidade de acesso às mais diversificadas fontes de informação sobre tecnologias, mercados, concorrentes, clientes, fornecedores e fontes de financiamento;

- A forma inovadora como certos setores de atividade nos quais elas estão inseridas são organizados;

- Estruturas organizacionais mais flexíveis, que lhes permitem uma maior capacidade de adaptação às mudanças;

- A existência de uma eficiente infra-estrutura de apoio local ou regional à inovação, formada por uma série de instituições governamentais e privadas;

- A capacidade de buscar novas competências e de realizar trocas constantes de informações e conhecimento com universidades e centros de pesquisa, até mesmo pelo fato de muitas dessas empresas terem sua origem em pesquisas acadêmicas aplicadas.

Outros autores também procuram caracterizar as empresas de base tecnológica como forma de auxiliá-las na identificação dos fatores críticos de sucesso. Acs e Audrestch (1992) destacam a vantagem em termos de potencial de inovação que as pequenas e médias empresas de base tecnológica têm, permitindo se desenvolverem mais facilmente do que as grandes empresas em certos nichos com potencial de inovação elevado. Segundo os autores, isso se deve ao fato destas empresas "aceitarem" melhor o risco inerente a projetos de grande inovação.

Kruglianskas et al. (1996, p.36), certas características estruturais das pequenas empresas, como "pequena capacidade produtiva, ausência de economias de escala, poder de barganha limitado, bem como a heterogeneidade de suas necessidades" as colocam em situação de possível desvantagem competitiva. 
Segundo Kruglianskas (2003), essas empresas demonstram uma extraordinária orientação "inovativa", termo que o autor faz referência ao potencial de inovação em produtos e serviços. Para o autor, essas empresas ainda se caracterizam por apresentar elevado grau de risco e incerteza, uma existência de ativos intangíveis, ausência de habilidades específicas e por enfrentarem dificuldades associadas ao início do negócio, uma vez que existe a demanda uma grande quantidade de capital inicial dado o caráter de inovação tecnológica e não têm ainda condições de manterem um fluxo de caixa saudável.

Ainda segundo esse pesquisador, como vantagens dessas empresas, cita-se ainda a proximidade com o cliente, identificando a sua necessidade de uma maneira mais rápida e barata e uma maior facilidade de comunicação entre os funcionários, uma vez que prevalece uma estruturação bem horizontal de divisão do trabalho e que por isso favorece também uma grande velocidade de se coordenarem em prol de uma nova oportunidade.

Entretanto, estas empresas apresentam uma altíssima taxa de mortalidade - de acordo com o SEBRAE, cerca de $80 \%$ das pequenas empresas fecham antes de completarem o primeiro ano de funcionamento. O principal motivo seriam problemas gerenciais enfrentados pelos novos empreendedores (SEBRAE, 2004).

Citam-se ainda, as dificuldades burocráticas, que incluem legislação complexa e exigente acarretando em altos custos burocráticos, tributários, de produtos e comercialização. Dificuldades concorrenciais para os micro e pequenos empresários que atuam em mercados oligopolizados, onde grandes empresas ditam prazos e condições de pagamentos para a aquisição de produtos e fornecimento de insumos. As altas taxas de juros sobre os empréstimos dificultando o acesso ao crédito. Completa esse quadro de entraves o difícil acesso a tecnologias para a inovação em produtos e em processos de produção (SIMPI apud SEBRAE, 2004).

Associado a todos estes obstáculos, a dinâmica e turbulência que o ambiente em que esta empresa se insere proporciona o fenômeno descrito por Stinchcombe (1965), a "suscetibilidade da novidade" descrita pelo autor que se refere a maior tendência de insucesso das novas organizações nas fases iniciais de sua criação, dificulta ainda mais as possibilidades de sobrevivência dessas empresas, tanto como empreendimentos capitalistas, quanto produtoras de novas tecnologias.

Assim, o risco associado a empreendimentos nascentes pode elevar-se significativamente, na medida em que estiverem vinculados a inovações tecnológicas, 
uma vez que estas estão sujeitas não só a insucessos de mercado como a insucessos técnicos. Por outro lado, conforme Porter (1998, 2002), as empresas de base tecnológica são as que apresentam maior potencial para geração de "prêmios de preço". Segundo o autor, as nações mais competitivas têm buscado viabilizar a constituição deste tipo de empresas, tanto em função de sua maior rentabilidade, quanto devido à natureza dos empregos que geram - mais exigentes em relação à qualificação dos recursos humanos e remuneração.

No caso das empresas de base tecnológica nacionais, a abertura do mercado brasileiro exigiu dos empresários uma preocupação crescente com a capacidade competitiva dos seus produtos/serviços. Para isso são vistas como fundamentais as práticas indutoras de processos de mudanças organizacionais, capazes de criar mecanismos internos facilitadores à incorporação de inovações e condições favoráveis à ampliação da capacidade competitiva. (FONSECA e KRUGLIANSKAS, 2000).

Entretanto, ao término do trabalho de caracterização das empresas de base tecnológica, verificou-se uma ausência de trabalhos e autores que se propusessem a estudar as práticas de gestão de projetos de acordo com a realidade dessas organizações apesar dos pesquisadores da área salientarem a necessidade de capacitação gerencial por parte dos pequenos empresários.

Assim, duas possibilidades podem ser levantadas: 1) as empresas de base tecnológica não suportam ou não demandam práticas estruturadas de gestão; 2) existe uma lacuna na teoria que trata de projetos nas pequenas empresas uma vez que, quando este assunto é abordado, discute-se somente a existência de projetos de inovação tecnológica como diferencial competitivo e não métodos e instrumentos de gestão de projetos voltados para as necessidades dessas empresas. 


\section{Metodologia}

Neste capítulo são tratados os aspectos que envolvem a escolha dos objetivos, estratégias e meios utilizados na pesquisa. A seleção do método levou em consideração a natureza da população estudada e os objetivos propostos. Como forma ilustrativa, o modelo teórico da pesquisa é proposto e discutido.

\subsection{Objetivos do trabalho e Questões de Pesquisa}

De maneira ampla, o objetivo deste trabalho pode ser definido como sendo o estudo teórico sobre o conceito de escritórios de projetos e a análise da sua aplicabilidade nas empresas de base tecnológica desenvolvedoras de software de São Carlos.

Conforme discutido no capítulo teórico sobre o tema escritório de projetos, o sucesso deste conceito dentro da organização depende de alguns fatores como: tipos de projetos, estrutura organizacional da empresa e como ela gerencia seus projetos (Valeriano, 2001).

Os resultados desta pesquisa contribuem para a teoria de gestão de projetos ao discutir a questão da aplicação das suas técnicas em pequenas empresas de base tecnológica. O objetivo é analisar um caso específico de empresas de base tecnológica procurando identificar o nível de maturidade em Gestão de Projetos destas empresas e os potenciais benefícios e desafios da aplicação do conceito de escritório de projetos.

Como forma de entender quais são os resultados esperados desta pesquisa, podese dividir este objetivo principal em objetivos secundários:

- Levantamento do grau de maturidade das práticas de gestão de projetos dentro das empresas estudadas;

- Descrição dos tipos de produtos e projetos executados pelas empresas; 
- Estudo dos possíveis tipos, papéis e serviços de um escritório de projetos típico;

- Descrição de possíveis relacionamentos entre os tipos, papéis e serviços de escritórios com a realidade das práticas adotadas de gestão de projetos nas empresas estudadas;

A partir do estabelecimento dos objetivos centrais e secundários do trabalho, foram elaboradas as seguintes perguntas de pesquisa, as quais serão utilizadas de maneira a orientar as ações futuras:

- Que práticas de gestão de projetos as empresas de software pesquisadas realizam? Qual é o nível de maturidade dessas práticas?

- Como se caracterizam os projetos executados por essas empresas?

- Quais serviços podem ser oferecidos por um escritório de projetos e que papéis são permitidos, segundo a literatura?

- Quais dos serviços típicos de um escritório de projetos poderiam ser úteis para as empresas estudadas, considerando os tipos de projeto e grau de maturidade?

\subsection{Abordagem Metodológica}

\subsubsection{Escolha do Método}

GIL (1999) define o método científico como um conjunto de processos, operações mentais e técnicas que se deve empregar em uma investigação, ou seja, é a linha de raciocínio adotada no processo de pesquisa. A escolha do método e das técnicas adequadas para cada caso depende de vários fatores, como o objetivo e o tipo da pesquisa.

As pesquisas podem ser classificadas em relação ao seu objetivo como exploratórias, descritivas ou explicativas. As pesquisas exploratórias visam desbravar novas áreas do conhecimento e construir hipóteses, as descritivas preocupam-se em descrever um fenômeno e as explicativas em estabelecer relações de causa e efeito, e entender o "porquê" das coisas (GIL, 1991).

Embora seja difícil classificar de maneira exata o objetivo da pesquisa entre exploratória, descritiva ou explicativa, de acordo com as definições realizadas e as 
questões de pesquisas deste trabalho, adota-se a abordagem descritiva para esta pesquisa, embora grande parte dos esforços despendidos durante este trabalho possam ser melhor classificados como de caráter exploratório.

A partir do objetivo da pesquisa, pode-se discutir qual o procedimento a ser adotado. Como forma de embasar esta decisão, cita-se o trabalho de YIN (2001) que destaca a dependência entre a decisão da estratégia a ser adotada com algumas condições, que são: 1) tipo da questão de pesquisa, 2) o nível de controle que o pesquisador possui sobre os eventos comportamentais efetivos, e; 3) o foco em fenômenos históricos, em oposição a fenômenos contemporâneos.

Contudo, não existe um método único ou específico para determinado projeto; no entanto, o que deve haver é coerência com o problema proposto, os objetivos do projeto e outras limitações práticas de tempo, custo e disponibilidade dos dados. Outra coerência que deve haver no trabalho de pesquisa é entre a abordagem, método e as técnicas de coleta e análise dos dados (ROESCH, 1999).

Para responder às questões de pesquisa deste trabalho, e atingir o objetivo proposto, será utilizado o instrumental metodológico do estudo de caso em um grupo de empresas de base tecnológica desenvolvedoras de software de São Carlos.

YIN (2001) propõe que o principal uso dos estudos de caso está relacionado a respostas a questões do tipo "como" e "por que", quando o pesquisador tem pouco controle sobre os eventos e quando o foco se encontra em fenômenos contemporâneos inseridos em algum contexto da vida real.

Dessa forma, um estudo de caso pode ser entendido como uma estratégia de pesquisa que compreende e abrange não só métodos de coleta de dados, mas também de análise dos resultados. Assim, o estudo de caso não se restringe somente as táticas de coleta ou modelagem do problema, mas como uma estratégia de pesquisa com elementos que se alternam de acordo com as possíveis variações do trabalho (YIN, 1994).

Buscando caracterizar melhor o conceito de estudo de caso, Yin (2001) define o estudo de caso como uma investigação empírica que:

- Investiga um fenômeno contemporâneo dentro de seu contexto da vida real;

- Os limites entre o fenômeno e o contexto não estão claramente definidos. 
Continuando com a definição técnica do termo, o autor acrescenta aspectos relacionados à coleta de dados e as estratégias de análise de dados, assim, a investigação de estudo de caso:

- Enfrenta uma situação tecnicamente única em que haverá muito mais variáveis de interesse do que pontos de dados, e, como resultado;

- Baseia-se em várias fontes de evidências, com os dados precisando convergir em um formato de triângulo, e, como outro resultado;

- Beneficia-se do desenvolvimento prévio de proposições teóricas para conduzir a coleta e a análise de dados.

Destaca-se ainda a visão pluralista do autor quanto ao estudo de caso, que descreve os diferentes propósitos deste tipo de estratégia de pesquisa: exploratório, descritivo ou explanatório.

Segundo Eisenhardt et al. (1989), o estudo de caso constitui-se como uma estratégia de pesquisa que se preocupa em entender a dinâmica presente em conjuntos individuais. Assim, estudos de caso podem envolver um único caso como também casos múltiplos e numerosos níveis de análise.

O autor ainda destaca que o estudo de caso pode utilizar técnicas de coleta de dados como arquivos, entrevistas, questionários e observações e a evidência do trabalho pode ser quantitativa ou qualitativa, dependendo da intenção do autor da pesquisa.

Vários outros autores discutem o uso da estratégia de estudo de caso como forma de atingir diferentes objetivos: permitir alguma descrição (KIDDER, 1982, apud EISENHARDT, 1989), testar alguma teoria (PINFIELD, 1986 e ANDERSON, 1983, apud EISENHARDT, 1989) ou elaborar alguma teoria (GERSICK, 1988, apud EISENHARDT, 1989). Este trabalho se localiza no primeiro objetivo descrito, uma vez que pretende descrever uma situação pouco conhecida.

\subsubsection{Modelo Teórico e Definições Operacionais}

Para melhor entendimento, a estratégia do estudo de caso pode ser decomposta em cinco componentes (YIN, 2001):

- As questões de um estudo;

- Suas proposições, se houver;

- Suas unidades de análise; 
- A lógica que une os dados às proposições, e;

- Os critérios para se interpretar as descobertas.

Portanto, como forma de garantirmos a existência destes componentes na pesquisa, tem-se a necessidade de elaborar a lógica que une, não só os dados da pesquisa e proposições, mas também o embasamento e conceitos teóricos adotados pelo trabalho.

Neste sentido, o modelo teórico do trabalho é apresentado na Figura 14, onde pode ser verificado os conceitos utilizados na pesquisa, autores e teorias que foram utilizados, bem como o processo de coleta e análise dos dados.

A partir da definição de escritório de projetos utilizado na pesquisa, são desenvolvidos os demais conhecimentos utilizados neste trabalho (maturidade e tipos de projetos), além de atividades e resultados do trabalho.

Assim, ao pesquisar o conceito de escritório de projetos deve-se atentar ao fato que na literatura estudada afirma-se que a forma dos escritórios de projetos depende do estágio da empresa nas práticas de gestão e da complexidade dos seus projetos. Portanto, para se averiguar a aplicabilidade do conceito de escritório de projetos no caso proposto decidiu-se pesquisar e medir conjuntamente a: 1) maturidade em gestão de projetos e, 2) caracterização dos tipos de projetos. Uma definição operacional para cada um dos conceitos utilizados é dada a seguir:

- Escritório de Gestão de Projetos - O escritório de projetos (EGP) deve ser entendido como sendo um corpo ou entidade organizacional à qual são atribuídas várias responsabilidades relacionadas ao gerenciamento centralizado e coordenado dos projetos sob seu domínio. As responsabilidades de um EGP podem variar desde o fornecimento de funções de suporte ao gerenciamento de projetos até o gerenciamento direto de um projeto. Este conceito constitui a abordagem teórica da pesquisa, uma vez que, foi elaborado um levantamento teórico sobre este conceito. E, ao término do trabalho, é apresentado uma síntese dos possíveis serviços, funções e papéis dos escritórios de projetos. A forma de utilização deste conceito depende da forma com que a empresa gerencia seus projetos (maturidade em gestão de projetos) e dos tipos de projetos existentes. 
- $\quad$ Maturidade em Gestão de Projetos - o nível de maturidade em gestão de projetos transmite o grau de sofisticação das atividades, técnicas e ferramentas que são realizadas ou utilizadas dentro do processo de gerenciamento de projetos de uma empresa. Assim, o diagnóstico da maturidade em gestão de projetos é a avaliação de como se dá o processo de gerenciamento de projetos da organização. Dessa forma, resta definir o conceito de:

○ Atividade: Um componente de trabalho realizado durante o andamento de um projeto;

○ Técnica: Um procedimento sistemático definido, usado por um recurso humano para realizar uma atividade a fim de produzir um produto ou resultado ou oferecer um serviço, e que pode empregar uma ou mais ferramentas;

- Ferramenta: Alguma coisa tangível, como um modelo ou um programa de software, usado na realização de uma atividade para produzir um produto ou resultado.

Como forma de avaliar e medir a maturidade das empresas, optou-se por utilizar o modelo de maturidade do OPM3, cujo questionário de diagnóstico também serviu como base para a confecção do primeiro instrumento de coleta. Este questionário (Apêndice A - Questionário de Maturidade Organizacional em Gestão de Projetos) propõe um diagnóstico das práticas em gestão de projetos nas pequenas empresas.

- Caracterização ou Levantamento de Tipologias de Projetos - a partir da síntese bibliográfica apresentada no item 2.1.3 foi demonstrado que havia três características a serem levadas em conta: grau de inovação, complexidade do produto e a configuração das equipes do projeto quando se tenta caracterizar os projetos das empresas. Assim, o modelo de tipologia dos projetos pode ser descrito como sendo a relação entre as três características citadas acima para um determinado projeto. A própria bibliografia sobre o tema foi utilizada para a confecção do instrumento de coleta, uma vez que, cada um destes aspectos possui classificações e as respectivas descrições. Portanto, este conjunto de classificações servirá como pauta para a entrevista (Apêndice B - Questionário para Caracterização dos Projetos nas pequenas empresas) no sentido que ajuda 
a identificar os três principais aspectos levantados na revisão teórica, ou seja, a complexidade dos produtos e serviços prestados, o grau de inovação e a configuração das equipes de projeto.

Portanto, de forma resumida, tem-se a estrutura da pesquisa ilustrada na Figura 14, em que se observa o relacionamento entre os conceitos teóricos e a estratégia de pesquisa adotada.

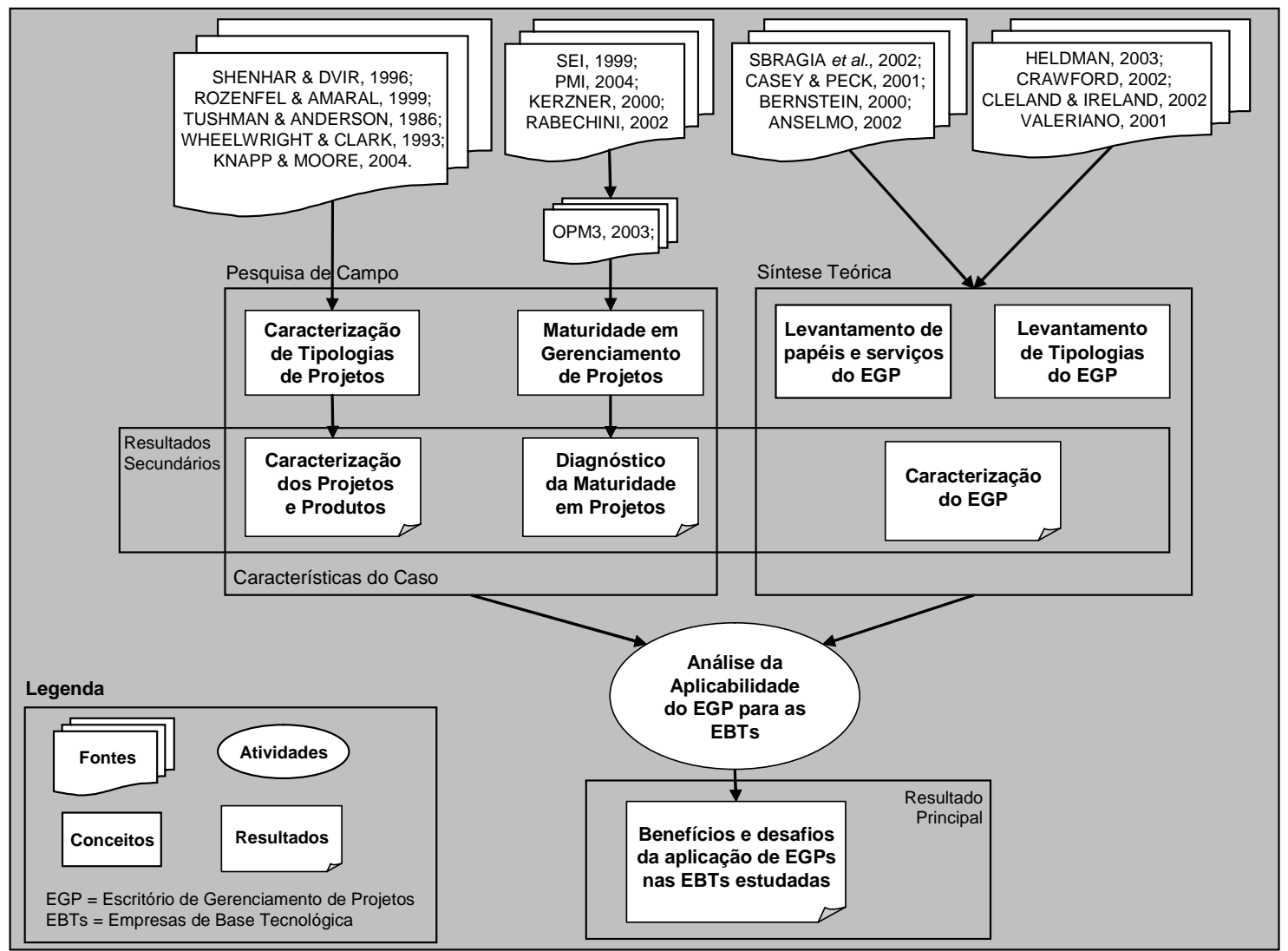

Figura 14 - Modelo Teórico de Pesquisa.

\subsection{Justificativa da escolha do caso}

A cidade de São Carlos se destaca no cenário internacional por ser concentrador de agentes institucionais que fomentam a criação de empresas de base tecnológica.

Destaca-se ainda, a presença da incubadora de empresas Fundação ParqTec que além de ser a gestora do Pólo Tecnológico de São Carlos, incentiva a criação de novas empresas por meio de instrumentos de apoio a novos negócios, como infra-estrutura compartilhada para as empresas e a elaboração de eventos, palestras, cursos e treinamentos voltados aos empreendedores que desejam começar um novo negócio. 
Dentro deste ambiente encontram-se mais de 150 empresas de base tecnológica nas áreas de automação, informática e tecnologia da informação, instrumentação eletrônica, mecânica de precisão, química fina, ótica e novos materiais instaladas, das quais 100 são filiadas à Fundação ParqTec.

Além da Fundação ParqTec ainda destaca-se a presença de outros agentes que favorecem o crescimento deste tipo de empresa, como os dois centros de pesquisa da EMBRAPA bem como as Universidades de São Paulo e Federal de São Carlos que fornecem mão de obra capacitada para trabalharem nos mais diversos tipos de empresas que estão instaladas em São Carlos e região.

De acordo com YIN (2001), a estratégia de estudo de caso, pode ser classificada com sendo de caso único ou múltiplo.

Segundo o autor, o primeiro tipo de estudo de caso é indicado quando:

- O caso é decisivo para se testar alguma teoria bem formulada;

- O caso é aquele em que representa um caso raro ou extremo, ou;

- O caso único serve para propósitos reveladores;

Para o segundo tipo de estudo de caso, o estudo de casos múltiplos, devem ser empregados quando cada caso servir para um propósito específico dentro da investigação; assim, a escolha de cada caso deve ser realizada de forma a:

- Prever resultados semelhantes (replicação literal);

- Produzir resultados contrastantes, por motivos previsíveis (replicação teórica).

Assim, deve-se atentar para o fato de que dentro de estudo de múltiplos casos a abordagem para a escolha dos casos não deve ser a mesma de um levantamento ou experimento, ou seja, a escolha por amostragem. Deve-se, entretanto, escolher os casos de forma que cada caso contribua de maneira única para os resultados da pesquisa.

Dessa forma, a seleção das empresas entrevistadas não segue nenhum critério de amostragem probabilística, sendo utilizada uma amostragem intencional das empresas do Pólo Tecnológico de São Carlos que atende aos objetivos presentes no Quadro 7.

\begin{tabular}{|c|c|}
\hline Critério & Justificativa \\
\hline Existência de projetos com níveis mínimos de & Suficientes para se justificar a necessidade de \\
\hline
\end{tabular}




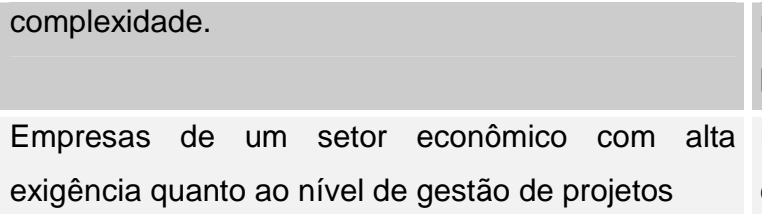

métodos e ferramentas para o gerenciamento de

projetos.

Necessidade da gestão de projetos ser fator crítico de sucesso para os projetos das empresas.

Quadro 7 - Critérios para a escolha dos casos a serem estudados.

Diante do cenário diversificado de empresas e ramos de atividades, optou-se por limitar a pesquisa a uma parte das empresas que deveriam ser analisadas durante as etapas de pesquisas de campo. A escolha do subconjunto de empresas ou setor precisava ser coerente com os critérios descritos no Quadro 7, portanto, optou-se pelas empresas do Pólo de Alta Tecnologia de São Carlos do ramo de informática. Trata-se de um setor empresarial no qual a gestão de projetos vem sendo cada vez mais exigida por parte das empresas-cliente, satisfazendo o terceiro critério.

Além disso, as empresas do ramo possuem projetos complexos envolvendo dezenas de profissionais para planejar, codificar e testar os softwares produzidos. Satisfaz-se assim o segundo critério. Por fim, existe uma iniciativa de trabalho cooperado entre as empresas deste setor presentes no Pólo de Alta Tecnologia de São Carlos, que inclui a formalização de uma entidade jurídica chamada de $\underline{\text { Cluster São }}$ $\underline{\text { Carlos de Alta Tecnologia, voltada para coordenar ações conjuntas que beneficiem }}$ todas as empresas.

As primeiras evidências de formação do arranjo deram-se a partir de alguns projetos realizados entre algumas empresas localizadas na cidade. SV Consultoria, Radium Systems e MZO Interativa compartilhavam origens muito parecidas dentro do mesmo ambiente e demonstravam interesses comuns de realizar projetos em parceria.

Estas empresas, apesar de não terem passado pelo processo de incubação na Fundação ParqTec, encontravam-se alinhadas com as iniciativas oriundas da fundação que suportava projetos de outras pequenas empresas, divulgando a cidade de São Carlos em um cenário mais amplo.

As empresas citadas já utilizavam outros agentes institucionais, além da incubadora ParqTec, como as universidades por meio da mão de obra qualificada e projetos de pesquisa com os departamentos de informática.

Em 2001 estas iniciativas anteriores e os relacionamentos pessoais entre os profissionais das empresas levaram os donos destas três empresas a criarem o Cluster São Carlos de Alta tecnologia. 
Assim, este arranjo foi oficialmente estabelecido em 18 de outubro de 2001. Sendo formado inicialmente por quinze empresas, hoje o arranjo reúne seis empresas (CLUSTER, 2004). Trata-se de uma iniciativa de empresas locais para tornar o município de São Carlos uma referência tecnológica de ponta, com foco no desenvolvimento de software e com base na formação de um aglomerado entre empresas, órgãos de fomento, universidades e governo.

Das seis empresas que compõem o arranjo descrito, a pesquisa utilizou cinco delas, esta escolha se deu por uma limitação da pesquisa e pelo fato da sexta empresa ter se transferido para a cidade de São Paulo o que dificultaria as entrevistas e coleta de dados necessários.

Os projetos realizados pelas empresas que compõem o arranjo estudado possuem complexidades diferentes e em campos de aplicação da informática bastante distintos (instrumentação agrícola, ambientes virtuais, automação). Estes projetos muitas vezes são executados por mais de uma empresa do arranjo formando equipes heterogêneas e dispersas.

De forma complementar aos dois fatores já citados (projetos complexos, projetos em conjunto), segundo os próprios pequenos empresários, as empresas analisadas carecem de sistemas e metodologias de suporte à gestão de seus projetos, o que facilita a pesquisa, uma vez que existe o comprometimento das empresas em cooperar com a pesquisa e utilizar os resultados finais do trabalho.

\subsubsection{Unidade de análise}

Além de único ou múltipo, YIN (2001) ainda ressalta que o estudo de caso deve ser entendido quanto à escolha da sua unidade de análise. E, de acordo com o autor a definição da unidade de análise está relacionada à maneira como as questões iniciais da pesquisa foram definidas.

Neste trabalho, cada caso será representado por uma empresa de base tecnológica desenvolvedora de software da cidade de São Carlos. A unidade de análise, de acordo com a Figura 15, é a caracterização da gestão de projetos da empresa, avaliada por duas variáveis: o nível de maturidade das atividades, técnicas e ferramentas e os tipos de projetos em cada empresa.

Cada variável da unidade de análise será pesquisada a partir de dois diferentes instrumentos de coleta de dados para alcançar o nível de detalhe esperado de acordo com os objetivos da pesquisa, que visam complementar-se. São elas: 1) a entrevista 
semi-estruturada norteada por pautas permitindo certa flexibilidade, mas garantindo profundidade na análise, e; 2) observação direta do pesquisador (observador participante) que poderá visualizar as informações fornecidas na entrevistas sendo utilizadas nos projetos existentes durante o estudo de campo.

Portanto, cada unidade de análise deverá ser submetida a duas entrevistas distintas, representadas por: 1 ) entrevista para diagnóstico da maturidade em gestão de projetos, e; 2) entrevista para caracterização dos projetos realizados nas empresas.

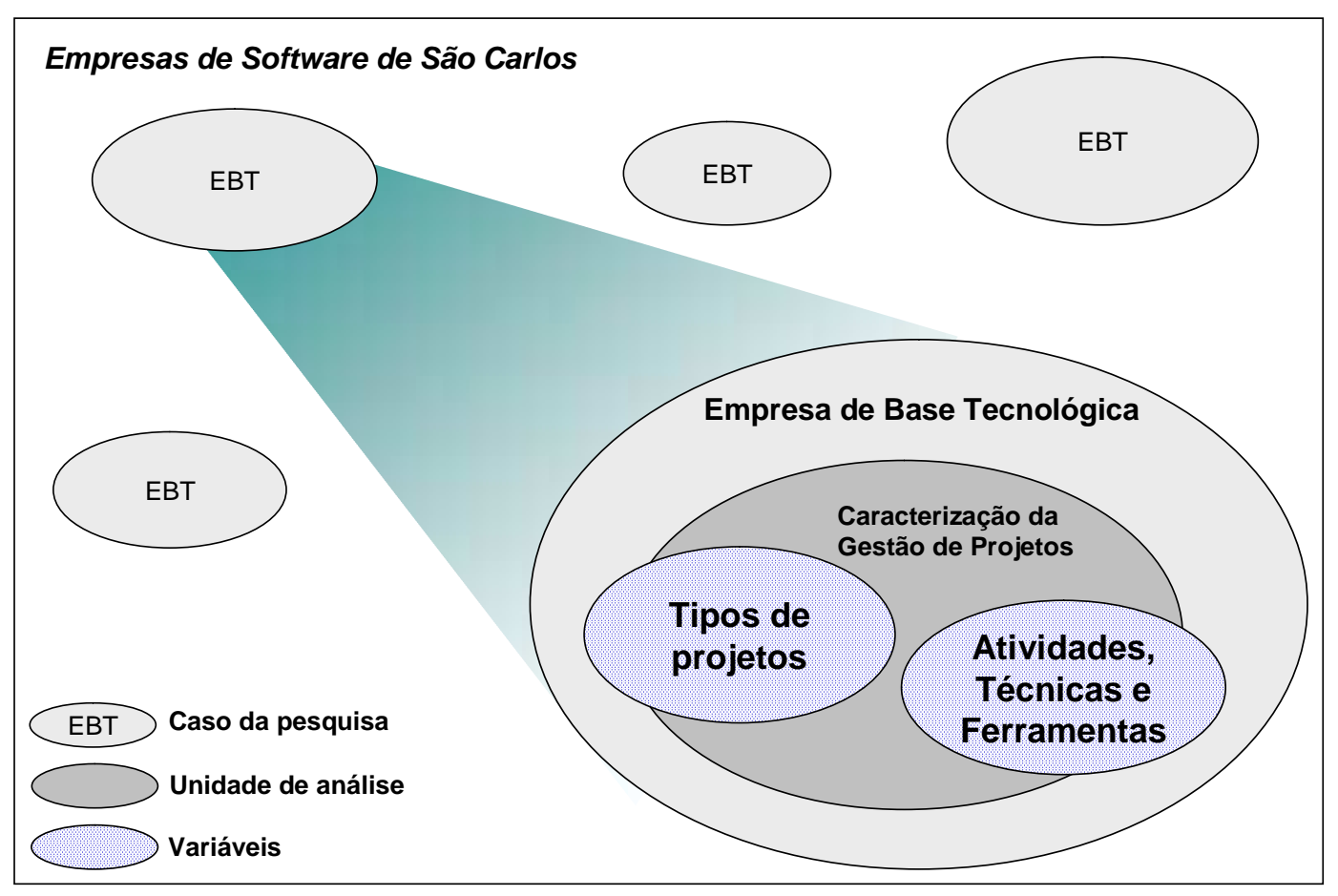

Figura 15 - Unidade de análise da pesquisa.

Para YIN (2001), dentro da estratégia de pesquisa definida como sendo o estudo de caso, tem-se ainda a possibilidade de se diferenciar projetos de estudo de caso considerando a quantidade de casos e unidades de análises da pesquisa. Esta divisão pode ser observada pela Figura 16. 


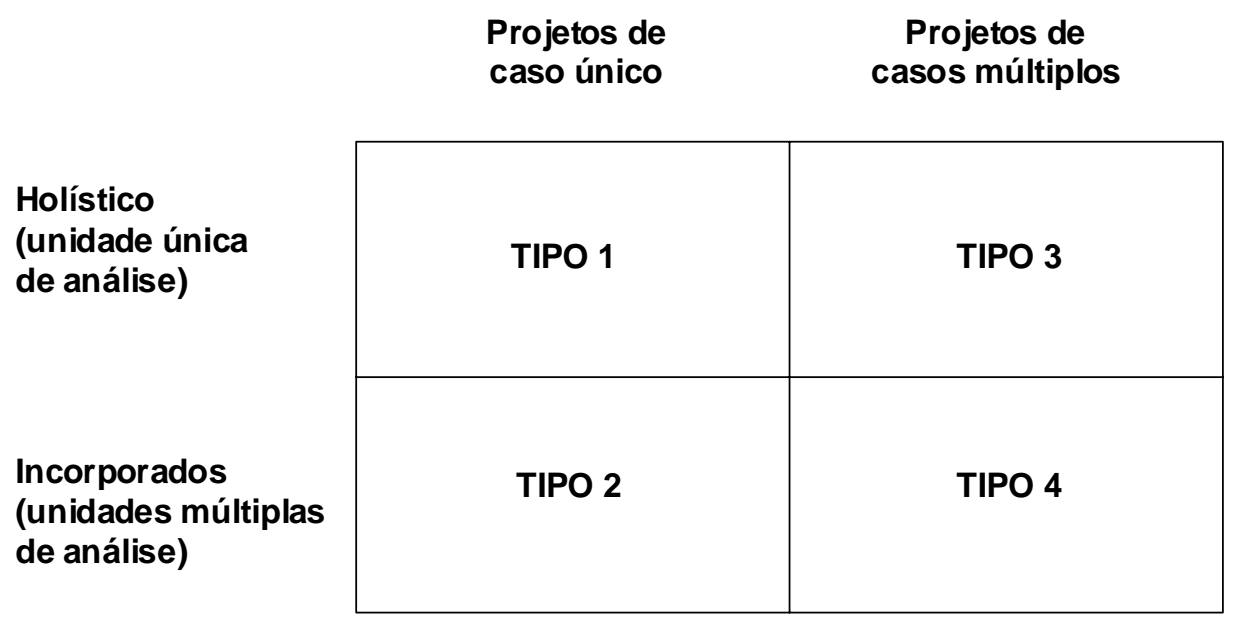

Figura 16 - Divisão entre tipos de estudo de caso (YIN, 2001).

Portanto, a partir do critério de classificação proposto pelo autor, este trabalho pode ser caracterizado como um estudo de casos múltiplos e holísticos (tipo 3), pois as unidades de análise são únicas por caso.

Quanto aos detalhes referentes à conveniência do uso dos diferentes tipos de estudo de caso, sugere-se uma leitura da referência teórica utilizada.

\subsection{Etapas da pesquisa}

De acordo com Mintzberg (1979 p. 585) não importa o grau de complexidade da amostra ou objetivo da pesquisa, o pesquisador deve iniciar seu trabalho com um foco muito bem definido, com o objetivo de coletar especificamente e sistematicamente os dados que lhe interessam.

Assim, o processo de pesquisa deve ser composto por passos ou etapas bem claras e condizentes com o tema e métodos propostos. De acordo com Eisenhardt (1989), o processo de construção teórica partindo do estudo de caso deve seguir alguns passos, os quais ele define como:

1. Início: definição das questões de pesquisa e possivelmente alguma construção inicial;

2. Seleção dos Casos: identificar casos significativos, geralmente pelo procedimento da amostragem intencional. A justificativa para a escolha dos casos pode se basear no caráter excepcional do caso ou por satisfazer um conjunto específico de critérios conforme conveniência aos objetivos do estudo;

3. Procura por instrumental: selecionar múltiplos métodos de coleta dos dados; 
4. Trabalho de campo: coleta e análise dos dados através da aplicação de métodos flexíveis e oportunos;

5. Análise dos dados: Análise dos casos de forma individual e busca de padrões entre os casos estudados;

6. Formação de hipóteses: Iteração das evidências para cada construção, replicação dentro dos outros casos estudados e busca de aspectos causais entre os relacionamentos;

7. Confronto bibliográfico: busca de fontes conflitantes e coerentes com os resultados encontrados;

8. Encerramento: saturação teórica, quando possível.

Seguindo a ordem das atividades proposta por Eisenhardt (1989), entretanto, adaptando para a pesquisa proposta neste trabalho, têm-se as seguintes fases elaboradas:

- Início - Fase exploratória - O início do trabalho deu-se com a análise e adoção de uma terminologia específica para gestão de projetos. Para tanto foram analisadas as mais difundidas (APM's Bok; PMBOK; IPMA; AIPM; ISO 10006) e a terminologia escolhida foi a proposta pelo Project Management Institute (Figura 2). Em seguida, através de uma pesquisa exploratória, foi realizado um levantamento bibliográfico e estudos aprofundados das diferenças entre os modelos de maturidade em gestão de projetos propostos na literatura.

- Início - Fase de construção - Dando continuidade fase inicial do trabalho, ainda na pesquisa bibliográfica, foi definido o conceito de escritório de projetos, as funções desempenhadas por ele e outras possíveis funções que se enquadrem na necessidade das pequenas empresas. Ainda sobre escritórios de projetos, foram pesquisados os tipos mais difundidos na literatura e quais as suas respectivas funções, sua abrangência e peso dentro da estrutura decisória da empresa.

- Seleção dos casos - A escolha das empresas estudadas deu-se por meio do interesse mútuo nos resultados da pesquisa visto que elas encontravam dentro de um trabalho de capacitação interno para as práticas de gestão de projetos.

- Construção do ferramental - O ferramental para a pesquisa foi constituído de uma análise das possíveis abordagens para atacar o 
problema de pesquisa proposta. Foi adotado o estudo de caso com caráter descritivo e exploratório.

- Trabalho de campo - O trabalho de campo se deu com a participação do pesquisador e empresas parcipantes. As informações necessárias para o estudo de caso foram realizadas através de entrevistas direcionadas aos diretores executivos (donos) e gerentes de projeto das empresas analisadas. As entrevistas foram baseadas em um mesmo roteiro de entrevistas contendo questões abertas que serviram como pauta para as discussões. O objetivo era revelar as características dos projetos destas empresas e como elas gerenciavam seus projetos, quais atividades eram realizadas e como eram realizadas durante os projetos, bem como identificar deficiências e potenciais melhorias. Procurou-se também confrontar as respostas com análises de documentos apresentados pelos entrevistados.

- Construção de hipóteses e conclusões - Portanto, de posse das informações obtidas durante as entrevistas com as empresas, a compilação realizada sobre o escritório de projetos foi resgatada com os tipos, papéis e serviços esperados. Pôde-se, assim, analisar quais das funcionalidades do escritório eram críticas para o sucesso das empresas em função do nível de maturidade de cada uma delas.

Por fim, segue a configuração adotada para o trabalho de pesquisa:

Quadro 8 - Caracterização do trabalho de pesquisa.

\begin{tabular}{|l|l|}
\hline \multicolumn{1}{|c|}{ Aspectos } & \multicolumn{1}{c|}{ Classificação } \\
\hline $\begin{array}{l}\text { Abordagem do problema } \\
\text { Método }\end{array}$ & $\begin{array}{l}\text { Pesquisa qualitativa } \\
\text { Estudo de caso }\end{array}$ \\
\hline $\begin{array}{l}\text { Número de casos } \\
\text { Unidade de Análise }\end{array}$ & $\begin{array}{l}\text { Casos múltiplos (5 empresas) } \\
\text { Caracterização da Gestão de } \\
\text { Projetos }\end{array}$ \\
\hline Variáveis & $\begin{array}{l}\text { Duas: } \\
\text { (1) Tipos de projetos, e; } \\
\text { ((2) Nível de maturidade das } \\
\text { atividades, técnicas e ferramentas) }\end{array}$ \\
\hline Procedimentos & $\begin{array}{l}\text { Pesquisa bibliográfica e } \\
\text { Pesquisa de Campo. }\end{array}$ \\
\hline Técnicas de coleta de dados & $\begin{array}{l}\text { Observação direta } \\
\text { Entrevista semi-estruturada }\end{array}$ \\
\hline
\end{tabular}




\section{Resultados}

Os resultados obtidos durante todo este trabalho de pesquisa e entrevistas são compilados neste capítulo, seguindo uma ordem que obedece a critérios lógicos não sendo necessariamente a ordem cronológica que foram gerados. São discutidos todos os pontos alcançados durante o estudo das empresas e os resultados serão subsídios para a discussão e considerações finais deste trabalho.

\subsection{Síntese de serviços e funcionalidades do escritório de projetos}

Conforme já discutido no item 2.2 do capítulo teórico, vários autores discutem o conceito de escritórios de projetos e propõe diferentes formas das organizações suportarem este tipo de estrutura, havendo, na literatura, uma lista extensa de papéis e responsabilidades que em tese podem ser atribuídas a esse tipo de estrutura.

A análise das proposições encontradas na literatura, descritas no item 2.2, demonstrou diferenças significativas nos tipos de serviços propostos como possíveis de serem oferecidos, não havendo nenhuma proposta suficientemente abrangente. A solução foi obter uma síntese das diversas propostas encontradas na forma de serviços de escritório de projetos. A síntese dos possíveis serviços do escritório de projetos foi elaborada a partir da bibliografia que trata deste conceito e a partir das observações realizadas nas empresas. Desta forma, alguns serviços são sugeridos nesta síntese, apesar de não serem tratados na bibliografia utilizada.

Os serviços foram agrupados seguindo o mesmo critério utilizado para agrupar as melhores práticas em gerenciamento de projetos no diagnóstico das empresas, de acordo com o Apêndice C - Tabela de Práticas de Gerenciamento de Projetos para Diagnóstico nas Empresas Entrevistadas. Isto se deve ao interesse deste trabalho em relacionar os possíveis serviços de um escritório de projetos de acordo com o grau de sofisticação das atividades de gerenciamento de projetos nas empresas. 
O resultado é a relação de serviços potenciais de um escritório de projetos, apresentada no Quadro 9:

\begin{tabular}{|c|c|c|}
\hline Áreas & Serviços & Autores \\
\hline \multirow[t]{2}{*}{ Início } & $\begin{array}{l}\text { Auxilia na organização de reuniões de kick-off de } \\
\text { projetos }\end{array}$ & \\
\hline & $\begin{array}{l}\text { Realiza a divulgação do início de um novo projeto } \\
\text { para toda a organização }\end{array}$ & \\
\hline Escopo & --- & \\
\hline \multirow[t]{3}{*}{ Atividades } & $\begin{array}{l}\text { Apóia a definição, levantamento da duração e } \\
\text { seqüenciamento das atividades do projeto por } \\
\text { meio de registros históricos }\end{array}$ & \multirow{3}{*}{$\begin{array}{l}\text { Cleland e Ireland } \\
\text { (2002); Crawford } \\
\text { (2002); Valeriano } \\
\text { (2001) }\end{array}$} \\
\hline & Apóia a elaboração do cronograma do projeto & \\
\hline & $\begin{array}{l}\text { Auxilia o gerente de projetos controlando o } \\
\text { andamento do cronograma, consolidando dados } \\
\text { das atividades do projeto }\end{array}$ & \\
\hline \multirow[t]{4}{*}{ Pessoas } & Apóia a elaboração das equipes de projeto & \multirow{4}{*}{$\begin{array}{l}\text { Cleland e Ireland } \\
\text { (2002); Valeriano } \\
\text { (2001) }\end{array}$} \\
\hline & $\begin{array}{l}\text { Mantém lista de perfis de profissionais para os } \\
\text { projetos }\end{array}$ & \\
\hline & $\begin{array}{l}\text { Auxilia na divulgação de vagas, entrevistas e } \\
\text { contratação de novos profissionais }\end{array}$ & \\
\hline & $\begin{array}{l}\text { Auxilia na distribuição de recursos de acordo com } \\
\text { prioridades estabelecidas }\end{array}$ & \\
\hline \multirow[t]{5}{*}{ Custos } & Apóia no planejamento dos recursos do projeto & \multirow{5}{*}{$\begin{array}{l}\text { Cleland e Ireland } \\
\text { (2002); Crawford } \\
(2002) \text {; Valeriano } \\
(2001)\end{array}$} \\
\hline & $\begin{array}{l}\text { Realiza cotações de serviços e recursos para os } \\
\text { projetos }\end{array}$ & \\
\hline & $\begin{array}{l}\text { Mantém lista atualizada de custos de recursos } \\
\text { para os projetos }\end{array}$ & \\
\hline & Auxilia na elaboração do orçamento do projeto & \\
\hline & $\begin{array}{l}\text { Mantém atualizado o orçamento do projeto } \\
\text { informando os stakeholders sobre desvios }\end{array}$ & \\
\hline \multirow[t]{5}{*}{ Risco } & $\begin{array}{l}\text { Apóia o levantamento de riscos e elaboração de } \\
\text { planos de contingência }\end{array}$ & \multirow{5}{*}{$\begin{array}{l}\text { Cleland e Ireland } \\
\text { (2002); Valeriano } \\
\text { (2001) }\end{array}$} \\
\hline & $\begin{array}{l}\text { Centraliza informações sobre o monitoramento de } \\
\text { riscos }\end{array}$ & \\
\hline & $\begin{array}{l}\text { Mantém registros históricos sobre riscos de } \\
\text { projetos e ações tomadas }\end{array}$ & \\
\hline & $\begin{array}{l}\text { Registra a identificação de conflitos e ações para } \\
\text { solução }\end{array}$ & \\
\hline & $\begin{array}{l}\text { Centraliza e atualiza as últimas informações sobre } \\
\text { planos de ação realizados }\end{array}$ & \\
\hline \multirow[t]{4}{*}{ Qualidade } & $\begin{array}{l}\text { Propõe, divulga, mantém e melhora padrões de } \\
\text { procedimentos e documentos para o } \\
\text { gerenciamento de projetos }\end{array}$ & \multirow[t]{4}{*}{$\begin{array}{l}\text { Cleland e Ireland } \\
\text { (2002); }\end{array}$} \\
\hline & $\begin{array}{l}\text { Audita a aplicação dos padrões de procedimentos } \\
\text { e documentos formais para gerenciamento de } \\
\text { projetos }\end{array}$ & \\
\hline & $\begin{array}{l}\text { Propõe critérios padronizados para a avaliação de } \\
\text { fases do projeto }\end{array}$ & \\
\hline & $\begin{array}{l}\text { Audita a aplicação dos critérios de avaliação para } \\
\text { o projeto }\end{array}$ & \\
\hline
\end{tabular}


Propõe indicadores de desempenho padrão para acompanhamento do projeto

Coleta informações, calcula e divulga os valores dos indicadores de desempenho durante a execução de cada projeto

Inspeciona e controla os resultados que estão sendo obtidos durante o projeto

Realiza auditorias pós-projetos para identificar problemas e lições aprendidas

Aquisição

Elabora e mantém modelos de contratos

Auxilia o desenvolvimento de novos fornecedores

Mantém lista de potenciais fornecedores para os projetos

Apóia o gerenciamento de contratos com fornecedores

Comunicação Centraliza todas as informações pertinentes aos projetos em todas as áreas da gestão de projetos (custo, tempo, recursos)

Elabora, divulga e mantém registro de relatórios para stakeholders dos projetos para diversas áreas da gestão de projetos (custo, tempo, recursos)

Fornece relatórios para instituições externas

\section{Técnicas e Ferramentas}

\section{Ambiente de Projeto}

Presta consultoria interna sobre todas as áreas da

Realiza melhoria contínua de processos de gestão gestão de projetos

\section{Treina as equipes sobre técnicas, ferramentas e} conceitos da gestão de projetos

Analisa opções de ferramentas de mercado e auxílio na implantação e utilização de sistemas de informação para o gerenciamento de projetos

Fomenta e centraliza as ações de comunidades de prática para projetos

Realiza a manutenção e arquivamento da documentação do projeto de projetos

Levanta e registra de "lições aprendidas"

Auxilia na organização da realização de reuniões para avaliação e revisão de projetos, fornecendo dados atualizados e análises sobre o desempenho dos projetos

Age como facilitador na interação entre gerentes funcionais e gerentes de projeto, em especial no planejamento e alocação de recursos

Elabora relatórios multiprojetos e interdepartamentais

Propõe, coleta informações, calcula e divulga os valores de indicadores de desempenho para o portfólio de projetos da organização
Wheelright e Clark (1992)

Cleland e Ireland (2002); Valeriano (2001)

Cleland e Ireland (2002); Crawford (2002); Heldman (2003); Valeriano (2001)

Crawford (2002)

Crawford (2002)

Heldman (2003)

Valeriano (2001)

Valeriano (2001)

Valeriano (2001);

Heldman (2003)

Valeriano (2001) 
Apóia a análise e aprovação de propostas de

Valeriano (2001) novos projetos segundo objetivos estratégicos da organização e critérios complementares

Quadro 9 - Síntese de possíveis serviços de um escritório de projetos de acordo com a bibliografia.

A primeira coluna do Quadro 9 indica a classificação do serviço, a segunda descreve-o e a terceira indica as fontes na literatura que os citaram. Os serviços cuja terceira coluna encontra-se vazia são aqueles que, embora não tenham sido formalmente citados na literatura, foram identificados como significativos pelo pesquisador no decorrer do trabalho.

Dentre as possíveis atividades não relacionadas na teoria, citam-se as atividades de "Início do Projeto" em que o escritório poderia auxiliar a equipe de projeto em aspectos de organização para a reunião de kick-off do projeto e, após esta reunião, na divulgação das informações de abertura do projeto formalizando o início de um novo projeto na organização informando dados relevantes para todos os profissionais envolvidos com projetos na empresa.

Outro conjunto de serviços que não foram tratados na teoria, mas que poderiam fazer parte, são as atividades que envolvem aquisições de recursos para os projetos. Uma explicação para a sua não inclusão é o fato dos autores citados estarem ligados fortemente ao universo das grandes corporações que dispõem de departamentos especializados em compras. Nas práticas das pequenas organizações ou empresas de base tecnológica é comum que parte significativa do tempo do gerente de projeto seja consumida com questões desta natureza. Por isso, decidiu-se incluir na lista de serviços potenciais de um escritório de projetos destinado a essas empresas. Ele poderia: 1) manter modelos de contratos para uso da equipe de projeto para os diferentes serviços e produtos que possam ser contratados durante a execução do projeto; 2) manter uma lista atualizada de potenciais fornecedores para as diferentes necessidades dos projetos; 3 ) caso seja necessário, auxiliar no desenvolvimento de novos fornecedores para o projeto, e; 4) auxiliar no gerenciamento do contrato com os fornecedores atuais, acompanhando o estabelecimento e o encerramento dos contratos.

Conforme discutido no capítulo teórico, devido à variedade de papéis e funções que o escritório de projetos pode assumir, existem diferentes configurações possíveis que dependem não só das características dos projetos executados, mas também da estrutura organizacional e do nível de maturidade que a empresa em questão se encontra em gerenciamento de projetos. Somente uma análise destes aspectos pode dizer como 
um escritório de projetos poderia auxiliar e agregar valor na qualidade dos resultados alcançados.

\subsection{Caracterização da gestão de projetos nas empresas}

\subsubsection{Apresentação das empresas e tipos de projetos}

As pequenas empresas de base tecnológica de São Carlos estudadas neste trabalho são caracterizadas por serem empresas do ramo de informática e estarem inseridas em um ambiente propício à criação de novos negócios baseados em tecnologias inovadoras. Destacam-se ainda pela presença do dirigente empreendedor característico neste tipo de organização e relatado na bibliografia estudada. Este dirigente empreendedor além de guiar o negócio, procura motivar as equipes de projeto em torno dos objetivos da organização.

Os projetos realizados pelas empresas estudadas possuem diferentes níveis de complexidade e em campos de aplicação da informática bastante distintos como instrumentação agrícola, ambientes virtuais e automação. Estes projetos, muitas vezes, são executados por mais de uma empresa utilizando equipes dispersas e heterogêneas durante a execução dos projetos.

Conforme apresentado no capítulo que discute o método de pesquisa do trabalho, o diagnóstico proposto foi realizado com instrumentos de coleta de dados semi-estruturados. Assim, para o estudo das empresas foram preparados dois roteiros de entrevistas diferentes. A primeira entrevista tinha o objetivo de caracterizar os projetos executados por elas. Em uma segunda entrevista, foram evidenciados os aspectos descritos no modelo de avaliação do grau de maturidade já apresentado.

O questionário aplicado foi elaborado seguindo as divisões feitas no modelo teórico, como Início, Integração, Escopo, e as informações obtidas nestes questionários foram compiladas em uma planilha em que foi calculada a incidência das melhores práticas executadas para cada nível proposto.

\subsubsection{Empresa A}

A empresa A está instalada na cidade de São Carlos é uma empresa de software que desenvolve projetos e aplicações para WEB.

Por meio de uma estrutura projetizada, a empresa A, além de desenvolver aplicações específicas para alguns clientes, comercializa linhas de produtos do tipo 
prateleira, isto é, pacotes que podem ser adaptados rapidamente para a necessidade do cliente.

Esta realidade da empresa $\mathrm{A}$, faz com que existam duas grandes áreas de desenvolvimento dos produtos: 1) uma delas voltada ao desenvolvimento de aplicações baseadas em plataformas e componentes de software livre que centraliza a maior parte dos recursos da empresa e; 2) outra, que utiliza uma plataforma de desenvolvimento proprietária e que na fase de coleta de dados não foram evidenciadas as práticas de gerenciamento de projetos adotadas por esta equipe.

Esta divisão entre as equipes de desenvolvimento de software se espelha nas técnicas utilizadas para o gerenciamento de software, dado que utilizam plataformas diferenciadas com características próprias de desenvolvimento. Neste trabalho, serão consideradas para a avaliação da maturidade da empresa em gerenciamento de projetos as práticas e técnicas utilizadas pela equipe 1 que é responsável pela linha de produtos que são comercializados para vários clientes por meio da parametrização e reutilização de componentes de software.

A empresa A destaca-se devido à preocupação com o melhoramento das práticas internas de gerenciamento. Assim, foi verificado que os recursos da empresa estavam mobilizados dentro de um programa de ações que tinha como objetivo trazer maior aderência das práticas e técnicas de gerenciamento de projetos e qualidade de software.

Vale ressaltar, entretanto, que o roteiro de entrevista e as observações foram realizados em um momento específico da empresa e, por isso, não evidencia este movimento presente internamente na organização.

Seus projetos podem ser classificados como de complexidade média, uma vez que, apesar da tecnologia utilizada ser de domínio do mercado, esta possui uma interface com o cliente bastante sofisticada contribuindo para o incremento da complexidade dos projetos.

Quanto ao grau de inovação dos projetos da empresa A, pode-se classificá-la como de baixa inovação dado que a maior parte dos seus projetos que são adaptados seguindo requisitos dos clientes e reutilizam componentes pré-existentes.

Com relação à configuração das equipes de projetos, os projetos são formados por equipes locais de colaboradores, que raramente são alocados fora da empresa durante a execução dos projetos. 


\subsubsection{Empresa B}

A empresa B caracteriza-se por ser uma empresa de tecnologia voltada para o ramo agroindustrial. Especializada em automação agrícola, a empresa B possui uma estrutura organizacional do tipo matricial forte em que o gerente de projeto possui grande autoridade sobre os recursos da empresa.

A empresa utiliza a incubadora de empresas local no início de suas atividades, busca as competências necessárias para o desenvolvimento dos projetos de base tecnológica dentro das universidades públicas da cidade e centros de pesquisa como a EMBRAPA, que participa ativamente nos projetos da empresa B.

Durante as entrevistas realizadas com os dirigentes na empresa, puderam ser verificadas certas iniciativas de melhoria no gerenciamento de projetos, como a busca de uma ferramenta de suporte gerencial aos projetos, além do incentivo por parte da gerência, da realização de treinamentos para os gerentes de projetos da empresa.

Estas iniciativas presentes na organização facilitaram a coleta de dados no sentido de propiciar um vocabulário comum entre entrevistador e entrevistado, além de garantir as evidências das práticas de gerenciamento utilizadas.

Seguindo a classificação proposta para a caracterização dos tipos de projetos, podem-se classificar os projetos da empresa B como de complexidade média a alta, uma vez que, somente parte da tecnologia utilizada nos projetos é de domínio do mercado, assim a empresa desenvolve algumas partes dos projetos de maneira inédita, outro aspecto que contribui para a complexidade dos projetos é a interface com o cliente bastante sofisticada contribuindo para o incremento da complexidade dos projetos.

Quanto ao grau de inovação dos projetos da empresa B, pode-se classificá-la como alta inovação dados que projetos são, na maioria das vezes, elaborados a partir da necessidade dos clientes e não da adaptação de produtos já existentes.

Com relação à configuração das equipes de projetos, os projetos são formados tanto por equipes locais de colaboradores, quanto por membros que trabalham em campo para certas atividades como levantamento de requisitos, homologação e testes da solução. Assim, a empresa B possui equipes dispersas de projeto.

\subsubsection{Empresa C}

A empresa $\mathrm{C}$ presta serviços de consultoria e desenvolve tecnologia na área de controle de acessos de pessoas para o mercado corporativo. 
Os produtos desenvolvidos pela empresa são baseados em uma tecnologia desenvolvida internamente e são utilizados por grandes empresas de diferentes ramos da economia. Estes produtos são compostos por um hardware e um software de controle, ambos desenvolvidos internamente.

Fundada por ex-pesquisadores das universidades da cidade de São Carlos a empresa conta com vários outros profissionais que vieram destes centros de pesquisa e integram as equipes de projeto.

Por meio de uma estrutura matricial forte, as equipes de projeto possuem um líder que direciona a equipe e gerencia as diferentes etapas do projeto.

A empresa incentiva o treinamento das equipes nas práticas de gerenciamento de projeto como forma de melhorar a qualidade das atividades de gerenciamento e disponibilizar um vocabulário comum entre os profissionais dedicados às atividades de projeto.

Devido à natureza das soluções da empresa $\mathrm{C}$, existem duas grandes equipes na empresa, além das áreas administrativas: a área de projetos de hardware e a área de projetos de software, sendo esta segunda a área objeto de estudo desta pesquisa.

Quanto à caracterização dos projetos da empresa $\mathrm{C}$, foram observados projetos de complexidade alta, uma vez que, além da interface do produto ser bastante sofisticada, a os produtos da empresa apresentam alta complexidade de funcionamento empregando projetos de software de baixo nível e hardware dedicado.

Além desta classificação, a empresa C, quanto ao grau de inovação dos projetos, apresenta projetos que podem ser bastante reutilizáveis permitindo uma adaptação às necessidades de cada cliente. Dessa forma, seus projetos podem ser classificados como apresentando baixo grau de inovação.

Sobre a configuração das equipes de trabalho, os projetos da empresa C são formados por membros que trabalham tanto internamente quanto em campo para determinadas atividades do projeto (levantamento de dados e requisitos, validação e testes da solução). Dessa forma, a empresa C apresenta uma configuração de equipe dispersa para seus projetos.

\subsubsection{Empresa D}

A empresa $\mathrm{D}$, além de prestar serviços de consultoria e desenvolver sistemas de automação agro-industrial, oferece suporte pós-venda aos seus produtos. As soluções 
desenvolvidas utilizam técnicas de processamento digital de imagens em conjunto de projetos de hardware.

A empresa tem sua origem em uma incubadora de empresas de tecnologia local, na qual é disponibilizada uma estrutura compartilhada de apoio às equipes de trabalho como laboratório de informática e biblioteca com notas técnicas.

Dessa maneira, as equipes são formadas pelas áreas de software e hardware e cada uma delas trabalha utilizando uma metodologia de desenvolvimento de produtos.

Apresentando uma organização matricial balanceada, destaca-se a figura do empreendedor que fomenta o uso de técnicas de gerenciamento de projetos como forma de trazer padronização dos procedimentos.

Utilizando os centros de pesquisas locais como fonte de mão de obra altamente especializada, a empresa D emprega alta tecnologia no reconhecimento de imagens. Os colaboradores da empresa possuem ótima formação técnica, mas baixa experiência em gerenciamento de projetos.

Dessa forma, a organização fomenta a participação de seus colaboradores em cursos da área como forma de suprir esta competência não desenvolvida na universidade.

Seus projetos podem ser classificados como sendo de complexidade alta uma vez que, além da interface ser sofisticada, a tecnologia utilizada emprega desenvolvimento de hardware e software específicos.

Devido à natureza específica dos projetos da empresa $\mathrm{D}$, tanto em questão de hardware como em software, estes são altamente dedicados para determinado negócio. Assim, a empresa apresenta um alto grau de inovação para seus projetos.

Com relação à configuração das equipes de projetos, os projetos são formados por equipes locais de colaboradores, que raramente são alocados fora da empresa durante a execução dos projetos.

\subsubsection{Empresa $E$}

A empresa E desenvolve produtos de software para diversas finalidades. Utilizando e desenvolvendo software livre dentro de seus projetos, a empresa E emprega o compartilhamento (interno e externo) de informações como forma de acelerar o desenvolvimento e aumentar a qualidade dos novos softwares produzidos.

A origem da empresa $\mathrm{E}$ difere, em linhas gerais, das demais empresas devido ao fato de não ter utilizado a estrutura da incubadora local. O crescimento da empresa está 
foi obtido graças a um projeto de financiamento de pesquisa da FAPESP, fazendo com que a empresa ingressasse no ramo de serviços de alta tecnologia.

Utilizando ferramentas de desenvolvimento de software que auxiliam no gerenciamento de projetos, estas ferramentas possibilitam desde o acompanhamento da produtividade até a criação da documentação necessária para o projeto.

Com uma estrutura matricial forte, a empresa $\mathrm{E}$ participa de projetos internacionais com equipes remotas de trabalho. Como forma de possibilitar este tipo de trabalho, a empresa utiliza intensivamente ferramentas de comunicação intra e entre projetos.

De acordo com a classificação proposta para a caracterização dos tipos de projetos, pode-se classificar os projetos da empresa E como de complexidade alta, devido: 1) tecnologia utilizada e desenvolvida não é totalmente dominada pelo mercado, e; 2) produtos da empresa possuem interface complexa.

Quanto ao grau de inovação dos projetos da empresa E, seus projetos apresentam baixa inovação, dado que são, na maioria das vezes, elaborados a partir da necessidade dos clientes; entretanto, por se tratarem de projetos de software baseados no uso de componentes, os projetos apresentam uma alta reutilização de componentes de produtos já existentes.

Com relação à configuração das equipes de projetos, os projetos são formados tanto por equipes de colaboradores que na maioria dos projetos encontram locais. Entretanto, a empresa desenvolve projetos em parceria com equipes dispersas. Assim, sua configuração pode ser classificada como local/dispersa para equipes de projetos.

A partir da caracterização dos projetos realizada nas empresas (Quadro 10) é possível ter uma visão geral dos tipos de projetos encontrados nestas empresas.

A caracterização da tipologia de projetos foi realizada a partir do roteiro de entrevista disponível no Apêndice B - Questionário para Caracterização dos Projetos nas pequenas empresas e a partir das informações obtidas e consolidadas, podem ser feitas algumas observações:

- Em sintonia com a bibliografia estudada sobre as empresas de base tecnológica, as empresas estudadas apresentam alto grau de complexidade em seus projetos. Esta complexidade pode ser originada devido ao tipo de tecnologia utilizada nos projetos ou mesmo da 
complexidade da interface existente para o desenvolvimento do produto ou serviço.

- Com relação ao grau de inovação, o resultado aparentemente contrário a bibliografia é devido ao fato das empresas que desenvolvem software, utilizarem componentes para desenvolverem seus projetos, proporcionando uma redução de tempo e risco para os projetos.

- Quanto à configuração das equipes o resultado foi misto, não apresentando uma situação única dentro do grupo de empresas estudadas. Todas as empresas apresentavam grande parte do esforço do projeto baseado em equipes locais e faziam uso de equipes dispersas com intensidades e momentos diferentes.

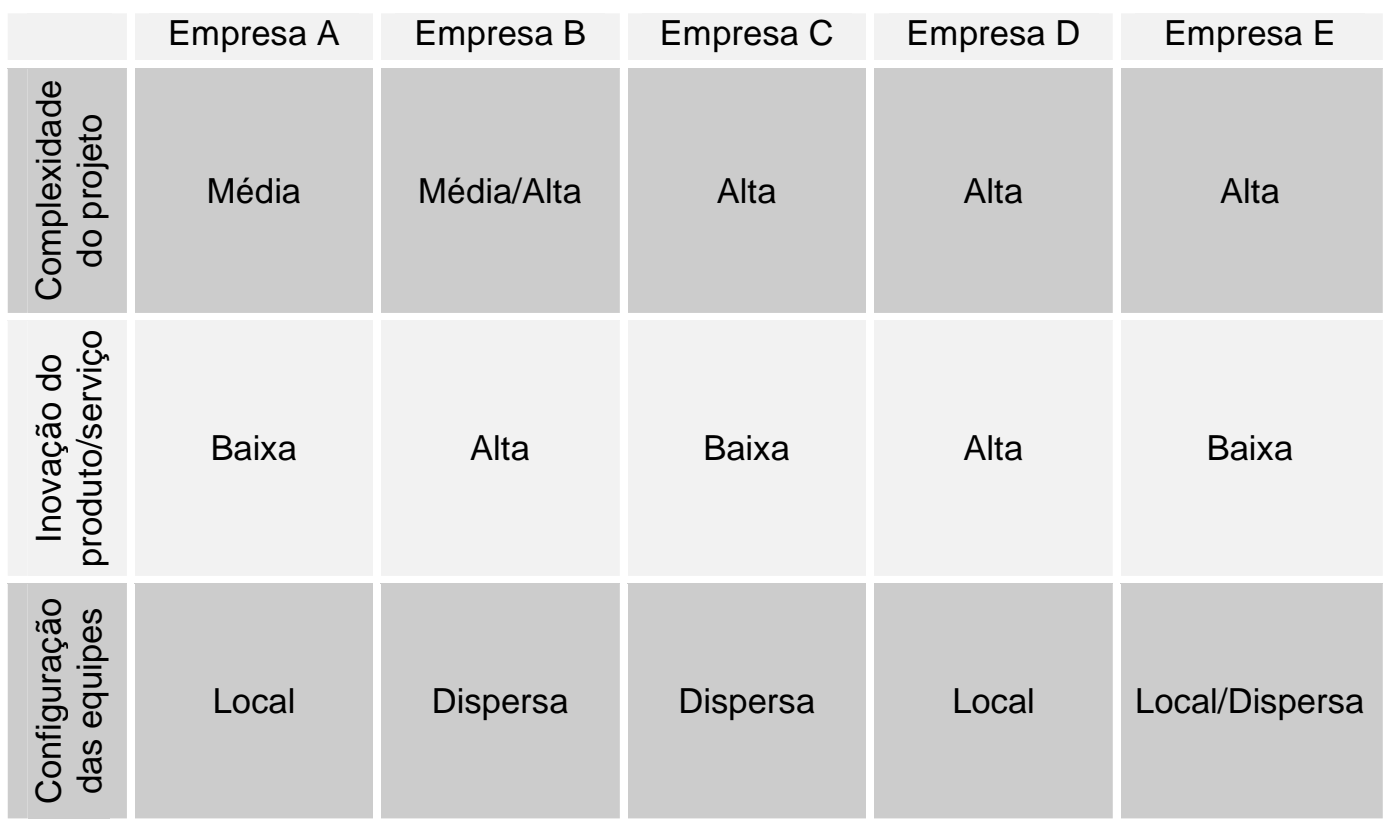

Quadro 10 - Caracterização da tipologia de projetos nas empresas estudadas.

\subsubsection{Descrição do modelo e método para avaliação do nível de maturidade}

Um dos objetivos deste trabalho é a determinação do grau de maturidade em gerenciamento de projetos das empresas analisadas, dessa forma, foram buscados modelos já existentes que facilitassem inferir o nível de maturidade das empresas. A decisão da escolha de um modelo pré-existente se deu por motivos relacionados ao corte dado à pesquisa que desde o início não se propôs a estudar os modelos de maturidade em si, que vêm nos últimos anos recebendo várias contribuições. A idéia era utilizar os modelos que já vêm sendo desenvolvidos. Para isto foram analisados os modelos que são reconhecidos dentro do universo estudado do gerenciamento de projetos. 
A partir dos modelos analisados durante a revisão teórica deste trabalho (RABECHINI, 2002; CMMI, 2002; KERZNER, 2000; SEI, 1999; OPM3, 2003), escolheu-se trabalhar com o modelo OPM3 que, apesar de ser um modelo recente, ainda não testado e validado como os mais consolidados, possui o escopo exclusivamente nas práticas do gerenciamento de projetos. Os demais modelos de RABECHINI, CMMI e SEI abordam outros aspectos, respectivamente: questões de estratégia da empresa, metodologias de projeto do produto e questões específicas de análise e desenvolvimento de software. Com relação ao modelo do KEZNER, cujo escopo é voltado especificamente para gestão de projetos, sua estrutura é menos completa que o OPM3.

Assim, a escolha do modelo teórico de maturidade em gerenciamento de projetos deve-se aos seguintes pontos:

- Foi elaborado a partir da contribuição de milhares de profissionais da área de gerenciamento de projetos.

- Devido ao instituto que liderou a sua elaboração já ser um agente que fomenta a construção de conhecimento na área de gestão de projetos, garante-se coesão dentro do vocabulário e conceitos utilizados entre o modelo e a teoria de gestão de projetos já existente e, desta forma;

- Propicia um vocabulário comum para todos os profissionais que trabalham com esse modelo de maturidade;

- Modelo trabalha exclusivamente com melhores práticas da gestão de projetos e não aborda outros temas como a qualidade do desenvolvimento de software (CMMI, 2002) ou a estratégia da organização (RABECHINI, 2002).

O modelo OPM3 (2003) propõe um checklist para avaliar o estágio de competência das organizações, apresentando os passos necessários para a evolução em direção a um estágio superior. Este checklist propõe um grupo de melhores práticas no campo de gerenciamento de projetos.

Estas melhores práticas foram avaliadas segundo os critérios:

- Realmente contribui para a maturidade em gestão de projetos na organização?

- A organização tem condições de implementá-la diretamente, sem a necessidade de pré-requisitos? 
- Permitem o uso de critérios de desempenho como forma de medir a eficiência da implementação?

Conforme já discutido no capítulo teórico, o estudo do OPM3 (2003) considera três elementos básicos para sua implementação dentro da organização: 1) Conhecimento; 2) Avaliação, e; 3) Melhorias.

Apesar das vantagens citadas pela adoção deste modelo teórico de maturidade, além de ser recente e em fase de consolidação, apresentou-se excessivamente extenso para aplicação por meio de entrevistas e observações. Adicionam-se a este fato certa redundância encontrada em sua construção, devido a sua aplicação para os projetos, programas e portfólios. E, por último, o instrumento de avaliação existente era composto de um questionário voltado para a auto-avaliação. Por tudo isso, o guia do OPM3 foi adaptado para sua devida utilização na pesquisa.

O trabalho de identificação do grau de maturidade das empresas foi realizado a partir das observações diretas da realização das atividades, utilização de documentos e da aplicação de uma entrevista realizada com pessoas envolvidas em novos projetos. Esta entrevista foi guiada por um roteiro elaborado baseando-se no modelo de avaliação adaptado OPM3 Self-Assessment (OPM3, 2003, Apêndice D, pg. 75) e nas suas melhores práticas descritas de acordo com a teoria utilizada. Assim, ao término da pesquisa pôde-se de maneira quantitativa analisar a incidência das melhores práticas em cada empresa entrevistada.

Esta fase posterior de análise quantitativa teve como objetivo permitir com maior detalhe as constatações sobre incidências das práticas nas diferentes empresas, ou seja, pôde-se comparar de maneira mais assertiva o nível de maturidade das empresas estudadas.

Dessa forma, após ser feita a adaptação do modelo original, foi realizada a extração das questões a serem inseridas no roteiro de entrevistas.

Com o objetivo de exemplificar este processo de criação do roteiro, toma-se a figura do gerente de projeto que é citada no modelo utilizado. As melhores práticas referentes ao gerente de projetos descrevem as atividades e responsabilidades durante $o$ projeto:

- Estabelecimento do papel e responsabilidades do gerente de projeto;

- Contribuição e relevância das decisões do gerente de projeto no escopo do projeto; 
Assim, buscou-se no questionário identificar estes tópicos por meio de questões que permitissem as empresas descreverem o papel e responsabilidades do gerente de projeto:

- Q1 - Todo projeto da empresa possui um gerente de projeto nomeado?

- Q2 - Quais são as responsabilidades esperadas de um gerente de projeto? Como estas responsabilidades são cobradas? Elas são formalizadas/documentadas?

- Q3 - Como é feita a nomeação dos gerentes de projeto?

Todas as questões respondidas deram subsídios para o preenchimento do modelo de avaliação adaptado, como apresentado no Quadro 11.

\begin{tabular}{|c|c|c|c|c|c|c|c|}
\hline empresa entrevistada & & \multicolumn{6}{|c|}{\begin{tabular}{c|r|r|r|r|r|}
$40 \%$ & $25 \%$ & $25 \%$ & $11 \%$ & $0 \%$ & $0 \%$ \\
23 & 14 & 14 & 6 & 0 & 0
\end{tabular}} \\
\hline Melhores práticas & Evidênias encontradas & 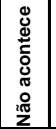 & $\begin{array}{l}\text { : } \\
\frac{1}{1} \\
\frac{1}{2}\end{array}$ & 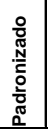 & 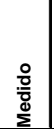 & 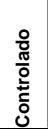 & 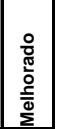 \\
\hline Inicialização das informações do projeto & $\begin{array}{l}\text { A utilizaçáo de modelos de documentos garante uma certa } \\
\text { padronização desta atividade. }\end{array}$ & & & $\mathbf{x}$ & & & \\
\hline Elaboração do plano do projeto & $\begin{array}{l}\text { A utilização de modelos de documentos garante uma certa } \\
\text { padronização desta atividade. }\end{array}$ & & & $\mathbf{x}$ & & & \\
\hline Execução do plano do projeto elaborado & $\begin{array}{l}\text { Acontece de maneira padronizada a partir do plano } \\
\text { estabelecido. }\end{array}$ & & & $\mathbf{x}$ & & & \\
\hline Controle e monitoramento de mudanças no plano do projeto & Executado de maneira ad-hoc. & & $\mathrm{X}$ & & & & \\
\hline
\end{tabular}

\section{Quadro 11 - Modelo de avaliação adaptado.}

As melhores práticas descritas foram agrupadas em itens ou grupos, de acordo com as áreas de conhecimento descritas no Quadro 1, com o objetivo de identificar em quais aspectos as empresas se encontravam mais desenvolvidas e possibilitar uma discussão de quais seriam as práticas encontradas nas empresas entrevistadas.

\begin{tabular}{|l|l|}
\hline \multirow{4}{*}{$\begin{array}{c}\text { Áreas do } \\
\text { Conhecimento }\end{array}$} & \\
\hline Iń́cio & Melhores práticas \\
\hline \multirow{4}{*}{ Integração } & Inicialização das informações do projeto \\
\hline \multirow{3}{*}{ Escopo } & Elaboração do plano do projeto \\
\cline { 2 - 2 } & Execução do plano do projeto elaborado \\
\cline { 2 - 2 } & Controle e monitoramento de mudanças no plano do projeto \\
\hline & Planejamento e definição do escopo do projeto \\
\cline { 2 - 2 } & Verificação do escopo durante o projeto \\
\cline { 2 - 2 } & Gerenciamento de mudanças de escopo \\
\hline
\end{tabular}

\section{Quadro 12 - Grupo de melhores práticas identificadas.}

Estas melhores práticas são produtos dos processos e atividades descritos pelo modelo de gerenciamento de projetos adotado (PMI, 2004) conforme tratado página 10. 
O modelo utilizado, conforme descrito no item teórico sobre maturidade, prescreve um modelo evolutivo composto por quatro níveis (Padronizado, Medido, Controlado e Melhorado).

Para este trabalho, o diagnóstico das empresas foi realizado com a adição dos níveis "inexistente", quando a melhores práticas não eram realizadas na organização, e “ad-hoc", para as melhores práticas que apesar de serem realizadas, não possuíam uma forma estruturada ou padronizada ou não eram realizadas para todos os projetos.

Portanto, além dos níveis sugeridos pelo OPM3 o trabalho de diagnóstico contou com níveis sugeridos, resultando assim, para cada prática analisada, as 6 situações possíveis (Inexistente, Ad-hoc, Padronizado, Medido, Controlado e Melhorado).

O modelo de avaliação adaptado discutido e utilizado neste trabalho segue no Apêndice C - Tabela de Práticas de Gerenciamento de Projetos para Diagnóstico nas Empresas Entrevistadas.

Após a realização das entrevistas foram consolidados os dados de cada pesquisa de maneira a clarificar o panorama encontrado em cada uma das empresas analisadas.

Este trabalho de consolidação dos resultados foi elaborado com todas as práticas de gerenciamento de projetos recolhidas do modelo adotado. Conforme já tratado de maneira mais detalhada na página 10, item que descreve as áreas de gerenciamento de projetos de acordo com o PMI (PMBOK, 2004), foram utilizadas as áreas de conhecimento deste modelo para agrupar as práticas de gerenciamento e identificar a ocorrências destas áreas dentro da organização como descrito no Quadro 12.

Dessa maneira, os resultados de cada área da gestão de projetos foram analisados utilizando para isso a contagem realizada e as evidências encontradas nas empresas após as entrevistas e observações das práticas, documentos e procedimentos internos conforme Quadro 13. 


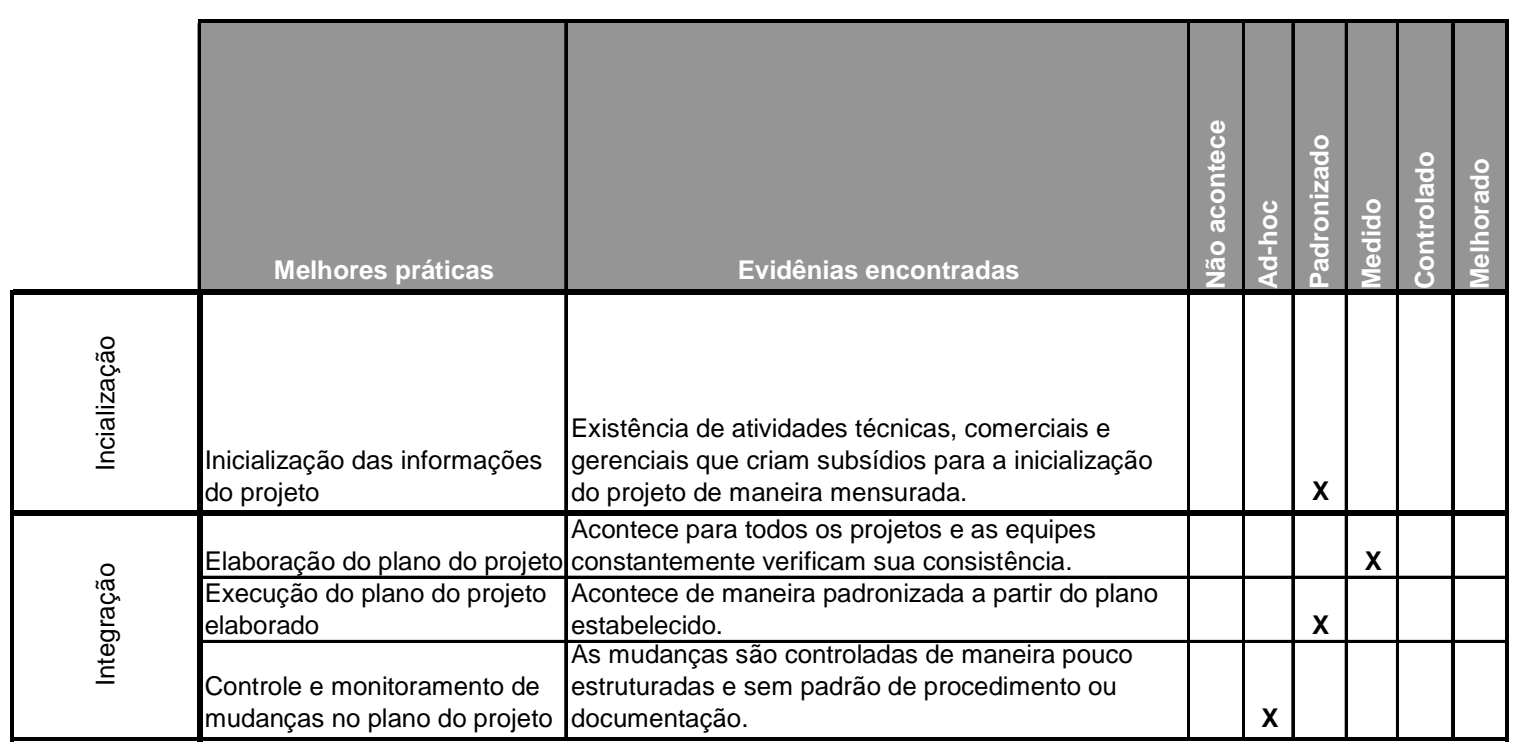

Quadro 13 - Exemplo dos resultados das pesquisas por áreas de conhecimento.

Após a consolidação destes dados, a contagem para cada grande área foi realizada utilizando média ponderada para a determinação do respectivo valor, ou seja, foi considerado um valor índice para cada nível de maturidade, conforme a Tabela 1 e, cada prática foi associada a um nível de maturidade a partir das evidências destas na organização pesquisada.

Dessa forma, o valor para cada grande área foi considerado como sendo a média de cada valor individual, como demonstrado na Tabela 1, em que são associados números de 0 a 5 para os 4 diferentes níveis de maturidade, além dos estados "Inexistente" e "Ad-hoc".

Tabela 1 - Valor associado a cada nível de maturidade.

\begin{tabular}{|l|c|}
\hline Nível de Maturidade & Valor associado \\
\hline Não acontece & 0 \\
\hline Ad-hoc & 1 \\
\hline Padronizado & 2 \\
\hline Medido & 3 \\
\hline Controlado & 4 \\
\hline Melhorado & 5 \\
\hline
\end{tabular}




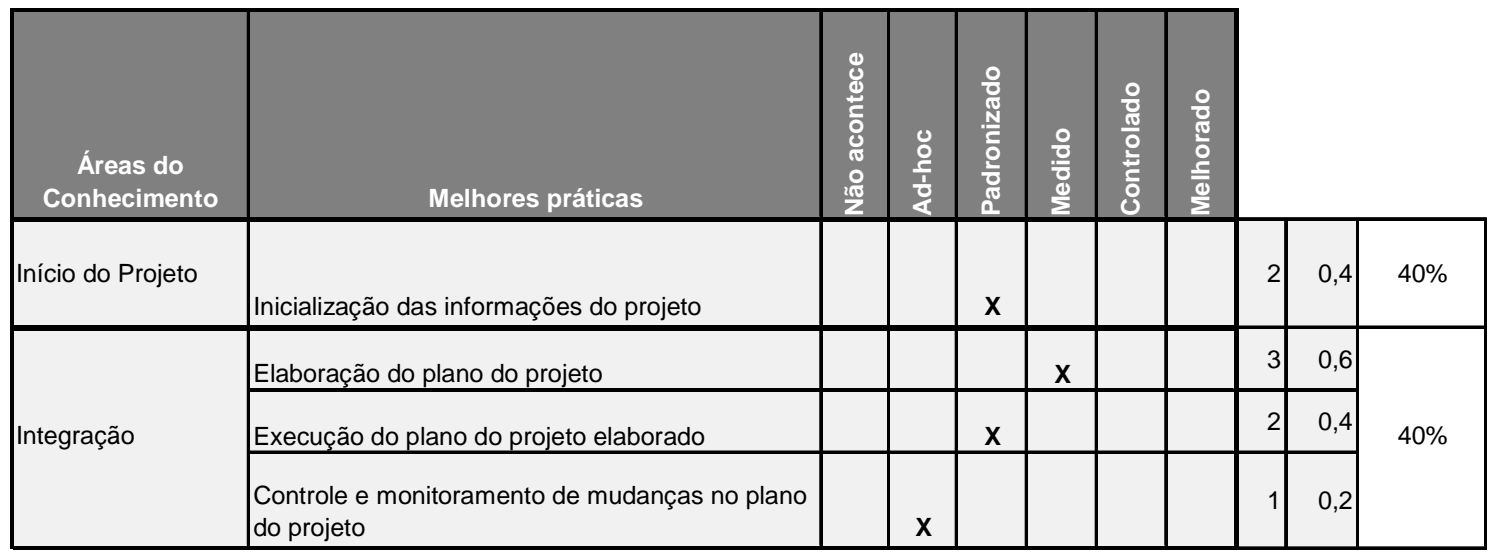

Quadro 14 - Sistema de contagem para consolidação dos resultados da pesquisa.

Para obter um número comparativo entre empresas e áreas, foi calculada a soma de todos os pontos das práticas relacionadas a uma área e dividida pelo número máximo de pontos possíveis. Explicando melhor, caso um grupo de práticas dentro de uma determinada área de conhecimento for realizado de maneira "Melhorado", a soma total da área terá o nível mais alto de pontuação em cada prática, o resultado final da área seria então 1 ou 100\%, conforme padrão utilizado pelo Quadro 14.

Quanto a este sistema utilizado para tentar quantificar o nível de maturidade das empresas, cabem algumas ressalvas sobre este objetivo. A forma de quantificação utilizada procura minimizar a subjetividade dos resultados comumente utilizados em trabalhos e descritos por termos como "pouco utilizados", "muito desenvolvidos", entre outros.

O processo descrito acima visou dar subsídios de comparação e análise de forma menos compromissada com valores ou percepções que não puderam ser discutidas, tratadas ou detalhadas neste trabalho e que são característicos da forma como foi realizada a coleta de dados desta pesquisa.

A partir deste trabalho realizado para todas as práticas diagnosticadas e para todas as empresas analisadas, pôde-se chegar aos resultados da pesquisa.

Após a realização das atividades de coleta de dados da pesquisa e a devida utilização do modelo de avaliação descrito anteriormente no item 4.2.2, foram obtidos os resultados que são inicialmente mostrados para cada empresa em particular.

A compilação dos resultados para cada empresa seguiu os critérios e valores descritos no modelo de avaliação, de acordo com o exemplo da Figura 17. 


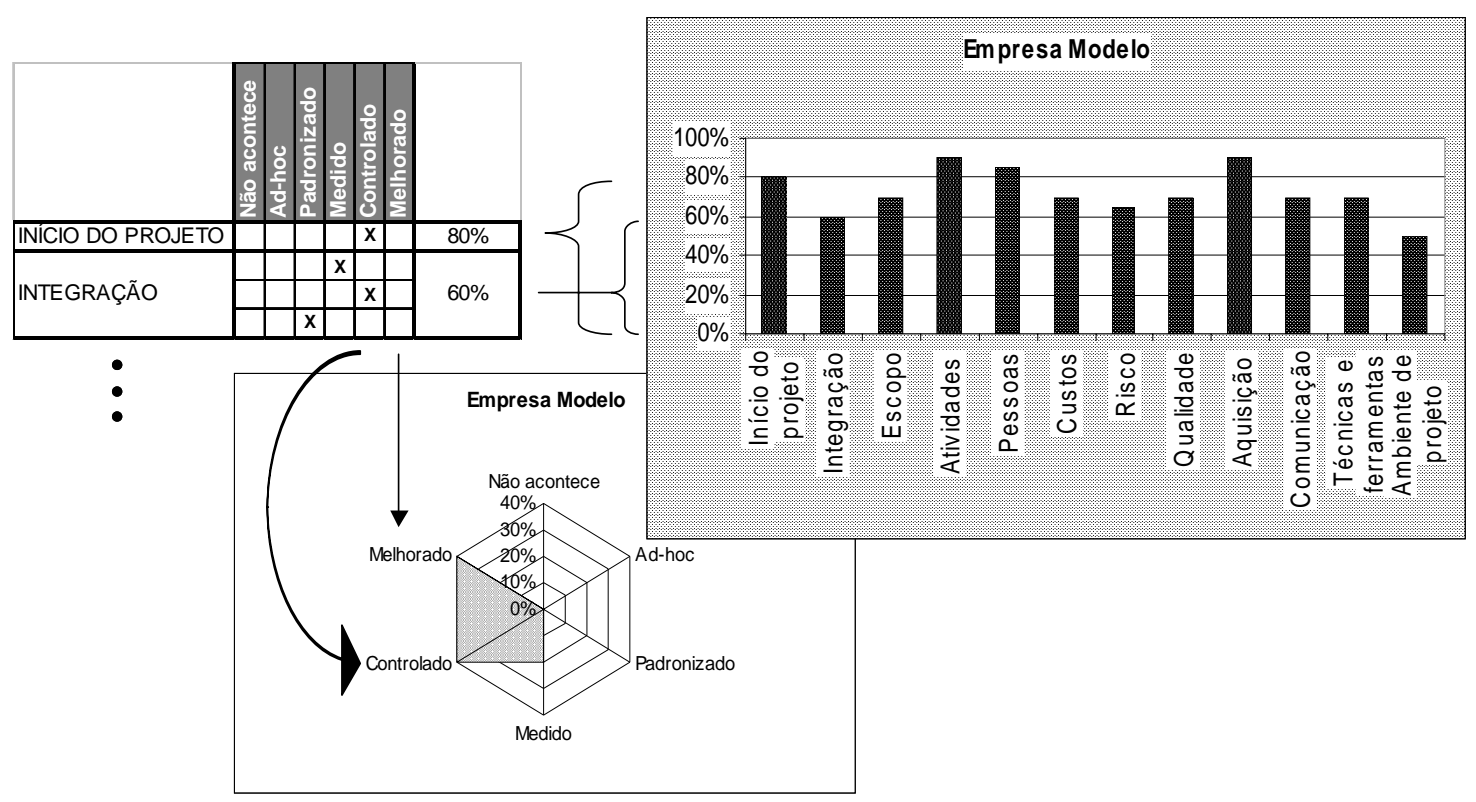

Figura 17 - Demonstração da lógica utilizada para a compilação dos resultados da pesquisa.

Para cada área da gestão de projetos obteve-se um valor a partir do diagnóstico realizado, conforme exemplo (Início do Projeto - 80\%; Integração - 60\%); estes valores são mostrados em gráfico de barras para cada empresa.

$\mathrm{Na}$ dimensão dos níveis de maturidade foi contabilizado o percentual das atividades que se encontravam em cada um dos 6 níveis propostos, este valor percentual foi estruturado em gráficos tipo radar.

\subsubsection{Resultados do diagnóstico}

\subsubsection{Empresa $A$}

A empresa A apresentou pontuação em todas as áreas de conhecimento com exceção na área de gerenciamento de riscos dos projetos. Merece destaque para a área de gerenciamento de tempo, ou atividades, em que a empresa já havia desenvolvido procedimentos e ferramentas para controle das atividades e tempos dos projetos, isto reflete na pontuação verificada para esta empresa no que se refere ao gerenciamento das atividades que atingiu a marca de $53 \%$ dentro da forma de cálculo descrita no Quadro 14.

A partir dos resultados obtidos durante a pesquisa com a empresa A, permite concluir que a empresa está em um nível de maturidade $a d-h o c$, com um movimento em direção ao nível Padronizado. 


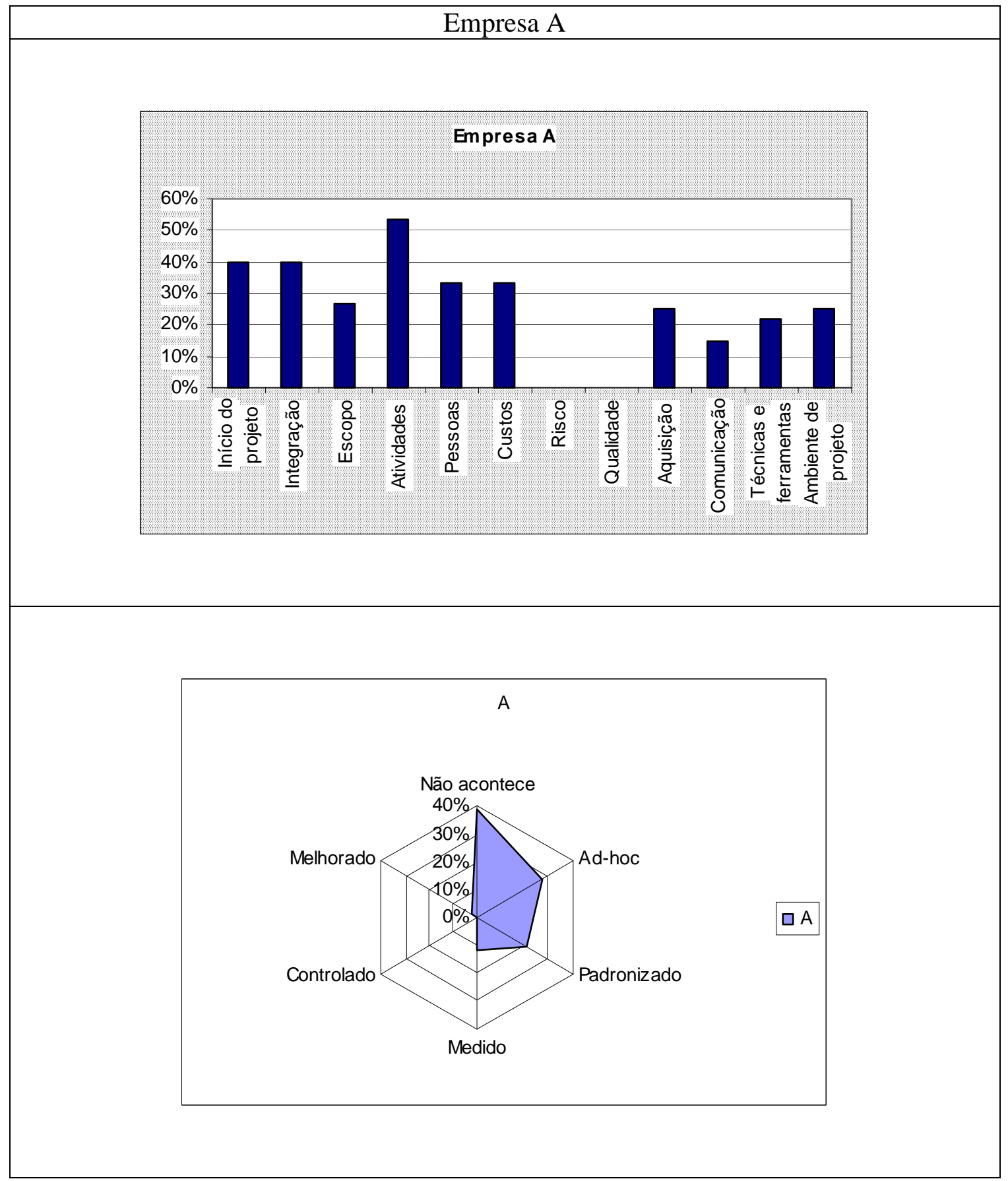

Gráfico 1 - Nível de maturidade da empresa A: (a) gráfico de barras; (b) gráfico tipo radar.

Durante o estudo realizado, a empresa A estava realizando um conjunto de ações no sentido de melhorar algumas atividades de gestão de projetos e implantar outras que inexistiam no momento do diagnóstico. Estas ações estavam sendo realizadas por meio de um recurso da própria empresa que detinha o papel de facilitador interno para fomentar estas mudanças. Merece destaque o comprometido da diretoria da empresa com os trabalhos de melhoria realizados, que por meio de reuniões debatiam as propostas de implementações de melhoria. 
Deve-se atentar ao fato, entretanto, que esta empresa possuía duas equipes de projeto e esta avaliação foi realizada dentro de uma das equipes não representando, portanto, o cenário global da empresa em termos de gerenciamento de projetos.

\subsubsection{Empresa B}

De maneira análoga à empresa analisada anteriormente, a empresa $\mathrm{B}$ também não apresentava nenhuma prática de gerenciamento de riscos do projeto.

Embora em menor grau, destacam-se nesta empresa as práticas de inicialização do projeto e de gerenciamento de atividades e pessoas que obtiveram pontuação de $40 \%, 33 \%$ e $33 \%$, respectivamente.

Analisando o comportamento geral de todas as práticas diagnosticadas, nota-se que $70 \%$ das atividades não existiam ou eram executadas de maneira particular para cada projeto e pouco estruturada.

Dessa maneira, os resultados da pesquisa para a empresa B permitem concluir que a empresa encontra-se em um nível ad-hoc de maturidade.

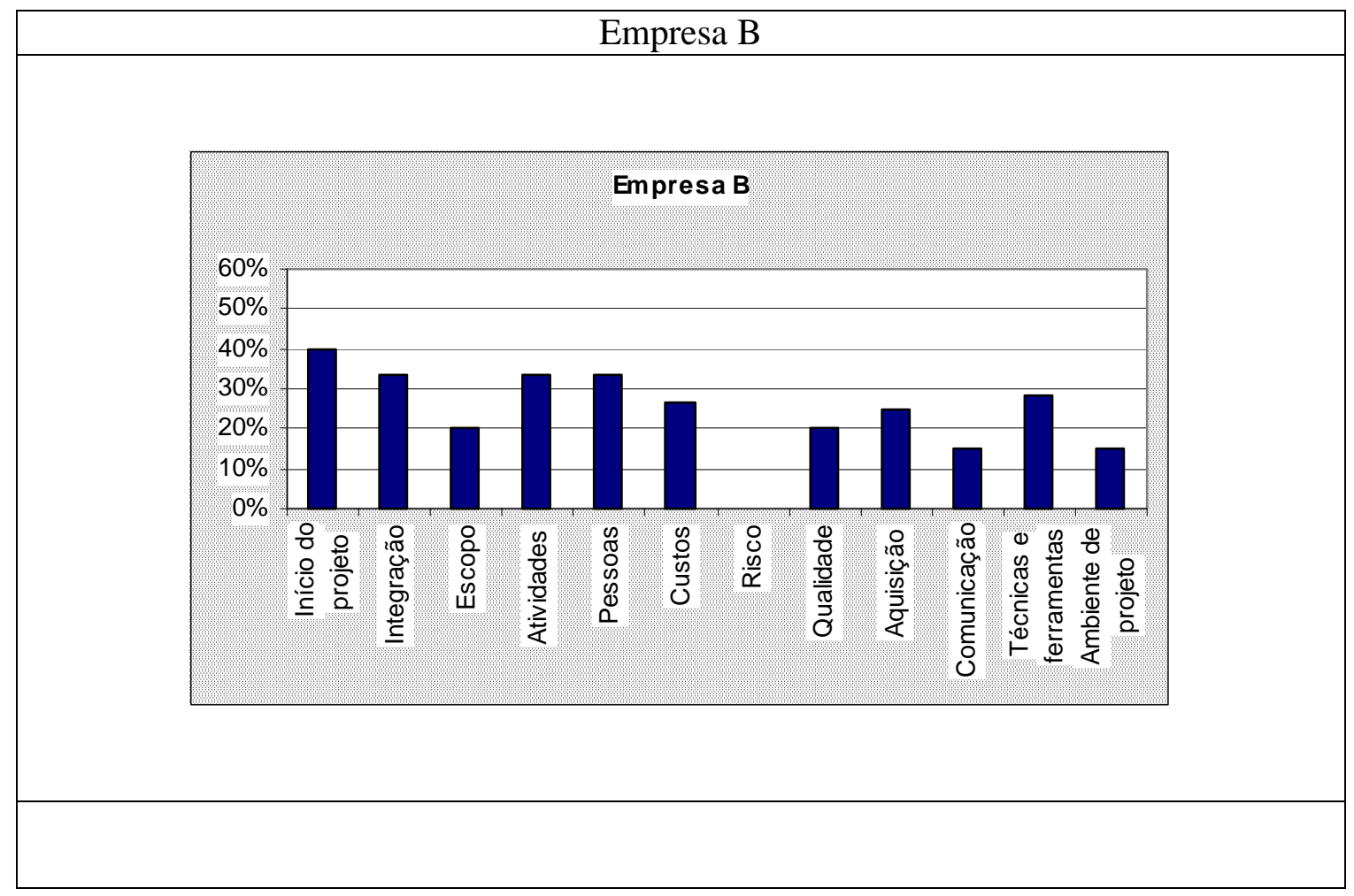




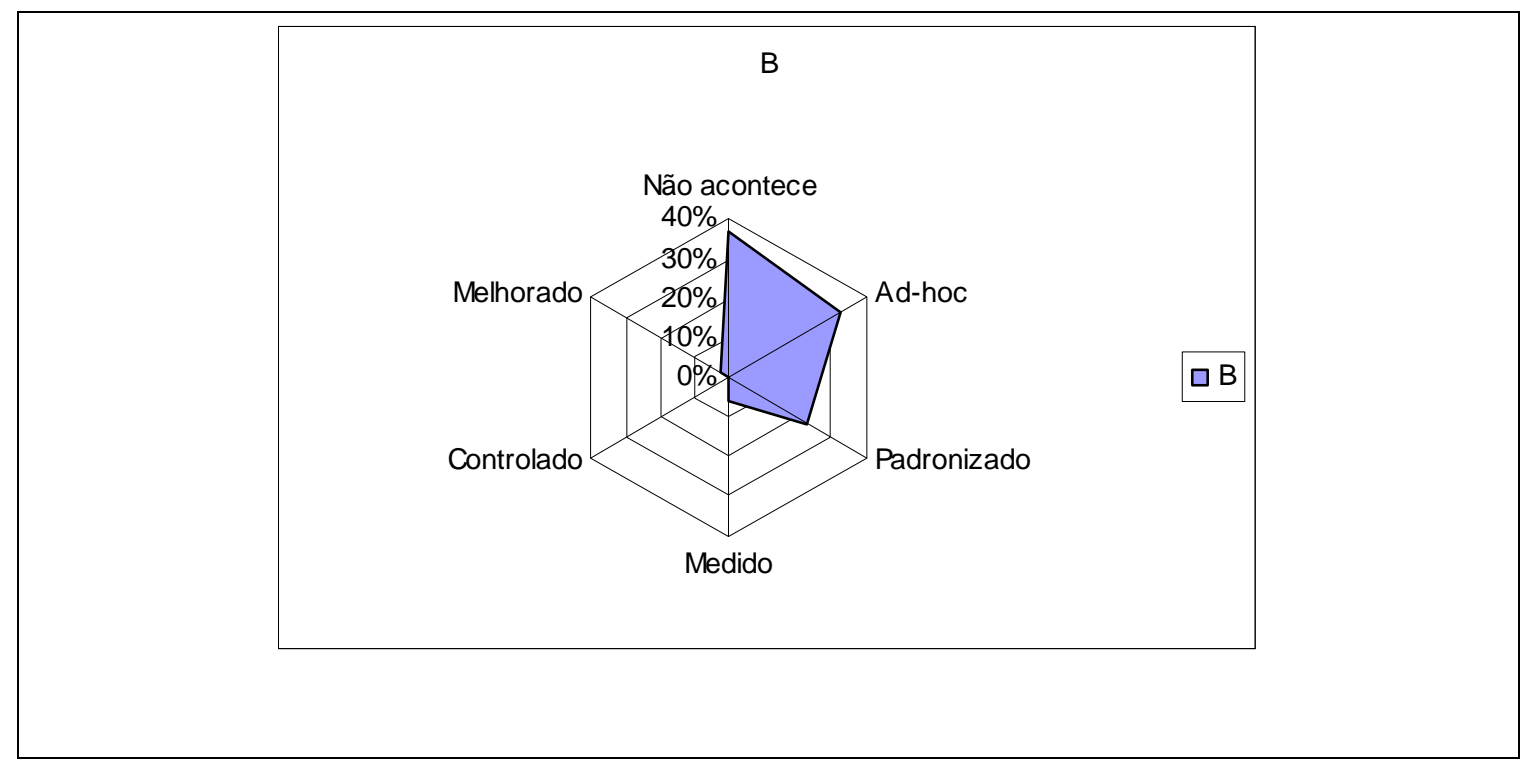

Gráfico 2 - Nível de maturidade da empresa B: (a) gráfico de barras; (b) gráfico tipo radar.

Esta empresa encontrava-se em um momento de buscar ferramentas de suporte as atividades de gerenciamento de projetos, além de participar de cursos de gerenciamento de projetos.

\subsubsection{Empresa C}

Dentro das empresas analisadas, a empresa $\mathrm{C}$, apesar de não apresentar nenhuma prática diagnosticada para o gerenciamento de riscos do projeto, como as demais já estudadas, possui uma das maiores pontuações em termos de práticas para $\mathrm{o}$ gerenciamento de custos do projeto.

Vale observar ainda que a empresa $\mathrm{C}$, dentro do universo de empresas analisadas foi a que possuiu menos atividades enquadradas como "Inexistentes" ou "Ad-hoc", apresentando 29\% das atividades diagnosticadas como "Padronizadas".

Assim, os resultados sobre o nível de maturidade para a empresa $\mathrm{C}$ remetem a um nível Padronizado para as atividades de gestão de projetos. Entretanto, vale ressaltar que a empresa não utiliza várias atividades que são sugeridas pelo modelo de avaliação utilizado. 


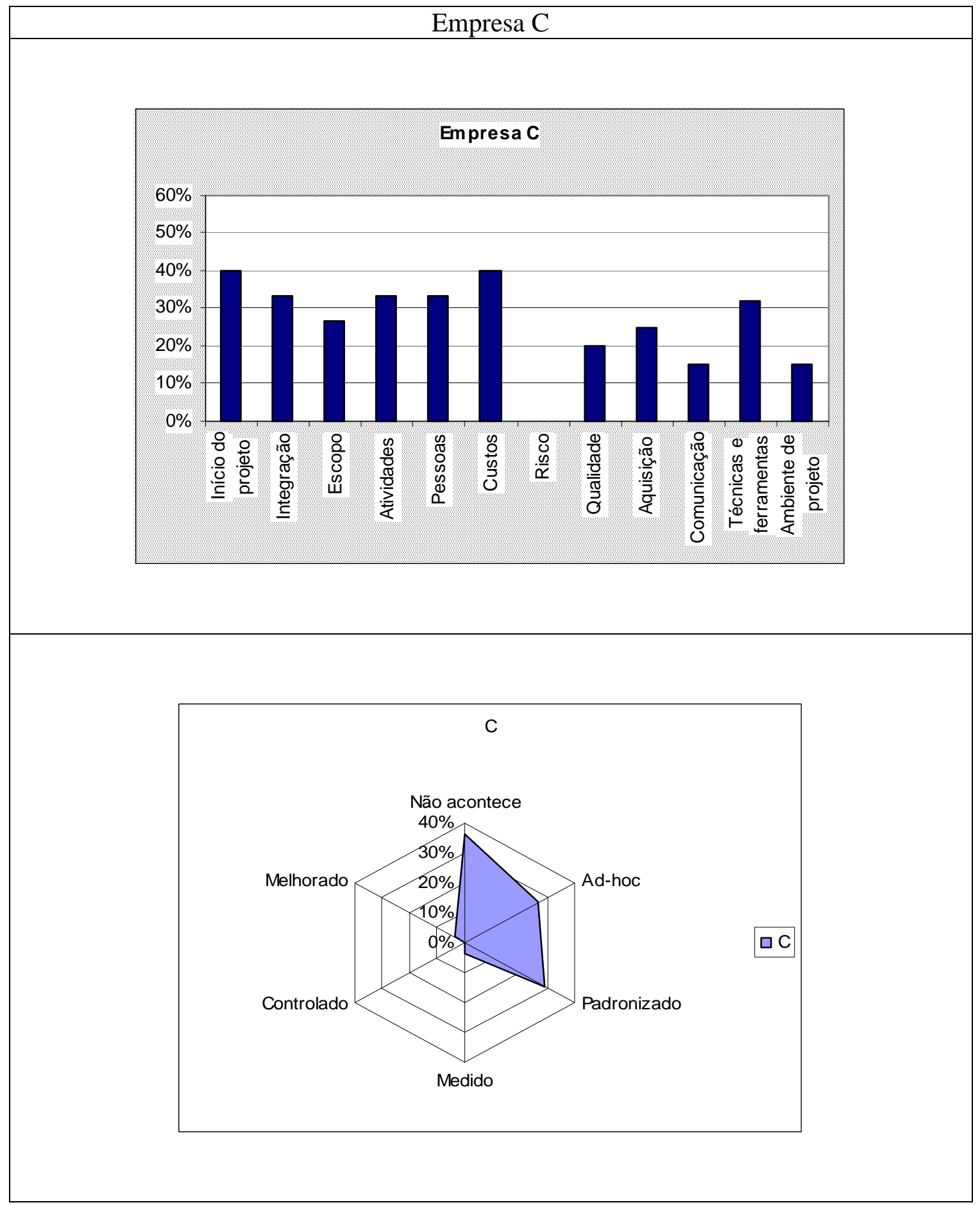

Gráfico 3 - Nível de maturidade da empresa C: (a) gráfico de barras; (b) gráfico tipo radar.

\subsubsection{Empresa D}

Os dados da empresa D são sumarizados no Gráfico 4 (a) e (b). Pode-se constatar que a empresa $\mathrm{D}$ apresentou uma elevada pontuação dentro das práticas voltadas para o gerenciamento de custos do projeto; entretanto, apresentou a menor pontuação dentro das práticas classificadas como "Técnicas e ferramentas". 
Observa-se ainda que, dentro do grupo de empresas entrevistadas, a empresa D foi a que apresentou a maior quantidade de práticas diagnosticadas como "Inexistentes".

A partir dos resultados, pode-se concluir que a empresa D encontra-se em um nível ad-hoc de maturidade, com uma excessiva quantidade de atividades não realizadas.

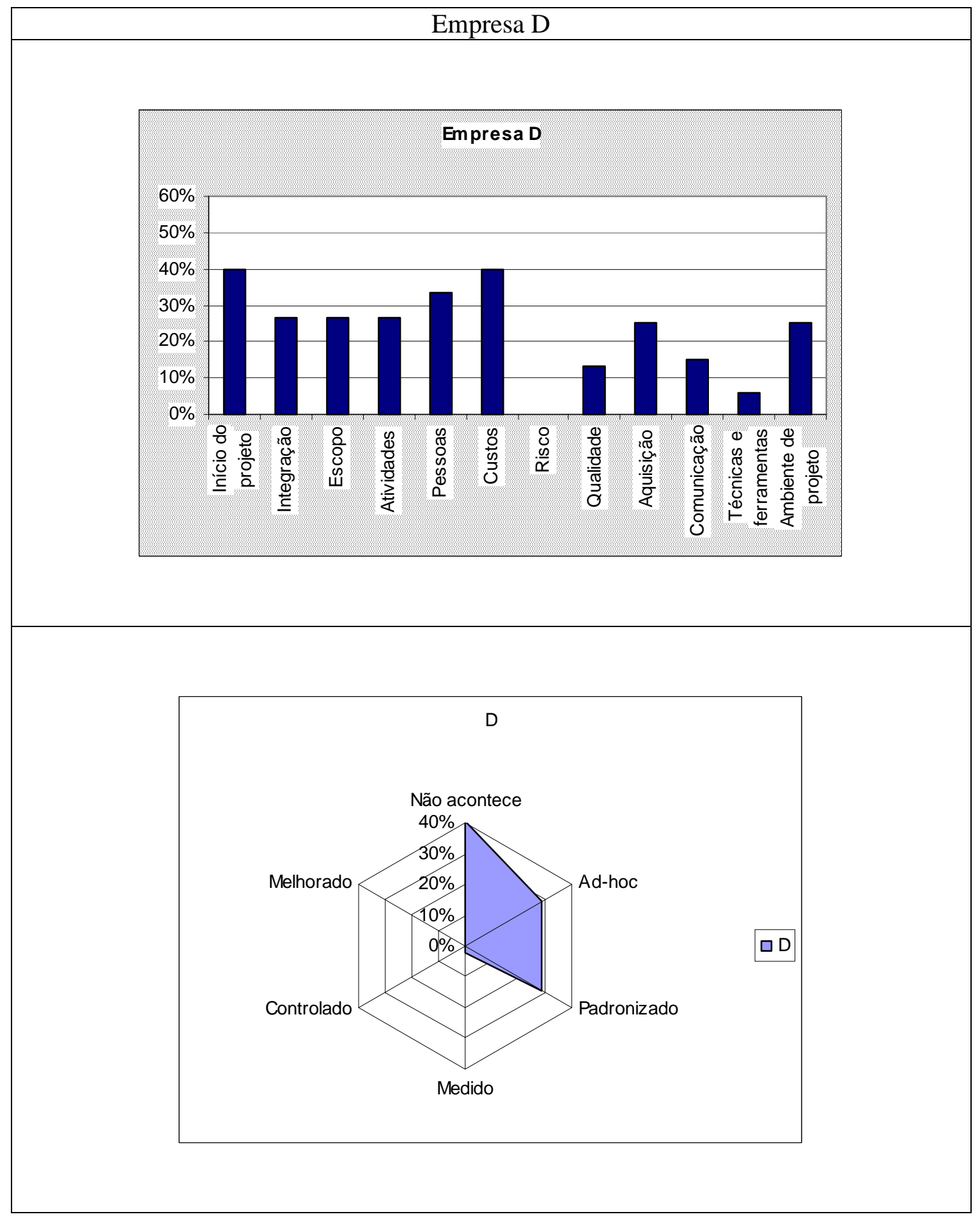

Gráfico 4 - Nível de maturidade da empresa D: (a) gráfico de barras; (b) gráfico tipo radar. 


\subsubsection{Empresa E}

A empresa $\mathrm{E}$, como todas as demais, não realizava nenhuma das práticas de gerenciamento de riscos diagnosticadas. Entretanto, esta empresa apresentou a maior pontuação dentro do grupo de práticas denominadas de "Técnicas e Ferramentas". Isto se deve ao fato da empresa utilizar para todos os projetos ferramentas de comunicação e procedimentos de documentação de lições aprendidas de maneira bastante efetiva.

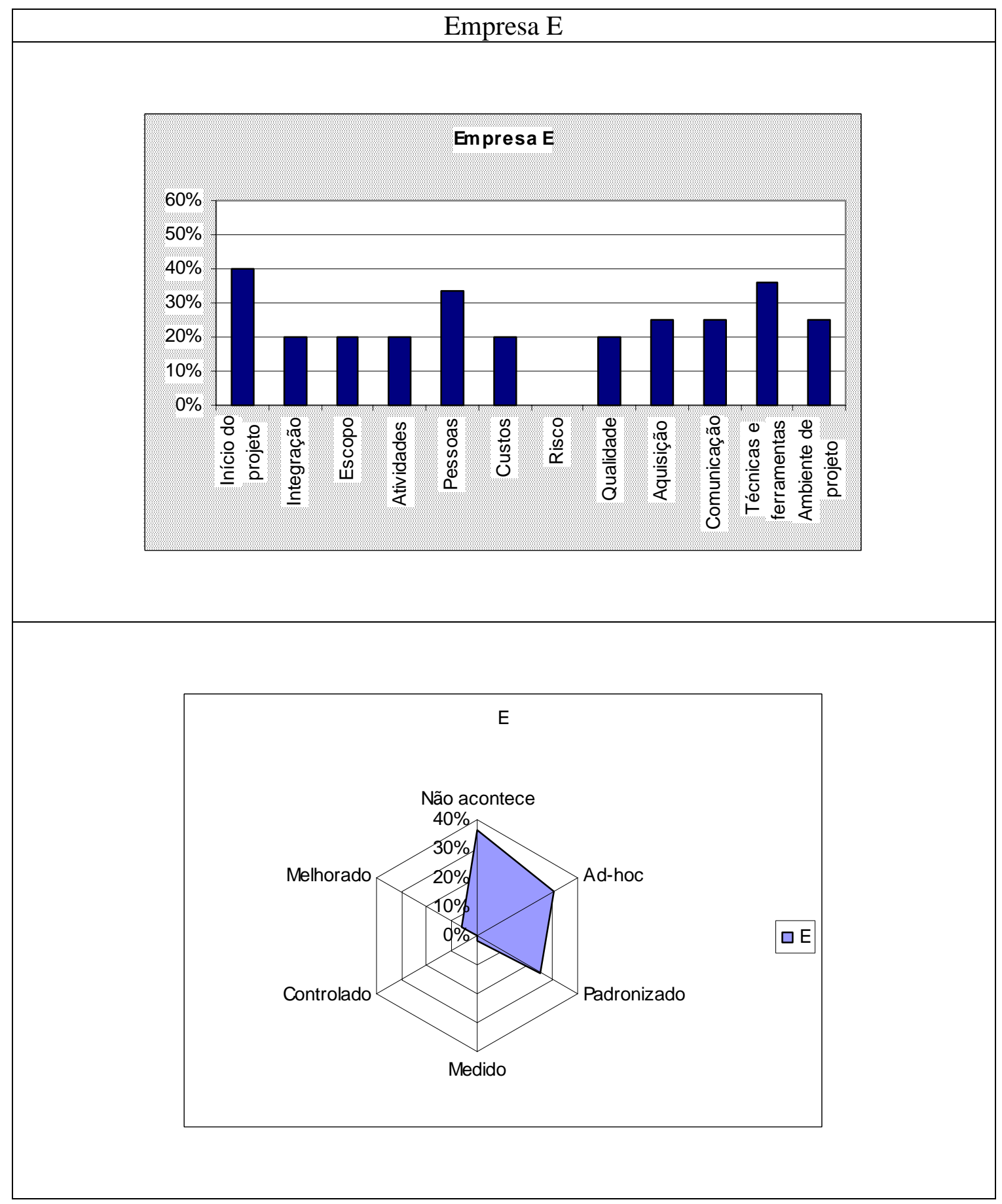

Gráfico 5 - Nível de maturidade da empresa E: (a) gráfico de barras; (b) gráfico tipo radar. 
Devido ainda a incidência de práticas voltadas a coleta e registro das lições aprendidas dos projetos da empresa E, esta apresentou o maior grupo de atividades diagnosticadas dentro do nível de "Melhorado".

Os resultados aferidos para a empresa E permite classificar o nível de maturidade da empresa como ad-hoc.

Para todas as empresas analisadas foi apresentado o estado atual de maturidade das práticas de gestão de projetos de forma individual. Entretanto, para possibilitar a discussão sobre os resultados obtidos foram reunidos os conjuntos de dados das empresas entrevistadas.

No próximo item será apresentado o resultado geral da pesquisa e após, tecida uma discussão a respeito da situação encontrada nas empresas analisadas.

\subsection{Discussão sobre o nível de maturidade das empresas estudadas}

Após a apresentação dos resultados individuais das empresas diagnosticadas, para que seja possível a realização de maiores considerações, realizou-se uma compilação dos resultados obtidos.

A Tabela 2 relaciona os valores de pontuação para todas as empresas. Pode-se assim observar o resultado do diagnóstico para todas as empresas.

Tabela 2 - Resultados da pesquisa, por área de conhecimento.

\begin{tabular}{lccccc}
\hline & A & B & C & D & E \\
\hline Início do projeto & $40 \%$ & $40 \%$ & $40 \%$ & $40 \%$ & $40 \%$ \\
\hline Integração & $40 \%$ & $33 \%$ & $33 \%$ & $27 \%$ & $20 \%$ \\
\hline Escopo & $27 \%$ & $20 \%$ & $27 \%$ & $27 \%$ & $20 \%$ \\
\hline Atividades & $53 \%$ & $33 \%$ & $33 \%$ & $27 \%$ & $20 \%$ \\
\hline Pessoas & $33 \%$ & $33 \%$ & $33 \%$ & $33 \%$ & $33 \%$ \\
\hline Custos & $33 \%$ & $27 \%$ & $40 \%$ & $40 \%$ & $20 \%$ \\
\hline Risco & $0 \%$ & $0 \%$ & $0 \%$ & $0 \%$ & $0 \%$ \\
\hline Qualidade & $0 \%$ & $20 \%$ & $20 \%$ & $13 \%$ & $20 \%$ \\
\hline Aquisição & $25 \%$ & $25 \%$ & $25 \%$ & $25 \%$ & $25 \%$ \\
\hline Comunicação & $15 \%$ & $15 \%$ & $15 \%$ & $15 \%$ & $25 \%$ \\
\hline Técnicas e ferramentas & $22 \%$ & $28 \%$ & $32 \%$ & $6 \%$ & $36 \%$ \\
\hline Ambiente de projeto & $25 \%$ & $15 \%$ & $15 \%$ & $25 \%$ & $25 \%$ \\
\hline
\end{tabular}

A Tabela 3 estratifica os percentuais das atividades de cada empresa que se enquadraram em cada nível de maturidade verificado (Tabela 1). 
Tabela 3 - Resultados da pesquisa, por nível de maturidade das atividades.

\begin{tabular}{lrrrrr}
\hline & A & B & C & D & E \\
\hline Não acontece & $38 \%$ & $37 \%$ & $37 \%$ & $40 \%$ & $37 \%$ \\
\hline Ad-hoc & $27 \%$ & $33 \%$ & $27 \%$ & $29 \%$ & $31 \%$ \\
\hline Padronizado & $21 \%$ & $23 \%$ & $29 \%$ & $29 \%$ & $25 \%$ \\
\hline Medido & $12 \%$ & $6 \%$ & $4 \%$ & $2 \%$ & $2 \%$ \\
\hline Controlado & $0 \%$ & $0 \%$ & $0 \%$ & $0 \%$ & $0 \%$ \\
\hline Melhorado & $2 \%$ & $2 \%$ & $4 \%$ & $0 \%$ & $6 \%$ \\
\hline
\end{tabular}

Os resultados obtidos, a partir do diagnóstico realizado junto às empresas, foram compilados no Gráfico 6, onde são apresentados os resultados de maneira comparativa entre as empresas pesquisadas.

O objetivo do trabalho de quantificar o grau de maturidade das atividades de gerenciamento de projetos realizadas pelas empresas, como observado na Tabela 2, foi gerar subsídios que possibilitassem esta fase de análise criteriosa das empresas que participaram da pesquisa. Assim, a fase de análise recebe valores para fomentar a discussão do diagnóstico e dos resultados obtidos.

\begin{tabular}{|c|c|}
\hline Faixa de valores & Nível associado \\
\hline $0 \%$ & Inexistente \\
\hline $20 \%$ & Ad-hoc \\
\hline $40 \%$ & Padronizado \\
\hline $60 \%$ & Medido \\
\hline $80 \%$ & Controlado \\
\hline $100 \%$ & Melhorado \\
\hline
\end{tabular}

Quadro 15 - Relação entre valores obtidos e nível de maturidade. 


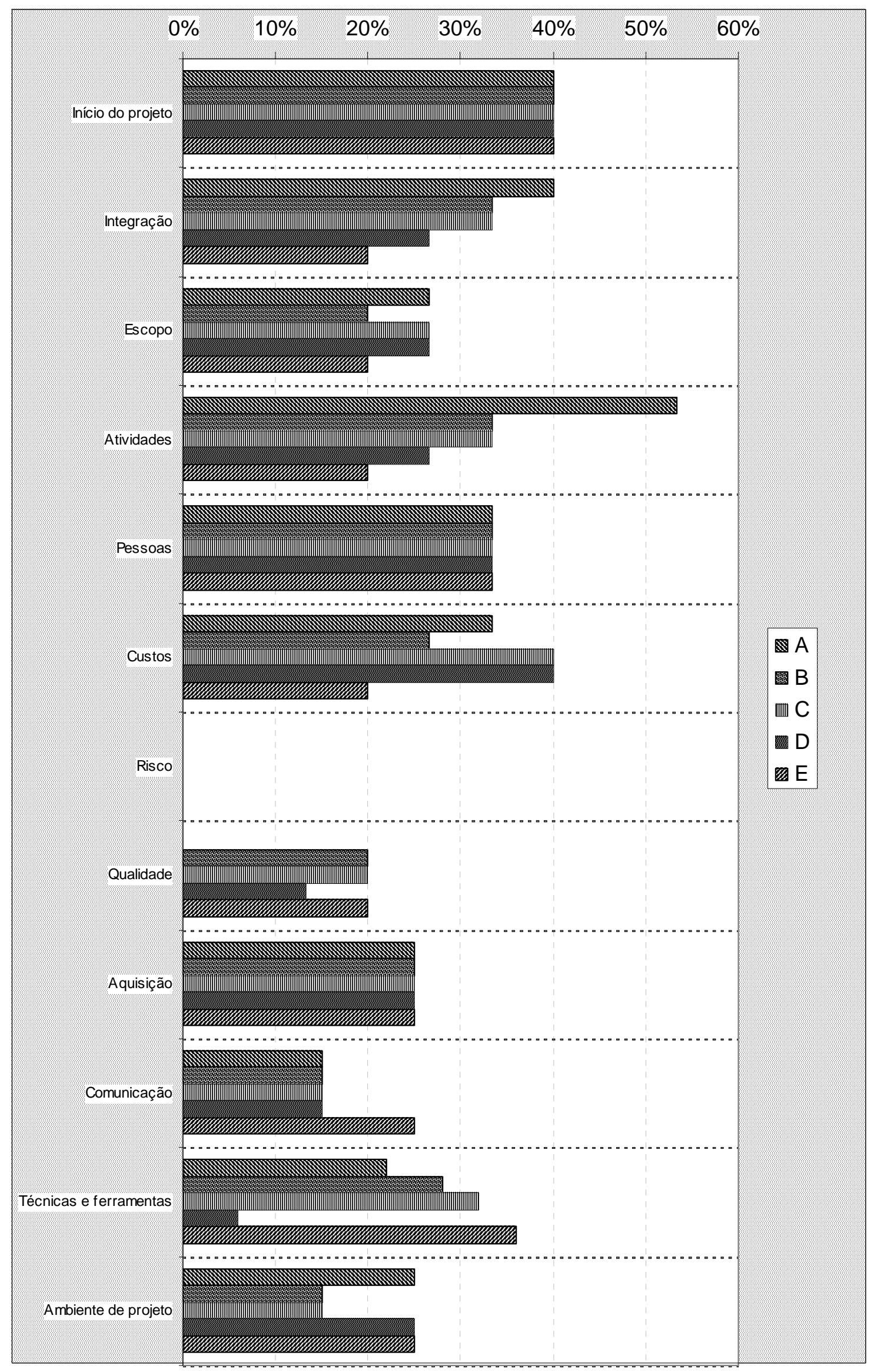

Gráfico 6 - Comparação entre os resultados da pesquisa, por área de conhecimento. 
Um fato interessante é que nenhuma das empresas entrevistadas possui alguma atividade que possa ser classificada como sendo do grupo de gerenciamento de riscos do projeto.

Por outro lado, apresentando uma relativa alta incidência, as atividades que envolvem o gerenciamento de pessoas, atividades e custos, estão mais presentes no dia a dia dos envolvidos em projetos destas empresas, seguem algumas hipóteses para este fato:

- O modelo de gestão básico para qualquer projeto envolve o planejamento e controle desta tríade (custo, tempo, pessoas);

- Existe um número considerável de ferramentas de software proprietárias e abertas que suportam o gerenciamento destas variáveis de projeto, enquanto outras áreas - como qualidade e risco - ficam por conta de poucas ferramentas proprietárias de difícil acesso a estas empresas;

- Das áreas de gerenciamento de projetos citadas neste trabalho o gerenciamento de tempo, custo e pessoas são as mais discutidas dentro de cursos e livros sobre gestão de projetos, assim, o acesso a este tipo de conhecimento é mais facilitado, enquanto que as demais áreas ganham características próprias para cada tipo ou natureza de projetos;

Entretanto, o mapeamento de riscos e o controle são absolutamente necessários devido à natureza dos projetos executados por estas empresas que envolvem projetos de inovação e novas tecnologias.

Outro ponto que merece destaque é a baixa pontuação de todas as empresas no campo de gerenciamento da qualidade do projeto. Isso não significa que a qualidade dos projetos destas empresas é ruim. Ele demonstra que há poucas ações sistemáticas nessa área, identificando que a gestão da qualidade dos produtos poderia ter significativa melhoria caso este item fosse aprimorado.

A correção desta deficiência poderia ser realizada por meio de uma padronização maior das atividades de projeto e a definição de parâmetros de controle de qualidade, incluindo ações para aumentar a rastreabilidade do projeto e a decorrente aceleração na resposta a problemas conforme a própria revisão teórica sobre o assunto.

Observa-se ainda pelo Gráfico 6 que as atividades de comunicação apresentaram uma baixa pontuação com relação às demais atividades. Esta característica pode ser 
explicada pela observação realizada nas empresas que participaram da pesquisa, onde a comunicação era realizada predominantemente de maneira informal, devido o ambiente de proximidade identificado, tanto entre as áreas da empresa como também com relação ao empresário empreendedor que interage ativamente dentro dos diferentes projetos assumindo o papel de comunicador entre as diferentes equipes de projeto e entre a organização e os gerentes de projeto.

Esta informalidade, não quantificada neste trabalho, também é refletida na pontuação das atividades classificadas como sendo do ambiente de projeto, dado que a estratégia e os objetivos da organização acabavam sendo transmitidos de maneira informal, por meio de discussões sobre os projetos entre o empresário e as equipes de projetos.

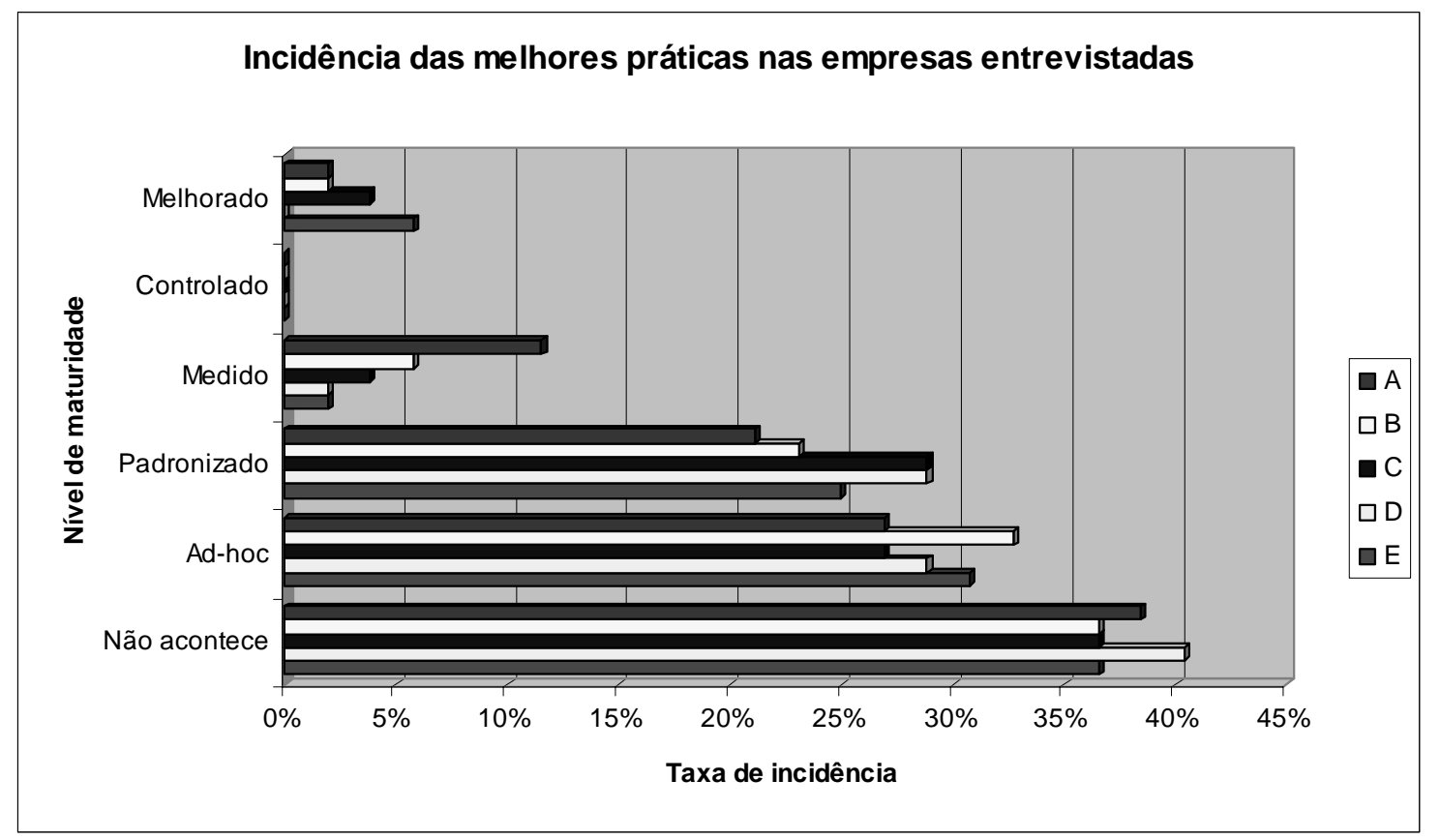

Gráfico 7 - Comparação entre os resultados da pesquisa, por nível de maturidade.

O Gráfico 7 detalha a classificação das atividades de cada empresa entre os níveis de maturidade adotados no início da pesquisa. Estes resultados foram consolidados a partir dos valores definidos para os diferentes níveis de maturidade do modelo de avaliação proposto, utilizado e demonstrado na Tabela 3.

A primeira constatação realizada, partindo-se destes resultados é a verificação de que grande parte das atividades, pelo Gráfico 7, mais de 35\% das melhores práticas sugeridas pela teoria de gerenciamento de projetos não são encontradas dentro dos projetos das empresas analisadas, o que demonstra que muito trabalho ainda deve ser 
feito dentro destas organizações com o objetivo de divulgar e treinar as equipes de projeto a fim conhecerem estas práticas e como utilizá-las.

O conjunto de práticas classificadas como “Ad-hoc”, ou seja, realizadas pelas empresas de maneira não replicável ou padronizadas totaliza mais de $25 \%$ das atividades diagnosticadas na pesquisa. Estas atividades são realizadas de maneira não padronizada e que respondem de maneira particular a necessidade do projeto para que foram realizadas.

A partir destes dois resultados iniciais, verifica-se que $60 \%$ das práticas de gerenciamento de projetos que foram analisadas durante a pesquisa, não são realizadas pelas empresas ou acontecem de forma não padronizada, o que demonstra a necessidade de discussão sobre possíveis formas de transmitir os conhecimentos necessários sobre técnicas, atividade e ferramentas para gerenciamento dos projetos.

Outro ponto a ser destacado dentro da análise realizada é que das práticas que eram realizadas pelas empresas, $47 \%$ destas práticas eram realizadas de maneira particular para cada projeto não seguindo nenhuma padronização, isto demonstra que a grande dificuldade para estas empresas neste momento é garantir um mínimo de padronização das suas práticas de projetos.

Ainda sobre as práticas encontradas nas empresas, a padronização atingia cerca de $40 \%$ destas práticas. Assim, observa-se que trabalhos propostos no sentido de definir e padronizar essas práticas e, posteriormente, criar mecanismos que permitam que estas empresas meçam os resultados dessas atividades e até possam ter controle sobre estes resultados, propiciaria um incremento significativo da situação das empresas quanto à gestão de projetos.

Por último, o conjunto de práticas que foram contabilizadas como de nível melhorado (menos de 5\% das atividades) faz referência as atividades que envolvem o registro e assimilação de lições aprendidas, e ocorre nas empresas que utilizam ferramentas computacionais de registro problemas e ações tomadas.

O conjunto de resultados, visualizado de maneira comparativa no Gráfico 8, demonstra que as características de todas as empresas estudadas são bastante semelhantes. Isto permite que façamos algumas generalizações quanto à situação das demais empresas de base tecnológica de São Carlos, ou seja, pode-se tratar este perfil identificado como sendo o perfil básico de empresas que se enquadram na mesma classificação das empresas estudadas. Esta generalização é útil para trabalhos que 
tentem reduzir algumas das deficiências apontadas ou mesmo propor ferramentas e treinamentos para elas.

Assim, identifica-se, dentro do panorama apresentado, um potencial de melhoria significativo para estas empresas em termos de práticas de gestão de projetos. E, a criação de escritórios de projetos, conforme apresentado na teoria, pode ser um importante instrumento para capacitar estas empresas.

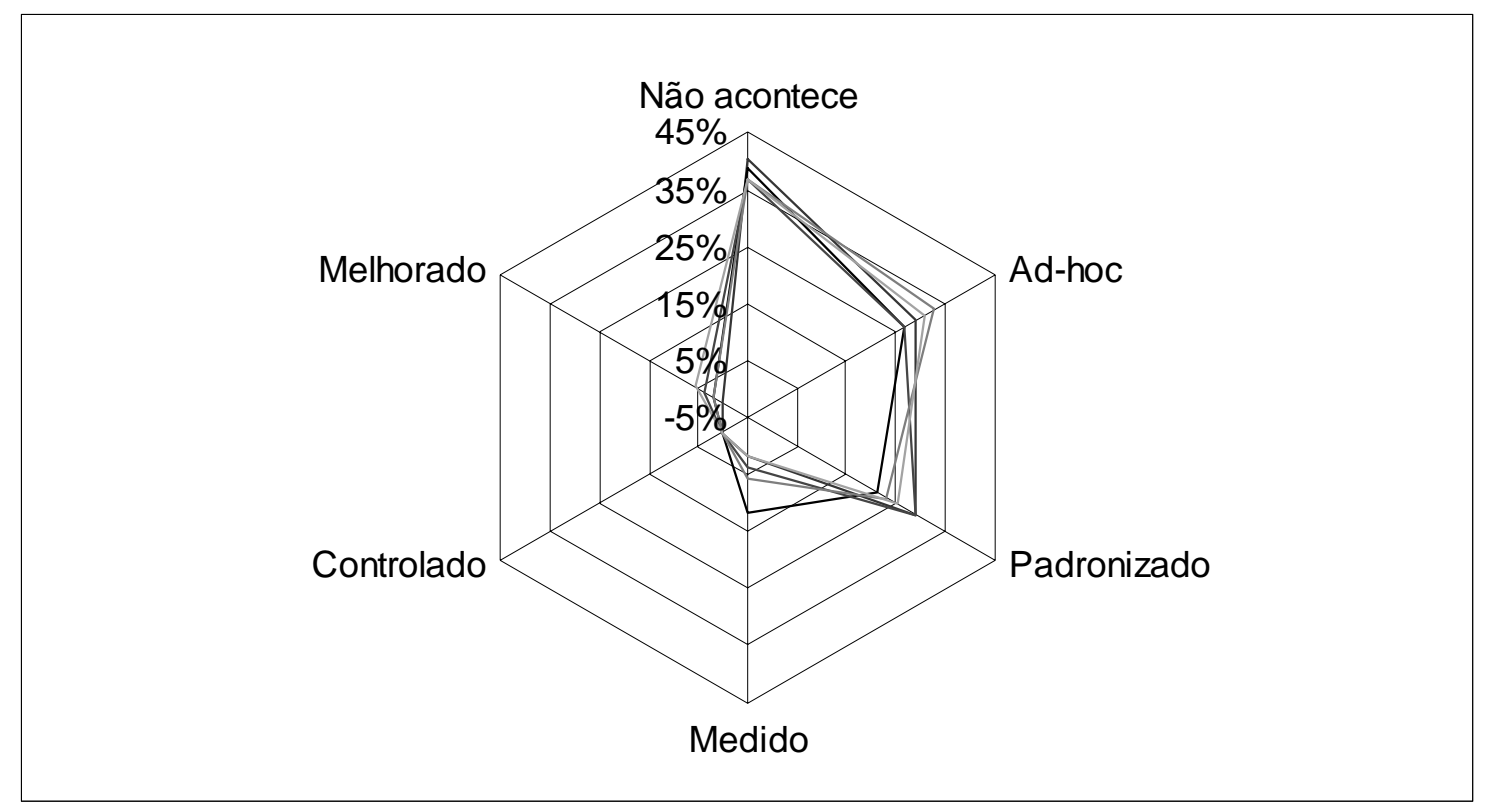

Gráfico 8 - Perfil das empresas entrevistadas.

Portanto, considerando o conjunto de dados é possível identificar que: 1) Há diferenças em termos de focos específicos entre as empresas, em decorrência aos tipos de projetos encontrados nestas empresas (Quadro 10); 2) Porém, principalmente pela Tabela 3 é possível constatar que estas diferenças não são significativas e que as empresas apresentam níveis de maturidade próximos entre si: com grande teor sobre padronização.

Deve-se destacar ainda que, durante a consolidação dos resultados desta pesquisa, as empresas analisadas já apresentavam um movimento consistente por meio de cursos e trabalhos realizados junto com a universidade com o objetivo de entender melhor suas deficiências e as possíveis soluções para reduzir ou minimizar estas lacunas. 


\subsection{Análise da aplicabilidade do escritório de projetos}

Até o momento, nada foi discutido sobre o conceito de aplicabilidade proposto no início deste trabalho.

A aplicabilidade do escritório de projetos refere-se à adequação do uso do escritório de projetos como forma de solução para as necessidades encontradas nas empresas de base tecnológica estudadas.

Dessa forma, falar em aplicabilidade é discutir os fatores que contribuem ou inibem o uso do escritório de projetos, de acordo com as características já discutidas desta estrutura.

Para a discussão proposta, devem-se resgatar as características encontradas nas empresas com relação às práticas de gestão de projetos e de forma estruturada identificar na compilação realizada sobre escritório de projetos se esta estrutura contribuiria com as empresas de base tecnológica (Figura 18).

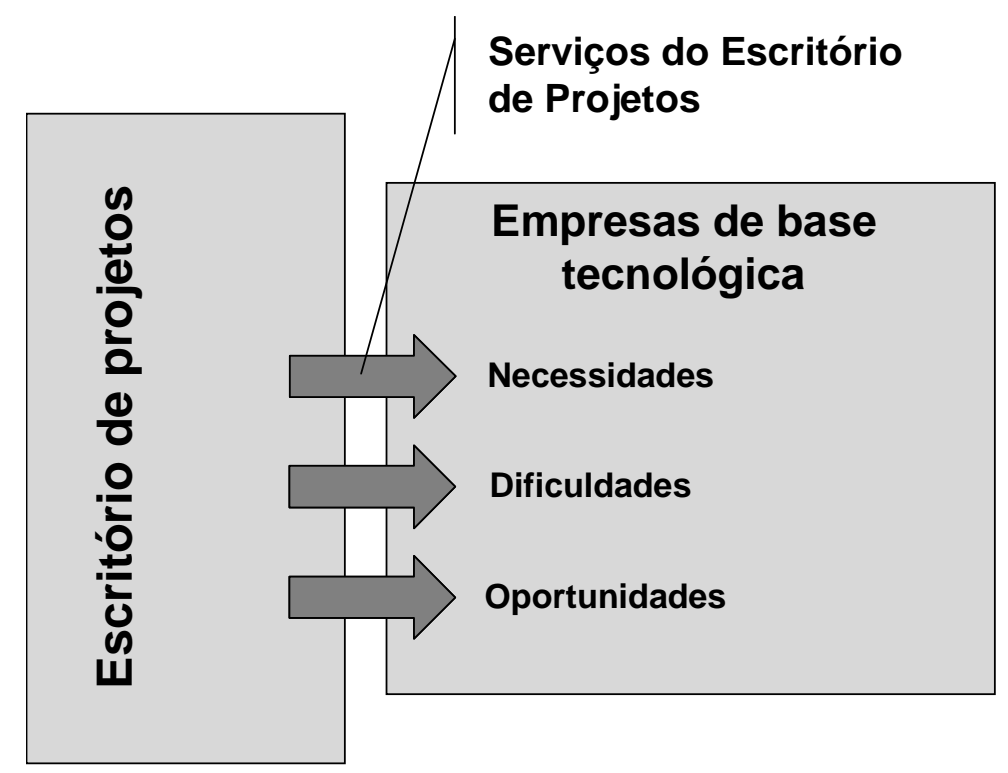

Figura 18 - Uso do escritório de projetos nas empresas de base tecnológica.

A partir da análise realizada nas empresas, cujo resultado pode ser observado no Gráfico 6, nota-se que para seis áreas da gestão de projetos, todas as empresas desenvolveram níveis de pontuação parecidos, citam-se as áreas: início do projeto, gestão de pessoas, qualidade, risco, aquisição e escopo.

Assim, de forma geral, todas essas empresas estudadas apresentam um nível de maturidade em gestão de projetos bem próximo entre si.

Apesar de caracterizadas diferentemente quanto aos tipos de produtos (Quadro 10), tamanho da estrutura, fornecedores e parceiros, todas elas encontram-se em um 
nível relativamente próximo, como observado inclusive pelo Gráfico 8 , onde nota-se que o perfil destas empresas é bem definido devido à similaridade entre elas.

Dessa forma, o fator proximidade da realidade das empresas em gestão de projetos é fator facilitador para o uso do escritório de projetos, pois este é um aspecto que pode facilitar o compartilhamento de um escritório de projetos. Caso os níveis fossem muito distantes, os serviços prioritários e críticos para cada empresa seriam distintos, inviabilizando um trabalho conjunto e a distribuição das despesas.

Este fator ainda pode se desdobrar em outros, caso fosse realizado o estudo para todas as áreas em separado, fortalecendo a posição inicial.

Outro ponto complementar ao discutido anteriormente, refere-se às deficiências comuns encontradas nas empresas, como: ausência de práticas voltadas para a gestão de riscos dos projetos, a qual houve unanimidade em termos de inexistência de práticas nesta área. Deve ser observado, finalmente, que dentro das práticas observadas e diagnosticadas que para certas áreas da gestão de projetos algumas empresas se destacavam, apresentando níveis de pontuação superiores as demais. Assim, devido a oportunidade de trocas de experiências e compartilhamento de melhores práticas, tem-se que o uso do escritório de projetos pode ser uma opção interessante.

Isso indicaria que se um escritório de projetos fosse instalado, seria um bom começo aproveitar a experiência prática das empresas mais avançadas em cada área, de forma a evitar redundância de trabalho.

Conclui-se que o escritório de projetos se apresenta como uma opção válida para busca da melhoria na qualidade das práticas de gestão de projetos dessas empresas. Assim, a aplicabilidade deste conceito se mostra positiva no sentido de apresentar fatores comuns que incentivam o uso do escritório de projetos nas empresas estudadas:

- Necessidades: proximidade da realidade atual das empresas em gestão de projetos;

- Dificuldades: as empresas apresentaram deficiências comuns durante diagnóstico;

- Oportunidades: foi identificada a oportunidade de trocas de experiências e compartilhamento de melhores práticas entre as empresas; 


\section{Conclusões e Considerações finais}

A partir do estudo do nível de maturidade nas empresas de base tecnológica, foram apontadas algumas deficiências em termos das práticas de gestão de projetos.

Grande parte dessas práticas diagnosticadas (67\%) inexiste de maneira formalizada ou ainda não foram padronizadas por essas empresas. Esta situação faz com que as equipes de projetos dediquem tempo em refazer documentos e atividades do seu gerenciamento de projetos, o que não permite que as empresas gastem energia e invistam tempo repensando e otimizando a forma de gerenciamento.

Ao mesmo tempo, somente $8 \%$ das práticas analisadas são medidas, controladas e melhoradas a partir dos resultados obtidos. Este dado confirma o fato do retrabalho causado nas atividades de projeto inibir a melhoria constante das práticas de gerenciamento de projetos.

Como deficiência, ainda foi apontada a necessidade de mais treinamentos nas práticas de gestão de projetos para as equipes, bem como a criação e manutenção de um vocabulário comum e técnicas de gerenciamento.

O estudo sobre os serviços e atividades do escritório de projetos demonstrou que esta estrutura pode ser responsável por grande parte dos esforços despendidos durante as fases dos projetos auxiliando sobremaneira os gerentes de projetos nas práticas a serem realizadas. Padronizar atividades, treinar recursos, medir resultados, além de reduzir custo marginal destas atividades, por projeto alocado, são exemplos de oportunidades geradas pelo uso de escritórios de projetos.

Outras atividades, que não foram citadas pela teoria consultada, foram propostas como forma de responder aos problemas das empresas de acordo com observação realizada durante as entrevistas.

A partir dos dados coletados, quanto à maturidade em gerenciamento de projetos e dos tipos de projetos executados nas empresas, e tratados no capítulo anterior, conclui- 
se que a opção de adoção de um escritório de projetos se mostra interessante para as empresas estudadas.

Algumas considerações também podem ser tecidas envolvendo a forma de implementação do escritório de projetos.

Devido ao fato destas empresas possuírem características comuns em termos de necessidades e dificuldades no gerenciamento de projetos, pode se imaginar não só o escritório de projetos auxiliando a empresa a gerenciar seus projetos, como também como uma estrutura compartilhada de apoio entre as empresas estudadas.

Assim, o escritório de projetos poderia não só auxiliá-las em suprir algumas deficiências encontradas e já discutidas (p.ex. falta de um vocabulário interno único, padronização de algumas práticas de gerenciamento), mas também como uma forma de permitir o crescimento comum das empresas com a troca de experiências e melhores práticas.

Outras vantagens desta forma de implementação baseada em um consórcio de empresas podem ser citadas, como a divisão dos custos inerentes a implementação e manutenção (p.ex. aquisição de material, contratação e treinamento de profissionais) entre as empresas participantes do consórcio.

Entretanto, de acordo com a bibliografia que trata do assunto, sabe-se que existem diversas etapas de implementação em que o escritório de projetos pode assumir diferentes papéis.

Portanto, cabe ainda saber sobre possíveis estratégias ou etapas de implementação do escritório de projetos para as empresas de base tecnológica. Apesar de não ser um objetivo deste trabalho, cabem aqui algumas considerações, de caráter exploratório, a cerca das estratégias que podem ser adotadas.

As considerações são realizadas baseadas na experiência do pesquisador após analisar os dados descritos no trabalho. Uma possível estratégia seria criar um escritório de projetos utilizando as seguintes etapas:

$\underline{\text { Fase A: }}$ o papel do escritório poderia ser focado em direcionar os esforços para o devido mapeamento dos processos bem como definição de padrões das práticas executadas durante os projetos. Os serviços que poderiam ser apoiados pelo escritório durante esta fase seriam:

- Treinamento básico para as equipes de projeto com o intuito de garantir um vocabulário comum; 
- Mapeamento e descrição das fases a serem seguidas por todos os projetos;

- Estabelecimento de padrões para as atividades, técnicas e procedimentos para a gestão de projetos;

Nesta primeira fase é essencial a participação efetiva de todas as empresas no sentido de haver uma troca inicial de experiências e compartilhamento das melhores práticas realizadas nos projetos individuais.

Fase B: Com todas as equipes tendo um vocabulário comum, conhecendo o processo de gestão e os padrões existentes; as técnicas de gestão deveriam ser exploradas; os serviços que poderiam ser beneficiados com a interação do escritório seriam:

- Treinamento avançado em técnicas para a gestão de projetos;

- Definição de critérios para o levantamento de riscos dos projetos;

- Escolha e adoção de ferramentas para controle de atividades, documentos e custos dos projetos;

Fase C: Esta fase poderia ser caracterizada pelas atividades de melhoria e entre as práticas que seriam apoiadas pelo escritório de projetos citam-se:

- Estabelecimento de fases de revisão dos padrões de práticas (técnicas, ferramentas e procedimentos) para proposição de melhorias;

- Estabelecimento de treinamentos de reciclagem das equipes de projetos;

- Estabelecimento da prática avaliação do processo de gestão de acordo com métricas estabelecidas;

As possíveis etapas foram citadas de forma intencional em uma ordem que sugere um caráter evolutivo no envolvimento da empresa com o conceito do escritório de projetos. Serve, portanto, como sugestão de próximos passos para as empresas implementarem tais movimentos.

Estes esforços poderiam ser realizados a partir de: 1) Consórcio, constituído de colaboradores de todas as empresas que seriam responsáveis pelas atividades de construção do escritório e reportariam os resultados em reuniões de acompanhamento; 2) Papel do facilitador que não pertenceria a nenhuma das empresas, mas seria um consultor externo responsável por direcionar os esforços necessários, ou; 3) Outra 
empresa interessada em centralizar as ações para implementação do escritório e, que por sua vez, poderia ser compartilhado entre as empresas ou totalmente terceirizado.

As implicações de terceirizações de atividades dos projetos deve ser foco de futuros trabalhos, não cabendo aqui relacionar os benefícios e malefícios desta decisão.

Portanto chega-se ao término deste trabalho, com os seus objetivos iniciais atendidos trazendo as seguintes contribuições:

- Levantamento abrangente dos serviços do escritório de projetos para possíveis implementações;

- Mapeamento do grau de maturidade das empresas de base tecnológica permitindo discussões sobre do tema e fomentar pesquisas que venham contribuir para a melhoria deste cenário;

- Discussão sobre alternativas de estratégias de implementação do escritório nas empresas analisadas.

Ao final dos resultados apresentados, cabem algumas considerações a cerca da contribuição para outros trabalhos que venham ser propostos relacionados a este tema.

Evidentemente, há limitações de abrangência na análise realizada, cujo foco principal foi as práticas existentes nas empresas e os serviços que podem ser oferecidos por meio desses instrumentos. Não foram considerados, portanto, os aspectos organizacionais, culturais e do ambiente institucional, relacionados com a adoção das práticas e de um escritório de projetos compartilhado, os quais podem mesmo até inviabilizar a proposta. Mas, é importante notar, que o caso apresentado nesta pesquisa demonstra que, dado a similaridade das empresas, existe um grande potencial para que isso seja realizado, ao menos dentro das empresas de software do pólo de alta tecnologia de São Carlos.

O fato das dificuldades e problemas serem semelhantes entre as empresas é um indício de que essa situação deve se repetir em empresas de base tecnológica não circunscritas ao pólo, indicando que o tema é de extrema relevância não apenas para o caso estudado, e sim para a competitividade das empresas de base tecnológica e, portanto, merece ser pesquisado. Como sugestões de trabalhos futuros têm-se os seguintes possíveis desdobramentos: 
1. Realizar estudos específicos sobre as barreiras e fatores habilitadores que poderiam auxiliar na implantação de um escritório de projetos compartilhado entre pequenas empresas;

2. Analisar os fatores do ambiente institucional que podem auxiliar as empresas de base tecnológica a desenvolver um esforço conjunto em termos de gerenciamento de projetos.

3. Dar prosseguimento a essa pesquisa realizando um estudo de caso profundo ou pesquisa-ação visando a criação de um escritório de projetos compartilhado;

4. Desenvolver ferramentas e metodologias específicas de planejamento e controle de projetos, voltadas para o apoio à gestão compartilhada de projetos; 


\section{Referências Bibliográficas}

ABERNATHY, W. J.; CLARK, K. B. (1984). Mapping the winds of creative destruction. Research Policy, n.14, p.3-23.

ACS, Z.J.; AUDRESTCH, D.B. (1992). Small firms and entrepreneurship: an eastwest perspective. Cambridge: Cambridge University Press.

ANDERSON, P.; TUSHMAN, M. (1990). Technical discontinuities and dominant designs: a cyclical model of technological change. Administrative Science Quarterly, n.35, p.604-633.

APMBOK (2000) - Association for project management. Miles Dixon. APM's Professional Board. 4th. ed. Reino Unido.

BLAKE, S.B. (1978). Managing for Responsive Research and Development. Freeman and Co. San Francisco, CA.

CÂNDIDO, G.A.; DIAS, S.T.A. (1998). A organização das pequenas e médias empresas: $\mathrm{O}$ que revelam os estudos brasileiros. Relatório de Pesquisa CNPQ/UFPB/PIBIC. João Pessoa; Ed. Universitária. 
CASSIOLATO, J.E. (1999). A economia do conhecimento e as novas políticas industriais e tecnológicas. In: Informação e conhecimento na era da globalização, organizado por Lastres H. e Albagli S. Rio de Janeiro: Campus.

CASSIOLATO, J.E.; LASTRES, H. M. M. (2002). O enfoque em sistemas produtivos e inovações locais. In: FISCHER (Org.). Gestão do desenvolvimento e poderes locais: Marcos teóricos e avaliação. Salvador: Casa da Qualidade, p.61-90.

. (2002). Novas Políticas na Era do Conhecimento: O Foco em Arranjos Produtivos e Inovativos Locais. UFRJ. Rio de Janeiro, 2003. Disponível em http://www.ie.ufrj.br/redesist/Artigos/LasCasParcerias.pdf. Acessado em 24 de Junho de 2004.

CLARK, K.B.; WHEELWRIGHT, S.C. (1993). Managing New Product and Process Development. New York: The Free Press, 896p.

CLELAND, D.I.; IRELAND L.R. (2002). Gerência de Projetos. Revisão técnica de Carlos A.C. Salles Jr. Rio de Janeiro: Reichmann e Affonso.

CLUSTER SÃO CARLOS DE ALTA TECNOLOGIA. (2004). Site institucional do Cluster São Carlos de Alta Tecnologia. Disponível em: http://www.clustersaocarlos.com.br. Acessado em agosto de 2004.

CMMI - CAPABILITY MATURITY MODEL INTEGRATION. (2002). CMMISM for systems engineering, software engineering, integrated product and process development, and supplier sourcing. Staged/Continuous Representation, v. 1.1. 
CRAWFORD, J.K. (2002). The strategic project office: a guide to improving organizational performance. New York, NY: Marcel Dekker Inc. 367p.

DOTY, H.D.; GLICK, W.H. (1994). Typologies as a unique form of theory building: Toward improved understanding and modeling. Academy of Management Review v.19, n.2, p.230-251.

EISENHARDT, K.M. (1989). Building theories from case study research. Academy of Management Review, vol.14, n.4, p.532-550.

EVARISTO, R.; FENEMA P.C. (1999). A typology of project management: emergence and evolution of new forms. International Journal of Project Management. v.17, n.5, p.275-281.

FONSECA, S.A.; KRUGLIANSKAS, I. (2000). Aspectos da inovação em microempresas situadas em incubadoras. $21^{\circ}$. Simpósio de Gestão da Inovação Tecnológica.Anais 2000. São Paulo - SP. 1CD.

GARTNER, Inc. (2001). Enterprise applications - Adoption of e-business and Document Technologies: 2000-2001. Worldwide. AIIM International.

GALBRAITH, J.R. (1997). Organization design. Addison-Wesley, Reading, MA.

GIL, A. C. (1991). Como elaborar projetos de pesquisa. 3rd. ed. Atlas, São Paulo.

GIL, A.C. (1999). Métodos e técnicas da pesquisa social. Atlas, São Paulo.

GOLD, R.L. (1969). Roles in sociological field observation. In G.J. McCall e J.L. Simmons (Eds.), Issues in Participant observation. Reading, MA: Madison-Wesley. 
HELDMAN, K. (2003). Gerência de Projetos: guia para o exame oficial do PMI. 2nd. ed., Editora Campus, 470p., Rio de Janeiro.

HARDING, R. et al. (2002). How important are regional clusters as hubs for entrepreneurial activity? Londres, IPPR.

IBGE - INSTITUTO BRASILEIRO DE GEOGRAFIA E ESTATÍSTICA. (2001). As micro e pequenas empresas comerciais e de serviços no Brasil, n.1.

INTERNATIONAL STANDARD ORGANIZATION. (1997). ISO 10006: Quality management - Guidelines to quality in project management. s.l.p., ISO.

KATE, B. (2000). Program Office: An Enterprise View. Disponível em http://www.pmforum.org/library/papers/.

KATE, B. (2004). Program Office: A Business Result Enabler. Disponível em http://www.pmforum.org/library/papers/ProgramOfficeFinal.htm. Acessado em 28 de Maio de 2004.

KERZNER, H. (2000). Applied project management best practices on Implementation. John Wiley e Sons, USA.

KNAPP, M.; MOORE, D. (2004). Project management maturity - Assessment Model. Disponível em: http://www.knappandmoore.com.au/pdf/Maturity_Assessment.pdf. Acessado: 23 de Junho de 2004. 
KRUGLIANSKAS, I.; RIMOLI, C. A.; SBRAGIA, R. (1996). Investigando a gestão tecnológica e o desempenho de MPEs de setores tradicionais. Encontro da Associação Nacional de Programas de Pós-graduação em Administração, v.20, Angra dos Reis-RJ, p.23-25. Anais. XX ENANPAD.

KRUGLIANSKAS, I. (1996). Tornando a pequena e média empresa competitiva. São Paulo: Instituto de Estudos Gerenciais e Editora.

_. (2003). Prof. Dr. Isac Kruglianskas: depoimento [junho.2003]. Entrevistador: Heródoto Barbeiro. São Paulo: Rádio CBN. Arquivo digital. Disponível: http://radioclick.globo.com/cbn/. Acessado em maio de 2004. Entrevista concedida à Rádio CBN no programa Mundo Corporativo.

LEMOS, C. (1999). Inovação na era do conhecimento In: Lastres, H.M.M., e Albagli, S., Informação e globalização na era do conhecimento. Rio de Janeiro: Campus.

LEVISTKY, J. (1996). Support systems for SME's. In: Developing Countries a Review. Paper commissioned by the Small and Medium Industries Branch n.2, Small Medium Programme, UNIDO.

LEVINE, H. A. (2000). Does your company need a CPO - A case for the Central Project Office and a Chief Project Office. The Project Knowledge Group, EUA, 2000. Disponível em http://www.pmforum.org/library/papers/Need_a_CPO.pdf. Acessado em 19/07/2003. 
MARCOVITCH, V.; SANTOS, S. A. e DUTRA, I. (1986). Criação de empresas com tecnologias avançadas: as experiências do PACTO/IA - FEA/USP. Revista de Administração, São Paulo, v.21, n.2.

MEREDITH, J.R.; MANTEL JR, S. J. (2002). Project management: A managerial approach, 5th. ed., John Wiley e Sons Inc.

MINTZBERG, H. (1979). An emerging strategy of "direct" research. Administrative Science Quarterly, v.24, p.580-589.

OPM3 - Organizational project management maturity model. (2003). Knowledge Foundation. Project Management Institute - PMI. Pennsylvania, EUA.

PERROW, C. (1992). Small firms network in networks and organizations: Structure, form and action. Organizado por Nohria, N. e Eccles, Robert G., Massachusetts: Ed. Harvard Business School Press.

PIEKARSKI, A.E.T.; TORKOMIAN, A.L.V. (2004a). As fontes de financiamento de P\&D e as redes de cooperação: o caso do PIPE/FAPESP em São Carlos. In: Anais do XXIII Simpósio de gestão da Inovação tecnológica. São Paulo: PGT/USP.

PIEKARSKI, A.E.T.; TORKOMIAN, A.L.V. (2004b). Cooperação para inovação: o caso do cluster de software de São Carlos. In: Anais do Congresso ABIPTI 2004. Brasília: Associação Brasileira das Instituições de Pesquisa Tecnológica.

PMBOK (2004). Um guia do conjunto de conhecimentos em gerenciamento de projetos, 3rd. ed., Project Management Institute, Inc. 
PMI (2004). Project Management Institute, ver PMBOK.

PORTER, M. (1998). "Clusters and the new economy of competition". Harvard Business Review. Nov-Dez. p.70-90, Cambridge, Mass.

. (2002). "Regions and policy", artigo enviado ao DTI Regional Policy Seminars, April 2002.

RABECHINI JUNIOR, R.; MAXIMINIANO, A.C.A. (2002). Maturidade em gestão de projetos - análise de um caso e proposição de um modelo. XXII Simpósio de Gestão da Inovação Tecnológica. Salvador.

RAD, P. F.; RAGHAVAN, A. (2000). Establishing an organizational project office. In: AACE International Transactions.

REDESIST - Rede de pesquisa em sistemas produtivos e inovativos Locais. (2004). Instituto de Economia da Universidade Federal do Rio de Janeiro. Site: http://www.ie.ufrj.br/redesist/. Acessado em 24 de Junho de 2004.

ROESCH, S.M.A. (1999). Projetos de estágio e de pesquisa em administração: guias para estágios, trabalhos de conclusão, dissertações e estudo de casos. 2nd. ed. São Paulo: Atlas.

ROMEIRO, E. F. (1997). O Setor de projetos e as novas tecnologias: elementos para uma discussão, II Congresso Brasileiro de Gestão de Desenvolvimento de Produto, São Carlos, SP - 30 e 31 de agosto de 2000. 
ROTHWELL, R.; DODGSON, M. (1993). Technology-based SME: Their role in industrial and economic change. Buckinghamshire, UK: Inderscience Entreprises.

ROZENFELD, H.; AMARAL, D.C. (1999). Proposta de uma tipologia de processos de desenvolvimento de produto visando a construção de modelos de referência. I Congresso Brasileiro de Gestão do Desenvolvimento de Produto (CBGDP).

SEBRAE - Serviço de apoio às micro e pequenas empresas de São Paulo. (2002). Subsídios para a identificação de clusters no Brasil: atividades da indústria. Pesquisa e planejamento estratégico, agosto de 2002.

. (2004). Estudos e pesquisas - SEBRAE nacional. As micro e pequenas empresas em números. Acessado em 07 de julho de 2004. Disponível em: http://www.sebrae.com.br/br/aprendasebrae/mpeemnumeros.asp.

SCHLICHTER, J. (2001). PMI's Organizational project management maturity model: Emerging Standards. Proceedings of the Project Management Institute, Annual Seminars e Symposium. Nashville, Tennessee, p.1-10.

SCHMITZ, H.; NADVI, K. (1999). Clustering and industrialization: introduction. World Development, v.27, n.9.

SHENHAR, A.J.; DVIR, D. (1996). Toward a typological theory of project management. Research Policy, v.25, p.607-632.

SIMPI - Sindicato da micro e pequena empresa indústria do estado de São Paulo. (2004). Disponível em: http://www.simpi.com.br/. Acessado em 20 de julho de 2004. 
SEI - Software engineering institute (1997). The capability maturity model for software, ver. 2B. Carnegie Mellow University.

STINCHCOMBE, A.L. (1965). Social structure and organizations. In March, James G., Handbook of Organizations: p.142-193. Chicago: Rand McNally.

TORKOMIAN, A. L.; FERRO, J. R. (1988). A criação de pequenas empresas de alta tecnologia. Revista de administração de empresas, Rio de Janeiro, n. 28, v.2 (abri./jun.), p.43-50.

TORKOMIAN, A. L. (1996). Estrutura de pólos tecnológicos. São Carlos: Editora: EdUFSCar.

TUSHMAN, M.L.; ANDERSON, P. (1986). Technological discontinuities and organizational environments. Administrative Science Quarterly, n.31, p.439-465.

WHEELWRIGHT, S.C.; CLARK, K.B. (1992). Revolutionizing product development. The Free Press, New York, NY.

VERZUH, E. (1999). The fast forward MBA in project management. John Wiley \& Sons, Inc.

WEBSTER (2004). Merriam-Webster online dictionary. Disponível em http://www.m-w.com/dictionary.htm. Acessado em 05 de Julho de 2004.

YIN, R. K. (1994). Case study research: design and methods. Beverly Hills, CA. Sage Publications. 
YIN, R. K. (2001). Estudo de caso: planejamento e métodos. Tradução de Daniel Grassi, 2nd. ed. Bookman. Porto Alegre. 


\section{Apêndices}

Apêndice A - Questionário de Maturidade Organizacional em Gestão de Projetos 


\section{APENNDICE A \\ ROTEIRO DE ENTREVISTA SOBRE MATURIDADE ORGANIZACIONAL EM GERENCIAMENTO DE PROJETOS}

Este documento faz parte de um trabalho de pesquisa realizado no programa de pósgraduação do Depto. de Engenharia de Produção da Escola de Engenharia de São Carlos.

Os resultados provenientes desse questionário, além de sigilosos, têm finalidades exclusivamente acadêmicas, estando a empresa isenta de quaisquer exposições involuntárias oriundas das respostas fornecidas.

Este questionário tem como objetivo identificar o grau de maturidade em gerenciamento de projetos nas pequenas empresas de tecnologia que compõem o Cluster São Carlos de Alta Tecnologia.

Assim, ele identifica evidências de práticas de gerenciamento de projetos em diferentes níveis organizacionais, e aborda os seguintes aspectos: estrutura organizacional, projetos e portfólio.

\section{$\underline{\text { Roteiro }}$}

\section{Estrutura Organizacional}

Este item do roteiro tem como objetivo identificar como a empresa se organiza, a formação de seus times de projeto, sua estrutura de decisão e as competências internas voltadas para o gerenciamento de projetos.

\section{Responsabilidades}

1) Como é a divisão de responsabilidades na empresa?

2) Qual é a responsabilidade e a participação das áreas funcionais dentro dos projetos da empresa?

3) Qual o papel dos donos da empresa dentro dos projetos existentes? Eles conhecem e/ou administram alguma etapa do projeto?

\section{$\underline{\text { Gerente de Projetos }}$}

4) Todo projeto da empresa possui um gerente de projeto nomeado?

5) Quais são as responsabilidades esperadas de um gerente de projeto? Como estas responsabilidades são cobradas? Elas são formalizadas/documentadas?

6) Como é feita a nomeação dos gerentes de projeto?

\section{Capacitação}

7) Existência de algum profissional interno capacitado para facilitar o gerenciamento dos projetos? Como sua existência é legitimada? Descrever sua função. 
8) A empresa mantém uma comunidade interna que fomenta discussões referentes ao gerenciamento de projetos na empresa?

9) A empresa incentiva a participação em comunidades externas de gerenciamento de projetos (associações profissionais, comunidades na internet ou outras iniciativas)?

10) Qual a postura da empresa diante novos cursos e treinamentos em gerenciamento de projetos? A empresa oferece cursos desta natureza? Existe algum treinamento básico para novos funcionários?

\section{Gerência do Projeto}

Neste item, encontram-se as perguntas referentes aos projetos da empresa, procura-se identificar como a empresa gerencia seus projetos individualmente, técnicas utilizadas e a existência de alguma metodologia, mesmo que informal.

Metodologia

11) A empresa possui um repositório de conhecimentos voltados ao gerenciamento de projetos? Os novos funcionários acessam este repositório? Quem acessa este repositório?

12) A empresa possui etapas ou fases definidas para os seus projetos? Descreva.

13) A empresa possui procedimentos-padrão para o gerenciamento de seus projetos? Quem os define (alta gerência, gerente do projeto, etc.)? Descreva.

14) A empresa possui modelos de documentos (templates) destinados ao gerenciamento de seus projetos? Descreva.

15) A empresa utiliza alguma técnica de gerenciamento de projetos durante as fases do projeto?

$\underline{\text { Iniciação }}$

16) Como se dá o início de um novo projeto? Existe alguma reunião de abertura? O início do projeto é documentado de alguma forma?

17) A empresa define objetivos e critérios de sucesso para o projeto?

\section{Planejamento}

18) Como são estabelecidos os times de projeto?

19) Como a organização comunica seus objetivos para os times de projeto?

20) A empresa define e documenta as estimativas de duração das atividades do projeto? Quem é o responsável pela definição e em quê ele se baseia?

21) Existe algum documento destinado a identificar os riscos associados a um novo projeto? Que informações são relevantes neste documento?

22) A empresa estabelece marcos de revisão em que é avaliado o atual andamento do projeto podendo se decidir por alterá-lo, congelá-lo ou encerrá-lo?

\section{Execução e Controle}

23) Qual a relação com o cliente durante a fase de desenvolvimento do projeto? $\mathrm{O}$ cliente é envolvido na tomada de decisão dentro do projeto?

24) Como a empresa sabe que está satisfazendo os requisitos do cliente durante o andamento do projeto?

25) A empresa revisa os objetivos e critérios de sucesso para o projeto durante o seu andamento? 
26) São realizadas reuniões para acompanhamento do projeto? Com que freqüência são realizadas estas reuniões? Quem freqüenta estas reuniões? O cliente do projeto participa?

27) A empresa mede de alguma forma o desempenho individual e dos times de projeto? Descrever?

\section{Encerramento}

28) A empresa divulga interna e externamente o encerramento do projeto. Descreva.

29) Existe alguma estatística sobre projetos encerrados? Existência de projetos que acabam fora do prazo? Existência de projetos que ultrapassam o orçamento estipulado?

\section{$\underline{\text { Portfolio }}$}

Este item do roteiro procura identificar com a organização gerencia seu portfólio de projetos. Assim, buscam-se evidências de fatores estratégicos que auxiliam na tomada de decisão.

30) A empresa possui uma lista de seus projetos atuais? Quantos são atualmente? Esta situação está na zona de normalidade? Comente.

31) Quais as variáveis de projetos contidas nesta lista?

32) A empresa ordena estes projetos segundo algum aspecto? Quais?

33) Quais informações são resgatadas de projetos anteriores? Em que situação e como se dá o resgate dessas informações?

34) A empresa mantém um clima de crescimento pessoal e profissional? Descrever.

35) A empresa mantém alguma estrutura física que possibilita e incentiva a troca de informações entre diferentes projetos?

36) Existe uma troca de experiência entre gerentes de projetos?

37) Os gerentes de projetos possuem acesso às informações de outros projetos como forma de compartilhar experiências e informações de projetos?

38) Os gerentes de projetos entendem como seus projetos atendem aos objetivos e estratégias da organização?

\section{$\underline{\text { Identificação }}$}

39) Nome do entrevistado.

40) Função do entrevistado na empresa.

41) Há quanto tempo nesta função?

42) Descrever os projetos que o entrevistado tem contato. 
Apêndice B - Questionário para Caracterização dos Projetos nas pequenas empresas 


\section{APÊNDICE B}

\section{ROTEIRO DE ENTREVISTA PARA A CARACTERIZAÇÃO DOS PROJETOS NAS PEQUENAS EMPRESAS}

Este documento faz parte de um trabalho de pesquisa realizado no programa de pósgraduação do Depto. de Engenharia de Produção da Escola de Engenharia de São Carlos.

Os resultados provenientes dessa entrevista, além de sigilosos, têm finalidades exclusivamente acadêmicas, estando a empresa isenta de quaisquer exposições involuntárias oriundas das informações fornecidas.

Este roteiro tem como objetivo caracterizar os projetos executados nas pequenas empresas de tecnologia que compõem o Cluster São Carlos de Alta Tecnologia. Serão utilizados três critérios (inovação tecnológica, complexidade do produto ou serviço e configuração das equipes de trabalho) previamente selecionados a partir do estudo da bibliografia que estuda tipologias de projetos.

\section{Caracterização da Empresa}

Este item procura caracterizar a empresa para o estudo de caso.

1) Como e há quanto tempo a empresa se formou?

2) Descrição dos produtos e serviços.

3) A empresa trabalha com linhas de produtos?

4) A empresa terceiriza alguma(s) etapa(s) do trabalho. Com empresas parceiras?

5) Quantos funcionários ela possui?

6) Quantos funcionários estão no primeiro emprego? A empresa possui estagiários?

7) Novos funcionários e estagiários passam por algum treinamento ao entrarem? Qual?

\section{Complexidade dos Produtos/Serviços}

Item que visa mapear os projetos das pequenas empresas segundo a complexidade de seus produtos e serviços. Níveis do grau de complexidade: baixo, ou produto que utiliza tecnologia já conhecida e permite uma interface simples com o usuário; médio, ou produto que utiliza tecnologia já conhecida, mas exige uma interface complexa com o usuário; e alto, ou produtos que utilizam uma tecnologia ainda não dominada pela empresa, independente da interface utilizada.

8) A empresa possui processos ou métricas para identificar a complexidade dos produtos desenvolvidos ou serviços prestados? Em caso positivo, descreva.

9) Relacionar a classificação proposta com a utilizada pela empresa.

10) A empresa utiliza diferentes tecnologias entre os diferentes projetos? Como é a escolha para o uso de determinada tecnologia para um novo projeto?

11) Como a empresa detalha a interface do produto?

\section{Grau de inovação}


Item que visa mapear os projetos das pequenas empresas segundo grau de inovação. Níveis do grau de inovação: inexistente, ou produto padronizado; baixo, ou produto adaptado para os requisitos do cliente; e alto, ou produto até então inexistente na empresa e desenvolvido de acordo com os requisitos do cliente.

12) A empresa possui alguma forma de identificar projetos de diferentes graus de inovação? Em caso positivo, descreva.

13) Relacionar a classificação proposta com a utilizada pela empresa.

14) Existem projetos que reutiliza resultados de projetos já encerrados? Qual a freqüiência?

15) Descrever o processo que resgata os resultados a serem reutilizados.

\section{Configuração das equipes de projeto}

Item que visa mapear os projetos das pequenas empresas segundo a configuração das equipes de projeto. Níveis possíveis para a configuração das equipes de projeto: local, quando todos os integrantes do projeto se encontram fisicamente próximos; disperso, quando um ou mais membros da equipe não se encontram presentes fisicamente na equipe de projeto; e virtual, quando cada membro da equipe do projeto se encontra em um local, que não o do projeto.

16) A empresa possui alguma forma de mapear projetos de acordo com a configuração da equipe do projeto? Em caso positivo, descreva.

17) Relacionar a classificação proposta com a utilizada pela empresa.

18) Como as equipes de projeto estão alocadas durante todo o projeto? (Quanto tempo na empresa e quanto tempo no cliente?)

19) Como o cliente participa da execução do projeto? Existe algum representante do cliente na equipe de projeto?

20) A empresa realiza projetos em parceria com outras empresas? Quais?

21) Como é composta a equipe de um projeto realizado em parceria? Como se dá o relacionamento entre os membros deste tipo de equipe?

\section{Ferramentas para Gerenciamento de Projetos}

Item que visa identificar características de ferramentas de gerenciamento de projetos que auxiliariam as pequenas empresas.

22) A empresa utiliza alguma ferramenta de Gerenciamento de Projetos? Qual? Caso contrário; vê a necessidade de utilizar alguma ferramenta desta natureza?

23) Descrever como foi a adoção desta?

24) Há quanto tempo a ferramentas vem sido utilizada?

25) Houve mudanças no modo de gerenciar projetos com a adoção da ferramenta?

26) Quem possui acesso à ferramenta?

27) Qual a funcionalidade mais utilizada?

28) Qual a funcionalidade menos utilizada?

29) Qual a funcionalidade que falta na ferramenta? 
Apêndice C-Tabela de Práticas de Gerenciamento de Projetos para Diagnóstico nas Empresas Entrevistadas 


\section{APÊNDICE C}

\section{TABELA DE PRÁTICAS DE GERENCIAMENTO DE PROJETOS PARA DIAGNÓSTICO NAS EMPRESAS ENTREVISTADAS}

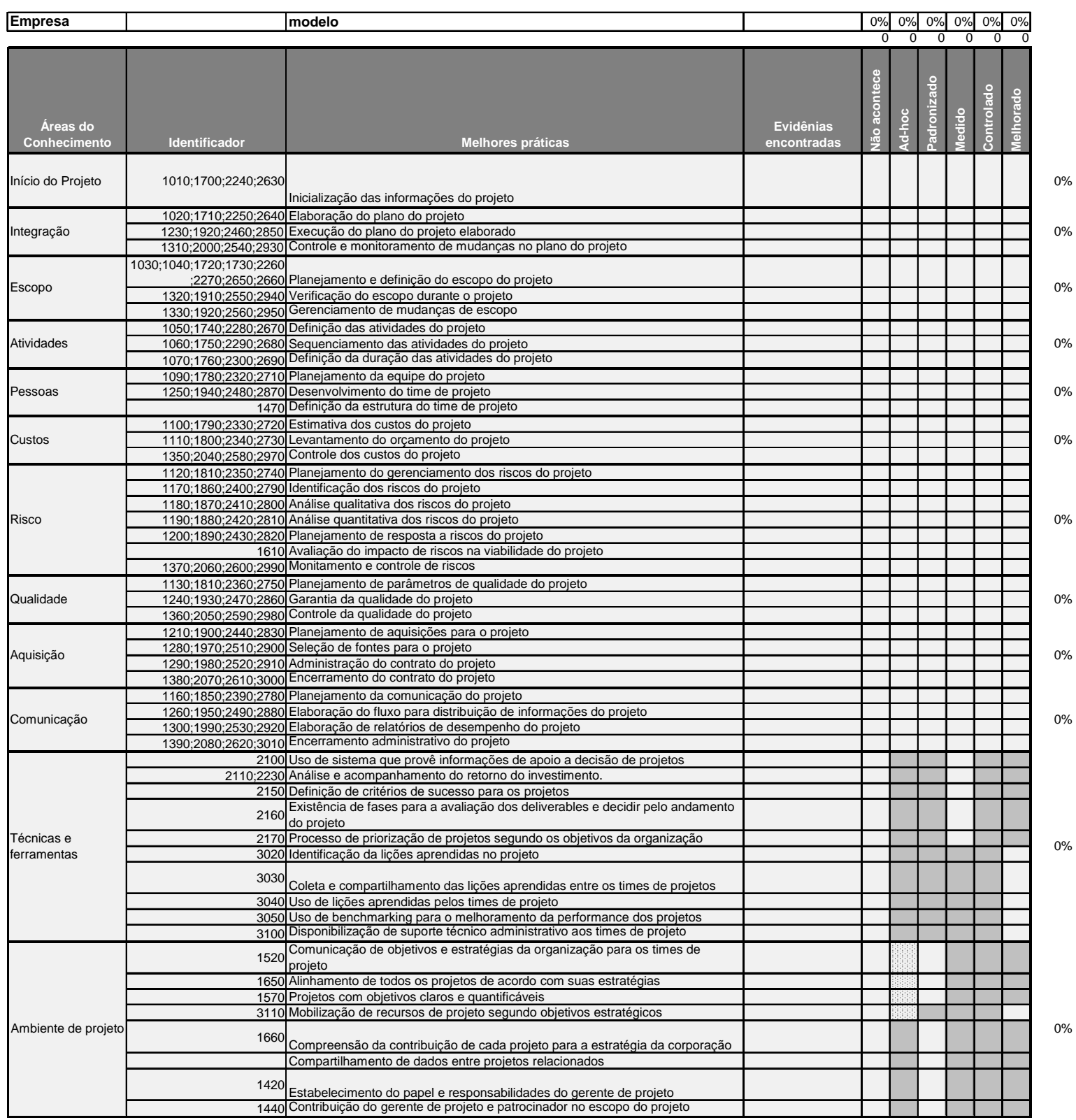

